\title{
Non-Invasive Evaluation of Acute Effects of Tubulin Binding Agents: A Review of Imaging Vascular Disruption in Tumors ${ }^{\dagger}$
}

\author{
Li Liu ${ }^{1}\left(\mathbb{D}\right.$, Devin O'Kelly ${ }^{1}$, Regan Schuetze ${ }^{1}$, Graham Carlson ${ }^{2}$, Heling Zhou ${ }^{1}$, Mary Lynn Trawick ${ }^{2}$, \\ Kevin G. Pinney ${ }^{2} \mathbb{D}$ and Ralph P. Mason $1, * \mathbb{C}$
}

1 Department of Radiology, University of Texas Southwestern Medical Center, Dallas, TX 75390, USA; Li.Liu@UTSouthwestern.edu (L.L.); Devin.OKelly@UTSouthwestern.edu (D.O.);

Regan.Schuetze@UTSouthwestern.edu (R.S.); helingzhou7@gmail.com (H.Z.)

2 Department of Chemistry and Biochemistry, Baylor University, Waco, TX 76798, USA; Graham_Carlson@baylor.edu (G.C.); Mary_Lynn_Trawick@baylor.edu (M.L.T.);

Kevin_Pinney@baylor.edu (K.G.P.)

* Correspondence: Ralph.Mason@UTSouthwestern.edu; Tel.: +1-214-648-8926

+ Dedicated to Mr. A. DeLuca, a superlative teacher, who could inspire a passion for chemistry.

check for

updates

Citation: Liu, L.; O'Kelly, D.; Schuetze, R.; Carlson, G.; Zhou, H.; Trawick, M.L.; Pinney, K.G.; Mason, R.P. Non-Invasive Evaluation of Acute Effects of Tubulin Binding Agents: A Review of Imaging Vascular Disruption in Tumors. Molecules 2021, 26, 2551. https:// doi.org/10.3390/molecules26092551

Academic Editor: Andreas Tzakos

Received: 27 March 2021

Accepted: 19 April 2021

Published: 27 April 2021

Publisher's Note: MDPI stays neutral with regard to jurisdictional claims in published maps and institutional affiliations.

Copyright: (C) 2021 by the authors. Licensee MDPI, Basel, Switzerland. This article is an open access article distributed under the terms and conditions of the Creative Commons Attribution (CC BY) license (https:/ / creativecommons.org/licenses/by/ $4.0 /)$.

\begin{abstract}
Tumor vasculature proliferates rapidly, generally lacks pericyte coverage, and is uniquely fragile making it an attractive therapeutic target. A subset of small-molecule tubulin binding agents cause disaggregation of the endothelial cytoskeleton leading to enhanced vascular permeability generating increased interstitial pressure. The resulting vascular collapse and ischemia cause downstream hypoxia, ultimately leading to cell death and necrosis. Thus, local damage generates massive amplification and tumor destruction. The tumor vasculature is readily accessed and potentially a common target irrespective of disease site in the body. Development of a therapeutic approach and particularly next generation agents benefits from effective non-invasive assays. Imaging technologies offer varying degrees of sophistication and ease of implementation. This review considers technological strengths and weaknesses with examples from our own laboratory. Methods reveal vascular extent and patency, as well as insights into tissue viability, proliferation and necrosis. Spatiotemporal resolution ranges from cellular microscopy to single slice tomography and full three-dimensional views of whole tumors and measurements can be sufficiently rapid to reveal acute changes or longterm outcomes. Since imaging is non-invasive, each tumor may serve as its own control making investigations particularly efficient and rigorous. The concept of tumor vascular disruption was proposed over 30 years ago and it remains an active area of research.
\end{abstract}

Keywords: imaging; bioluminescence; photoacoustics; magnetic resonance imaging; vascular disrupting agents; inhibitors of tubulin polymerization; breast cancer; kidney cancer; lung cancer; combretastatins

\section{Introduction}

Solid tumor growth beyond about 1-3 $\mathrm{mm}$ in diameter depends extensively on angiogenesis initiating neovasculature for the supply of nutrients and oxygen [1]. However, tumor neovasculature is abnormal, in terms of both structure and function, and has been proposed as a specific target for therapeutic intervention [2-6]. Notably, tumor endothelial cells undergo rapid proliferation and vessels generally lack pericyte coverage [7,8]. Two types of therapy have been proposed to target tumor-associated vasculature: angiogenesis inhibiting agents (AIAs) inhibit the development of blood vessels a priori [9], while vascular disrupting agents (VDAs) specifically target existing neovasculature $[4,5,10,11]$. Many small-molecule VDAs interact with the tubulin-microtubule protein system including the well-characterized vinca alkaloid and colchicine binding sites, which are located separately on the $\alpha \beta$-tubulin heterodimer $[12,13]$. In the late 1970 's, Pettit and co-workers discovered the combretastatins in the South African bush willow tree, Combretum caffrum, of which 
combretastatin A-1 (CA1) [14] and combretastatin A-4 (CA4) [15] are two of the most potent compounds, each exhibiting pronounced biological activity as inhibitors of tubulin polymerization and as selective VDAs. VDA activity results from microtubule disruption in activated endothelial cells, which initiates a signaling pathway characterized by profound cytoskeletal and morphological changes $[16,17]$. Consequently, endothelial cells round up, leading to enhanced vascular leakage, and detachment from each other and from the underlying substratum to clog the tumor blood vessels [18]. Direct vascular disruption is predicted to cause massive downstream starvation and hypoxiation, thereby potentiating the local effect and generating extensive necrosis [4] (Figure 1).

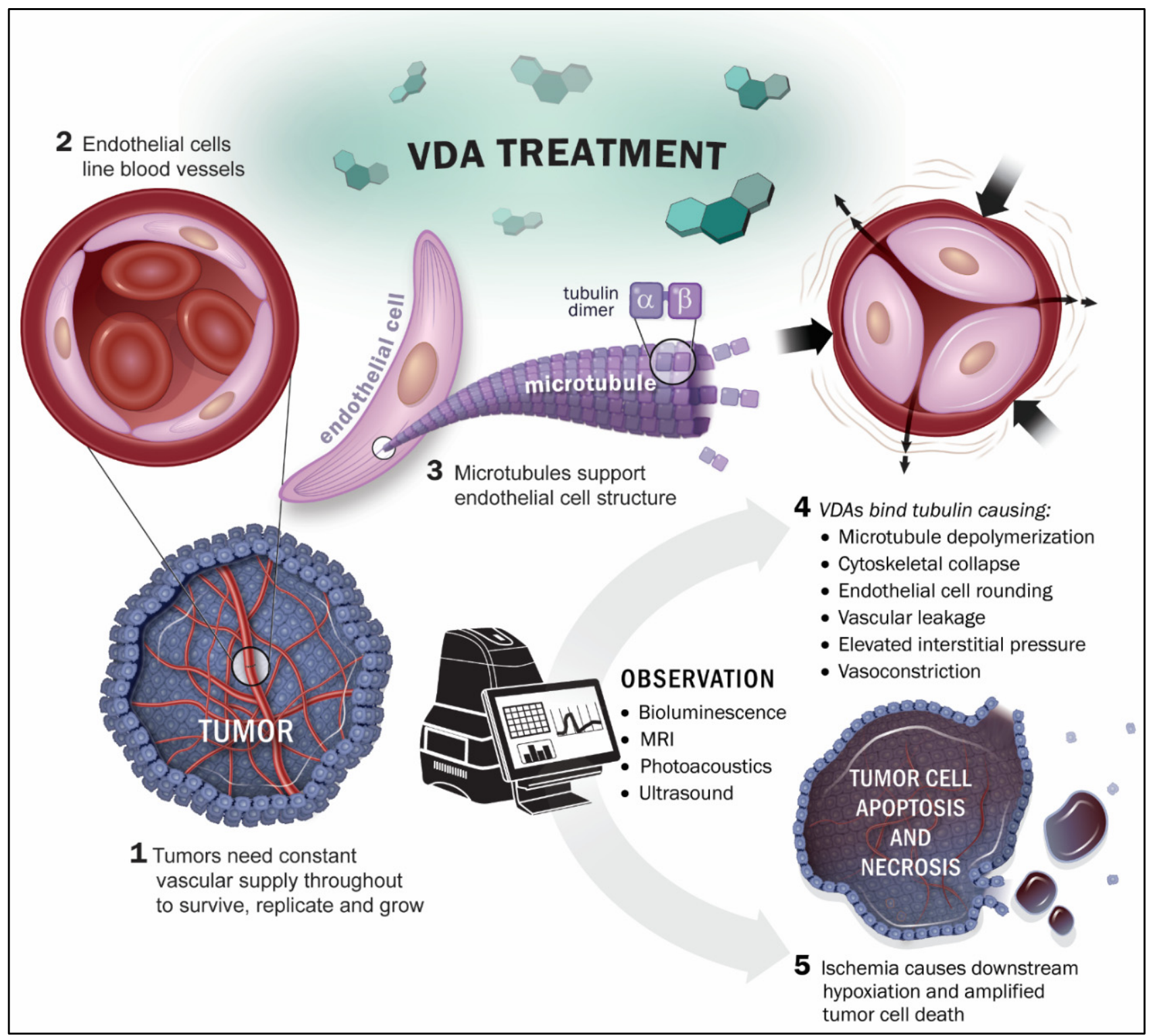

Figure 1. Imaging the action of VDAs on tumor-associated blood vessels.

While the concept of vascular targeting was proposed some 30 years ago, we note a dramatic recent increase in interest, particularly efforts to develop next generation agents: 6700 Web of Science citations of "combretastatin" in 2020 represented a 15-fold increase since 2000. Several VDAs have been evaluated in clinical trials, though to date none has received FDA approval [19-22]. Table 1 outlines the status of several VDAs and lists clinical trials that included substantial imaging. Several VDAs (CA4P, DMXAA and ZD6126) 
underwent Phase 2 clinical trials and CA4P and AVE8062 reached Phase 3 [21,23]. CA4P was granted the status of an orphan drug by the European Medicines Agency (EMA) and Federal Drug Administration (FDA) [19]. Several clinical trials are listed at ClinicalTrials.gov, but only one is currently active: "Modulation Of The Tumour Microenvironment Using Either Vascular Disrupting Agents or STAT3 Inhibition in Order to Synergise With PD1 Inhibition in Microsatellite Stable, Refractory Colorectal Cancer (MODULATE)" which examines BNC105P and is organized by the Australasian Gastro-Intestinal Trials Group. To date imaging, as a biomarker, has been incorporated into relatively few clinical trials and the potential value and shortcomings were discussed extensively by $\mathrm{O}^{\prime}$ Connor et al., particularly regarding the parameters measurable by DCE-MRI [24].

Table 1. Vascular disrupting agents. Status and use of imaging during recent clinical trials $[19,25]$.

\begin{tabular}{|c|c|c|c|c|}
\hline Agent & Imaging Modality & Tumor Type & Trial & References \\
\hline $\begin{array}{c}\text { CA4P } \\
\text { (fosbretabulin; Zybrestat) }\end{array}$ & $\begin{array}{l}\text { DCE-MRI or -CT } \\
\text { a DWI-MRI } \\
\text { b } 15 \text { O-PET }\end{array}$ & $\begin{array}{l}\text { Lung cancer, ovarian, } \\
\text { renal, breast }\end{array}$ & Phase 1 & $\begin{array}{l}{[26-29]} \\
\text { a }[30] \\
b[31]\end{array}$ \\
\hline $\begin{array}{c}\text { CA1P } \\
(\mathrm{OXi} 4503)\end{array}$ & $\begin{array}{l}\text { DCE-MRI } \\
{ }^{15} \mathrm{O}-\mathrm{PET}\end{array}$ & Various & Phase 1 & [32] \\
\hline BNC105P & DCE MRI & Various & $\begin{array}{c}\text { Phase } 121 \text { patients; } \\
\text { now in Phase } 2\end{array}$ & [33] \\
\hline CYT997 & DCE-MRI & Various & 31 patients & {$[34]$} \\
\hline $\begin{array}{c}\text { AVE8062 } \\
\text { (Ombrabulin) }\end{array}$ & DCE-US & $\begin{array}{l}\text { Various, mostly } \\
\text { ovarian }\end{array}$ & 25 patients & [35] \\
\hline $\begin{array}{c}\text { NPI2358 } \\
\text { (Plinabulin) }\end{array}$ & DCE-MRI & Various & 38 patients & [36] \\
\hline ZD6126 & DCE-MRI & Colon & & [37] \\
\hline $\begin{array}{c}\text { EPC2407 } \\
\text { (Crolibulin) }\end{array}$ & DCE- \& DWI-MRI & Various & 11 subjects, Phase 1 & [38] \\
\hline $\begin{array}{c}\text { MN-029 } \\
\text { (Denibulin) }\end{array}$ & DCE-MRI & Various & 34 subjects, Phase 1 & [39] \\
\hline $\begin{array}{c}\text { DMXAA } \\
\text { (ASA404; } \\
\text { 5,6-dimethylxanthenone-4-acetic acid; } \\
\text { vadimezan) }\end{array}$ & DCE-MRI & Various & Phase 1 & [40] \\
\hline
\end{tabular}

Abbreviations. DCE: dynamic contrast enhanced; DWI: diffusion weighted imaging; MRI: magnetic resonance imaging, CT: computed tomography; US: ultrasound; PET: positron emission tomography.

It is recognized that VDAs are ineffective as monotherapies, since a thin peripheral rim of cells, thought to receive nutrients from the host vasculature survives, even after destruction of the tumor vasculature. While the tumor center may necrose, the rim often repopulates rapidly. As such, several VDAs have been tested in combination with additional therapies [11,41], including radiotherapy [41-46], antiangiogenic agents (such as bevacizumab) [47,48], traditional cytotoxic chemotherapy (e.g., carboplatin, paclitaxel) [41,49-54] and recently immunotherapy $[55,56]$. There is a current resurgence of interest in VDAs and frequent reports describe novel agents, many based on the colchicine/combretastatin motif [57-72] (Figure 2A). These molecules are typically hydrophobic and are modified as phosphate prodrugs to enhance aqueous solubility and allow ease of delivery. The phosphates are intrinsically less active, particularly in terms of tubulin binding, as assessed in cell free assays [73,74], but non-specific phosphatases are abundant in cells providing rapid release of the active agents [75]. Recent reports have explored the encapsulation of combretastatin and DMXAA in targeted nanoparticles, sometimes in combination with co-encapsulated chemotherapy or anti-angiogenesis drugs to enhance tumor retention and prolong effective release [76]. While combretas- 
tatins have seen substantial progress in clinical development (Phase I-III clinical trials, Table 1), several other molecular structures can selectively lead to destruction of tumor vasculature and examples are shown in Figure 2B. Notably, arsenic trioxide (Trisinox; ATO) is used clinically to treat promyelocytic leukemia and has been shown to cause vascular disruption in solid tumors [77-79], though at low doses it interferes with mitochondrial activity and actually increased tumor oxygenation, as revealed by ESR and ${ }^{19} \mathrm{~F}$ MR oximetry [80]. Selective vascular destruction has also been achieved using antibody targeted tissue factor (anti-VCAM-1.TF) [6,81] and physical approaches based on photodynamic therapy [82-85], microwave heating [86] or high dose radiation [87] potentially enhanced with high-z nanoparticles [88]. The application of imaging for non-invasive assessment of vascular disrupting agent activity is presented in Table 2.

Table 2. Pre-clinical Imaging of VDAs.

\begin{tabular}{|c|c|c|c|}
\hline Agent & Imaging Modality & Tumor Type & References \\
\hline CA4P & $\begin{array}{c}{ }^{\text {a }} \text { BLI, }{ }^{\text {b }} \text { MRI, } \\
{ }^{c} \text { MSOT } / \text { PAT, } \\
{\text { d } P E T / C T,{ }^{e} \text { EPR, }}^{\text {f }} \text { US, } \\
\text { g SPECT }\end{array}$ & $\begin{array}{c}\text { Breast, liver, colorectal, } \\
\text { bladder, pancreatic, prostate, } \\
\text { lung, melanoma }\end{array}$ & $\begin{array}{c}\text { a [5,89-93] cf. Figures } 3 \text { and } 4 \\
\text { b [5,27,91,93-107] } \\
\text { c [92] cf. Figures } 8 \text { and } 9 \\
\text { d [105,108], e [95] } \\
\text { f [109-112], g [113] }\end{array}$ \\
\hline CA1P & $\begin{array}{l}\text { a BLI, }{ }^{b} \text { MRI, }{ }^{c} \text { MSOT, } \\
\text { d PET/CT, }{ }^{\text {}} \text { US }\end{array}$ & Colorectal, H\&N, breast & $\begin{array}{c}\mathrm{a}[5,114,115] \\
\mathrm{b}[103,105,114,116,117] \\
\mathrm{c}[118,119] \\
\mathrm{d}[105],{ }^{\mathrm{f}}[5,91]\end{array}$ \\
\hline BNC105P & BLI & Kidney & [120] \\
\hline AVE8062 & BLI, MRI, FDG-PET, CE-US & Colon, Ovarian, H\&N & [121-123] \\
\hline NPI2358 & DCE-MRI & Breast, sarcoma & {$[124]$} \\
\hline ZD6126 & DCE-MRI, BOLD MRI & $\begin{array}{l}\text { Colon, breast, prostate, } \\
\text { fibrosarcoma }\end{array}$ & {$[11,37,125-128]$} \\
\hline BPR0L075 & BLI & Breast & [129] \\
\hline EPC2407 & $\begin{array}{l}\text { BOLD MRI, DCE-MRI, MSOT, BLI, } \\
\text { US }\end{array}$ & $\begin{array}{l}\text { Head \& Neck, glioma, } \\
\text { prostate }\end{array}$ & [130-132] \\
\hline DMXAA & a ${ }^{\text {BLI, }}{ }^{\text {b }}$ MRI, ${ }^{c}$ MSOT, ${ }^{d}$ FDG-PET & $\begin{array}{l}\text { Breast, colorectal, glioma, } \\
\text { kidney, H\&N }\end{array}$ & $\begin{array}{l}\text { a }[133,134], \mathrm{b}[91,96,134-138] \\
\quad \text { c }[133,139,140]^{\mathrm{d}}[141]\end{array}$ \\
\hline OXi8007 & BLI, MRI, US & Breast, prostate & {$[17,74,93]$ cf. Figures 5,9 and 11} \\
\hline $\mathrm{C} 118 \mathrm{P}$ & MRI & Liver (rabbit) & [142] \\
\hline ABT-751 & MRI & Glioma (rat) & [143] \\
\hline CA4P analogs & BLI, US & Breast, prostate, lung & {$[66,74,144-147]$} \\
\hline Targeted prodrugs & BLI & $4 \mathrm{~T} 1$ breast & [148] \\
\hline Nanoparticles & MRI, optical, MSOT & 4T1, MCF-7 breast & [149-153] \\
\hline Conjugates & MSOT & Colon & [154] \\
\hline
\end{tabular}




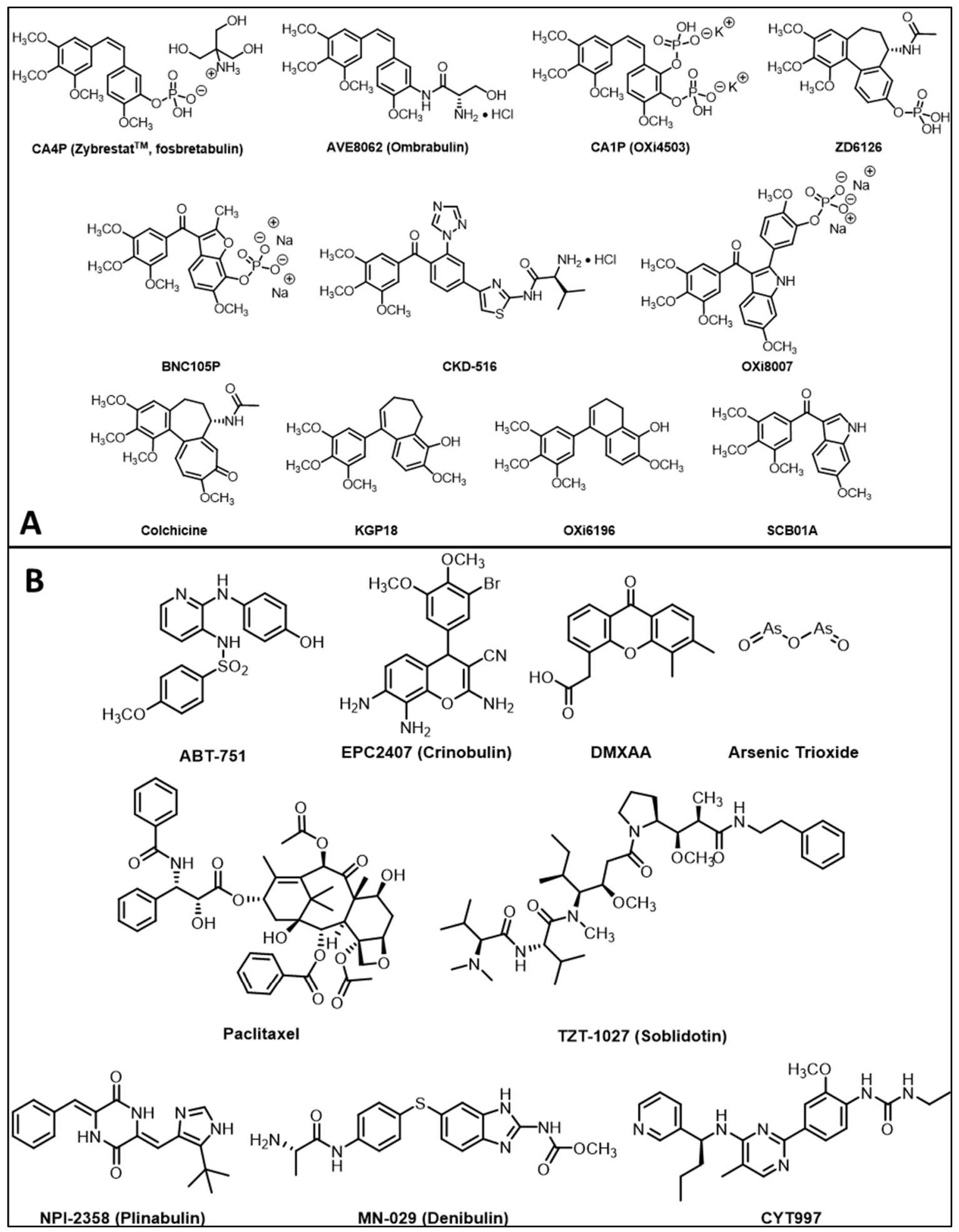

Figure 2. Structures of small-molecule vascular disrupting agents. (A) Natural products and combretastatin-inspired molecular structures found to be effective tubulin binding agents causing vascular disruption. Combretastatin A4 [15], AVE8062 [155], combretastatin A1P [14], ZD6126 [156], BNC105P [157], CKD-516 [158], OXi8007 [17], colchicine, KGP18 [144], OXi6916 [159] and SCB01A [160]. (B) Diverse molecular structures binding tubulin or causing vascular disruption: ABT751 [143], EPC2407 [131], DMXAA [138], arsenic trioxide [161], paclitaxel [162], TZT-1027 [163], NPI-235 [124], MN-029 [39] and CYT997 [34]. While paclitaxel is a tubulin binding agent, we found no evidence for acute vascular shutdown (see Figure 6e). 
Ultimately, therapeutic efficacy is determined by tumor growth delay and ideally tumor control. However, a crucial intermediate assay is acute vascular disruption. Historically, this was evaluated histologically in excised tumor tissue. Blood vessels themselves can be observed using antibody stains such as anti-CD31 [7,164,165] (Figure 3). However, in the context of vascular disruption it is dynamic changes in flow, perfusion and vascular patency that are critical. These have been measured using perfusion markers such as Hoechst 33342 dye, indocyanine green, DiOC7, colored microspheres or radiolabeled iodoantipyrine (IAP) $\left({ }^{125} \mathrm{I},{ }^{14} \mathrm{C}\right)$ to reveal extent of perfusion $[17,75,157,166-168]$. Pulse chase approaches with differentially colored dyes, microspheres or lectins allow direct interrogation of changes within specific blood vessels of individual tumors $[169,170]$. Given the significance of VDAs, there have been several previous reviews [22]. [6,19,25,47,71,171,172], but few have focused on the ability to examine activity non-invasively $[5,132,173,174]$, the emphasis of this current review.
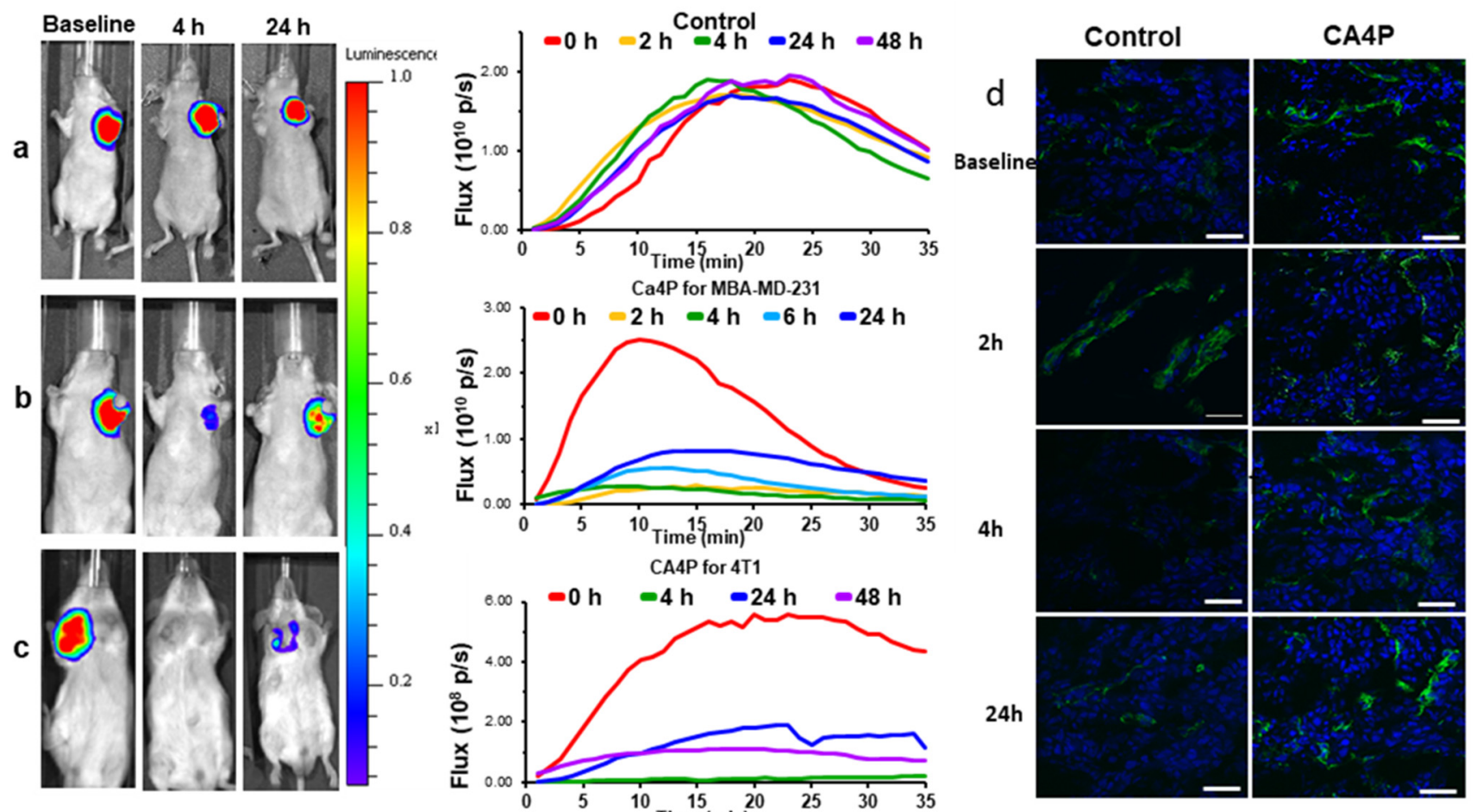

Figure 3. Efficacy of acute VDA activity revealed using dynamic BLI in orthotopic breast tumors. Left: BLI signal intensity images overlaid as heat maps on gray scale photographs of mice at about $10 \mathrm{~min}$ after administration of luciferin at selected time points following administration of (a) saline or (b) CA4P (120 mg/kg IP) to MDA-MB-231-luc xenograft tumor bearing nude mice. See also Video S1; (c) CA4P to syngeneic 4T1-luc tumor in BALB/C mouse. All intensity maps have same heat scale. Center: corresponding BLI intensity curves for the respective individual mice at left showing differential variation over a period of $35 \mathrm{~min}$ following administration of luciferin at baseline (red), $2 \mathrm{~h}$ post (orange), $4 \mathrm{~h}$ (green) and $24 \mathrm{~h}$ (blue), $48 \mathrm{~h}$ (purple). (d) Tumor sections from four tumors showing vascular extent based on CD31 stain (green) and perfusion marker Hoechst 33342 (blue) at different times following treatment with CA4P. Severely diminished perfusion was seen at $4 \mathrm{~h}$, while controls tumors showed highly consistent extensive perfusion as seen in right hand column. Scale bar: $50 \mu \mathrm{m}$.

\section{Imaging Technologies}

Imaging provides non-invasive insights into VDA activity in vivo and potentially early predictive biomarkers of therapeutic response. Many non-invasive imaging methods are available [175], and diverse modalities have been applied to evaluate VDAs, including radionuclide approaches, MRI, ultrasound, and more recently photoacoustic and optical (Table 2), as discussed in the following sections. While the focus of this review is on evaluating therapeutic vascular disrupting activity on tumors, it must be remembered that 
there may also be off-target toxicity [176], which can also be assessed by imaging. Many of these technologies also allow translational imaging in patients, offering the potential for companion studies of efficacy [177].

\subsection{Bioluminescence Imaging (BLI)}

BLI is likely the simplest imaging modality for pre-clinical cancer investigations and has found widespread application to monitor tumor development, growth and metastatic spread, particularly in mice $[178,179]$. Tumor cells must have been transfected to express luciferase and luciferin substrate is required, though some other enzyme/substrate pairs are becoming available [179]. Instrumentation simply requires a sensitive CCD camera and dark observation chamber and the earliest instruments were built in individual laboratories $[89,180]$. Sensitivity and ease of use were greatly improved in commercial systems, which became available some 15 years ago and popularity was stimulated by the IVIS systems developed by Xenogen and now produced by Perkin Elmer. There are currently several manufacturers marketing systems with various levels of sensitivity, throughput and additional capabilities.

In Vivo Optical Imaging Systems are available from: PerkinElmer (Waltham, MA, USA) [181], Spectral Instruments (Tucson, AZ, USA) [182], Scintica (Webster, TX, USA) [183], Sonovol (Durham, NC, USA) [184], Medilume (Montreal, QC, Canada) [185], Vieworks (Anyang-si, Gyeonggi-do, Republic of Korea) [186]. Current systems can typically image five mice simultaneously and in several cases include planar X-ray capability to provide skeletal context. 3D capability has been developed based on multiple angle detection using multiple cameras or mirrors [187-189] or depth resolved wavelength dependent spectroscopy $[189,190]$. Anatomical context is normally provided by overlay on a gray scale surface image of the mouse, but planar X-rays can provide skeletal co-registration, which is particularly relevant for investigating bone metastases [191]. A recent innovation is combination with ultrasound to reveal soft tissue anatomy and vasculature [184]. Mice must be anesthetized and many systems have onboard vaporizers to deliver isoflurane in air or oxygen, though injectable anesthetics such as ketamine/xylazine or pentobarbital have been used. We favor oxygen carrier gas, which promotes survival, during the stress of anesthesia. While imaging is non-invasive, mere anesthetization of animals with a high tumor burden receiving an experimental therapeutic can cause animal loss. BLI is of course limited to observing tissues, which have been transfected to express luciferase. Transfection optimally generates a single high expressing clone, though cells selected for high luciferase expression may no longer fully represent typical heterogeneous tumors. Meanwhile, polyclonal approaches may suffer from differential cellular expression, whereby faster growing clones, which may have lower expression, dominate tumor development in vivo. A typical experimental approach is described in Appendix A. Luciferin is now readily available from many sources and the price has fallen sufficiently that the luciferin substrate required for a typical investigation costs less than $\$ 1$ per mouse.

The reporter substrate luciferin can be injected directly into a tumor, but luciferin has a remarkable ability to cross membranes including the placenta and blood brain barrier and thus systemic delivery works effectively. Luciferin may be administered intravenously (IV), but this leads to rapid clearance kinetics and is technically challenging for routine use, particularly if multiple sequential doses are to be delivered. Traditional administration was intraperitoneal (IP), but we favor subcutaneous (SC) in the fore-back neck region $[89,180,192]$. Luciferin rapidly reaches the bloodstream, whereupon it is carried to tumor cells wherever they are located in a mouse and undergoes a light emitting reaction catalyzed by luciferase according to Equation (1).

$$
\mathrm{ATP}+D \text {-luciferin }+\mathrm{O}_{2} \longrightarrow \text { luciferase } \longrightarrow \text { oxyluciferin }+\mathrm{AMP}+\mathrm{PPi}+\mathrm{CO}_{2}+\text { light }
$$

Signal intensity generally increases for a period of about 5-15 min followed by decline over the next $1 / 2 \mathrm{~h}$, though specific kinetics depend on the extent of vascularization and disease site (Figures 3-6). Highly reproducible series of images may be observed follow- 
ing repeat administration of luciferin over a period of several hours (Figure 3a), though signal may increase over days due to tumor growth sometimes noticeable within 24 to $48 \mathrm{~h}$ (Figure 6a). Recognizing the dynamic variation in signal following administration of luciferin, we favor observing a whole time course, rather than a single time point, and light emission may be compared based on area under the light emission curve, maximum intensity, or intensity at a specific time post administration. Since luciferin must be transported to the tumor, vascular shutdown following administration of a VDA is revealed by reduced light emission (Figures 3-6, Video S1). Indeed, very similar activity was observed in three distinct breast tumors growing orthotopically in the upper mammary fat pad of SCID mice indicating $>80 \%$ signal reduction within 2 to $4 \mathrm{~h}$ following CA4P administration at $120 \mathrm{mg} / \mathrm{kg}$ IP (Figures 3 and 4). Reduced perfusion was confirmed using fluorescence microscopy, whereby anti-CD31 staining indicated extensive tumor vasculature, but Hoechst 33342 perfusion dye showed much less accumulation when administered 2 or $4 \mathrm{~h}$ after CA4P (Figure 3c).
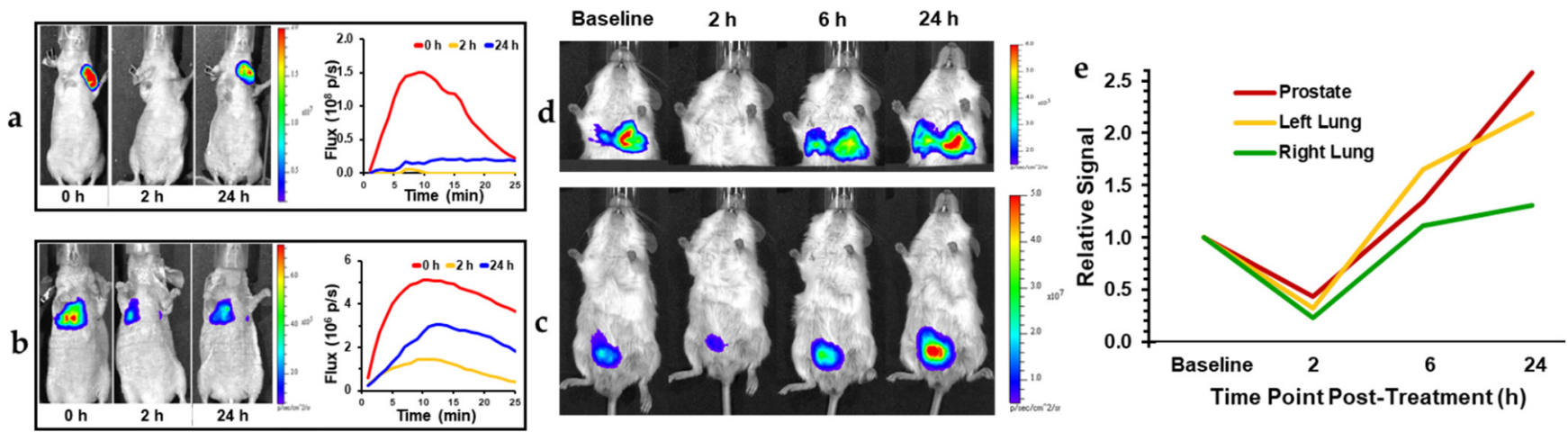

Figure 4. CA4P response for BrCa and PCa with implanted spontaneous lung metastases. (a) Orthotopic MCF-7-luc human breast cancer tumor in upper mammary fat pad response to CA4P treatment $(120 \mathrm{mg} / \mathrm{kg}$ IP) assessed by BLI at 0,2 , and $24 \mathrm{~h}$ after treatment. BLI intensity images overlaid on photos of mice, (b) Equivalent results for MCF-7-luc lung colonization tumor model generated by IV injection of tumor cells. Corresponding dynamic time course intensity traces are shown for each time following administration of luciferin. At $2 \mathrm{~h}$, there was about $80 \%$ reduced light emission corresponding to vascular shutdown in mammary fat pad tumor, but less loss $(60 \%)$ in the lungs. Similarly, orthotopic PC3-luc tumor (c) and its spontaneous lung metastases (d) in SCID mouse at baseline, 2, 6 and $24 \mathrm{~h}$ following CA4P. (e) The PC 3 tumors appeared to be somewhat more resistant to VDA activity with less signal loss.

Optical techniques are subject to attenuation at depth due to absorption and scattering of light, and thus superficial tumors are most easily detected, specifically subcutaneous, or at disease sites near the surface such as mammary fat pad (Figure 3). However, light can penetrate several millimeters and effective signal is observed by BLI in deeper tissues such as the lungs [187,193-195], prostate [196-198], brain [199,200], pancreas [201,202], liver $[203,204]$, head and neck [114], bone $[205,206]$ and kidney $[138,207]$ in mice. The most common implementation of BLI in oncology is simply to relate signal intensity to tumor burden and indeed several studies have shown that there is a strong correlation for untreated control tumors up to about $2 \mathrm{~cm}^{3}[89,208]$. Beyond this size, absorption of light emitted from deeper tissues by overlaying tumor causes attenuation and a signal intensity plateau [208]. Acute vascular shutdown prevents substrate luciferin from reaching tumor cells, thereby yielding less light and revealing ischemia, as we exploit to observe the effects of VDAs (Figures 3-6). 

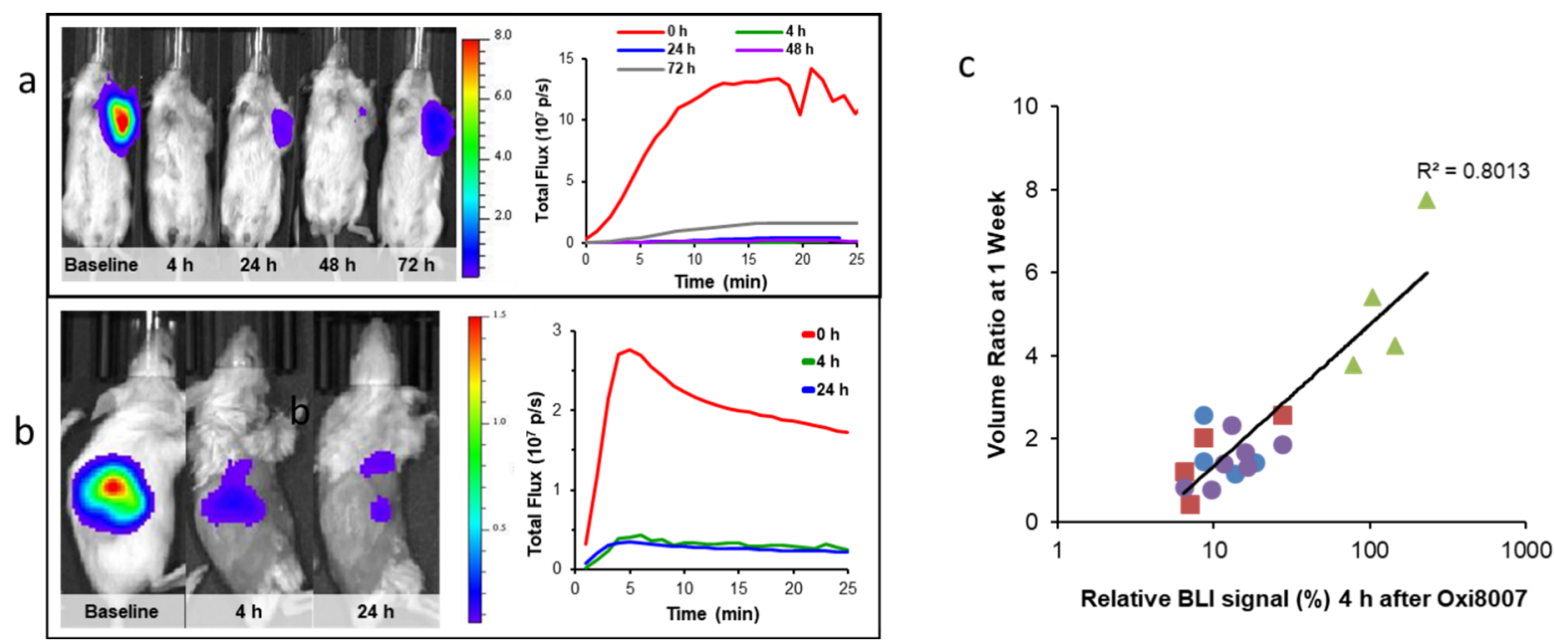

Figure 5. Demonstrating efficacy of new VDA in tumors growing in mice. (a) MDA-MB-231-luc breast tumor response to OXi8007 treatment ( $350 \mathrm{mg} / \mathrm{kg}$ IP) assessed by BLI at 4, 24, 48 and $72 \mathrm{~h}$ after treatment. BLI intensity images overlaid on photos of mice. Corresponding signal intensity curves at right; (b) similarly, orthotopic RENCA-luc kidney tumor bearing mouse at baseline, 4 and $24 \mathrm{~h}$. Dynamic time course intensity traces are shown for each time following administration of luciferin. At 4 and $24 \mathrm{~h}$ there was an approximately $80 \%$ reduction in light emission corresponding to vascular shutdown and matching the MSOT observation in Figure 10; (c) BLI as predictive imaging biomarker. For groups of MDA-MB-231-luc tumors (control, low and high dose OXi8007 as well as combination with carboplatin) there was a strong correlation between the signal shutdown at $4 \mathrm{~h}$ after administering VDA and the tumor growth over the next 7 days $\left(\mathrm{R}^{2}>0.8\right)$.

BLI of VDA activity has most commonly been applied to primary implanted tumors, but investigations have also examined pseudometastases, such as breast tumor colonization of the lungs, following tail vein injection of MDA-MB 231-luc cells (Figure 4b). Some primary tumors effectively yield spontaneous metastases, which are readily observed, although the primary tumor may need to be masked for effective imaging due to relative signal intensities (Figure 4c,d). Dynamic BLI was initially applied to known VDAs to establish the technique, e.g., CA4P [209] (Figures 3 and 4), CA1P [114], DMXAA [134,210], BPR0L075 [129], and ATO [161]. It has also been validated by comparing changes in BLI signal against alternative technologies such as MRI [209], ultrasound [161], photoacoustics [92] and histology (Figure 3), each of which has shown effectively correlated data. This provided confidence to apply dynamic BLI to new agents such as the indole OXi8007 [17,93], and efficacy is shown against orthotopic breast and kidney tumors in Figure 5. BLI is particularly effective at demonstrating dose response for new potential VDAs $[17,66,74,145-147,211]$, as exemplified for a novel amino benzosuberene analog (KGP321) of KGP18 (Figures 2A and 6). The combretastatins CA4P and CA1P and indole analog OXi8007 and benzosuberene analog KGP265 are administered as water soluble phosphate prodrugs, which are readily dephosphorylated releasing the active molecules, which bind tubulin and cause microtubule disaggregation yielding vascular collapse and ischemia, as evident from reduced BLI signal. Meanwhile, the microtubule stabilizing therapeutic paclitaxel caused no signal loss over $48 \mathrm{~h}$ (Figure 6e) matching a reported lack of change in BLI signal from 4T1-luc breast tumors growing as pseudometastases in the mouse lung after IV injection of cells [212].

Dynamic BLI is very effective for initial evaluation of potential VDAs, providing high throughput results with relative ease and low cost. There are distinct limitations, though many are readily overcome: (i) requires transfected cells to express luciferase effectively (many stably transfected cell lines are now available); (ii) requires administration of luciferin substrate (currently readily available, cheap and non-toxic); (iii) requires optical imaging system (typically cheapest of all available modalities); (iv) typically limited to mice due to light scattering by tissues, although BLI has been reported in rats including prostate [198], 
brain $[178,213]$ and lung tumors [214]. Other more sophisticated technologies provide alternative imaging approaches.
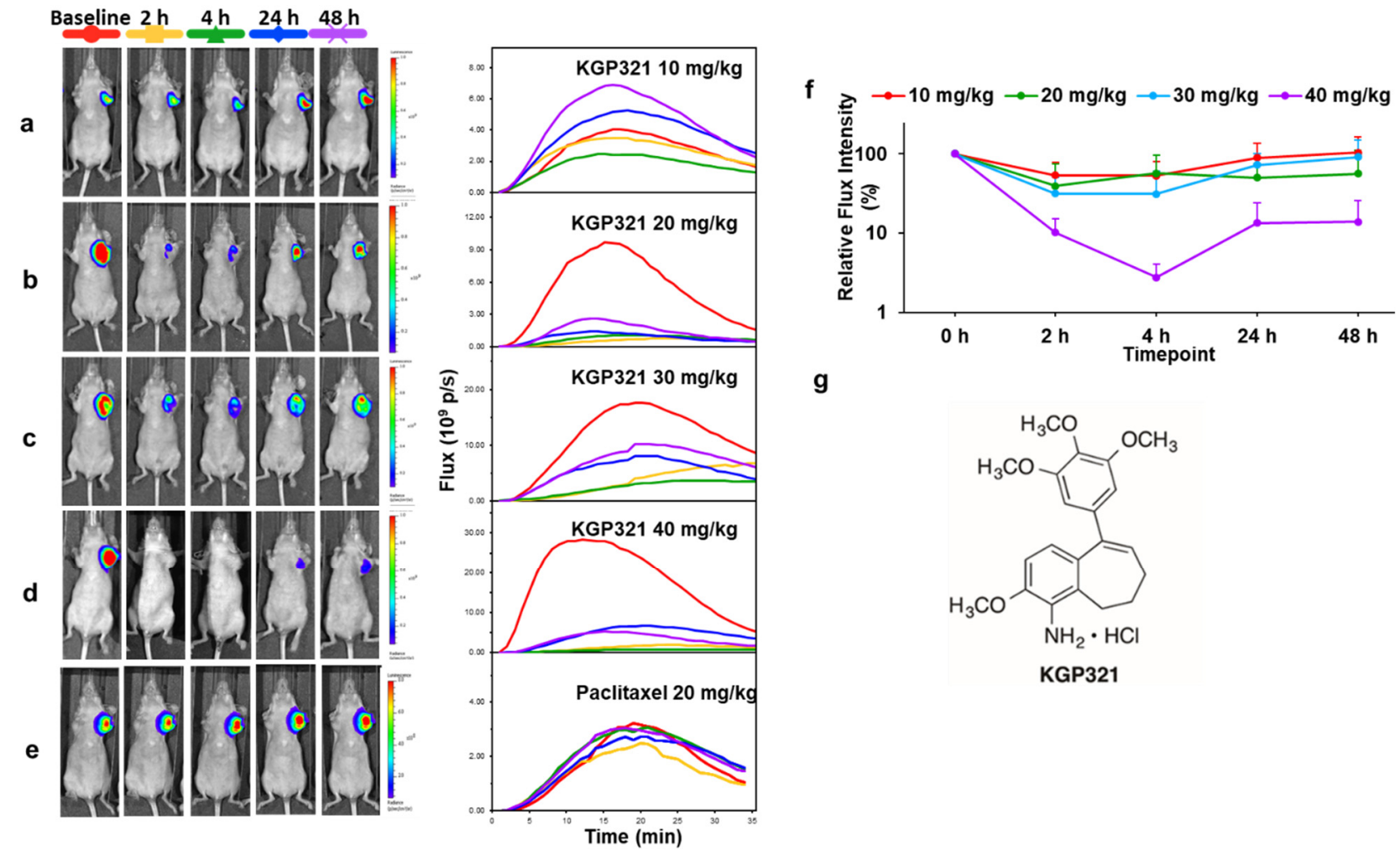

g<smiles>COc1cc(C2=CCCc3c(O)cc(OC)c([N+](=O)[O-])c32)cc(OC)c1OC</smiles>

Figure 6. Dose response of MDA-MB-231-luc MFP tumors to KGP321. Left: BLI signal intensity images overlaid as heat maps on gray scale photographs of nude mice at 16 min following administration of luciferin at selected time points following administration of KGP321. Center: BLI intensity curves for the respective individual mice at left show differential variation over a period of $35 \mathrm{~min}$ following administration of luciferin at baseline (red), $2 \mathrm{~h}$ post (orange), $4 \mathrm{~h}$ (green) and $24 \mathrm{~h}$ (blue), $48 \mathrm{~h}$ (purple). (a) $10 \mathrm{mg} / \mathrm{kg}(n=4) ;$ (b) $20 \mathrm{mg} / \mathrm{kg}(n=3) ;$ (c) $30 \mathrm{mg} / \mathrm{kg}(n=3) ;(\mathbf{d}) 40 \mathrm{mg} / \mathrm{kg}(n=3) ;(\mathbf{e})$ Paclitaxel $(20 \mathrm{mg} / \mathrm{kg})$ showing no acute changes in BLI signal. (f) BLI relative intensity change curves showing variation over a period of $48 \mathrm{~h}$ following administration of different doses of KGP321. Line colors $10 \mathrm{mg} / \mathrm{kg}$ (red); $20 \mathrm{mg} / \mathrm{kg}$ (green); $30 \mathrm{mg} / \mathrm{kg}$ blue) and $40 \mathrm{mg} / \mathrm{kg}$ (purple). ANOVA based on Fisher's PLSD indicated that over the $72 \mathrm{~h}$-time course all doses 10-40 mg/kg gave significantly different light emission from vehicle alone $(p<0.005)$, but there was no significant difference between the doses. At 30 and $40 \mathrm{mg} / \mathrm{kg}$ there was significantly less light emission at 2 and $4 \mathrm{~h}$ compared with baseline $(p<0.05)$ and this continued up to $72 \mathrm{~h}$ for $40 \mathrm{mg} / \mathrm{kg}(p<0.0001)$. (g) Structure of KGP321, a novel aminobenzosuberene-based VDA.

\subsection{Magnetic Resonance Imaging (MRI)}

Historically, MRI was the most commonly used modality for non-invasive investigations of VDA activity. MRI not only provides detailed anatomical images and high spatial resolution to reveal tumor location and heterogeneity, but can also provide insights into pathophysiology and pharmacodynamics in response to interventions. Pre-clinical MRI uses a high field magnet (typically, 3 to 11.7 Tesla available from two primary manufacturers for pre-clinical investigations: Bruker (Billerica, MA, USA) [215] and MR Solutions (Guildford, Surrey, UK) [216]) to polarize the nuclear magnetic spins and radio frequency stimulation to excite signals, most commonly the tissue water. Applied magnetic field gradients provide spatial resolution and signal relaxation produces contrast. Typical images in living mice have submillimeter in-plane resolution and millimeter slice thickness and may be presented as two-dimensional tomographic or three-dimensional volume images. MRI is particularly versatile in terms of pulse sequences, whereby combinations of excitation pulses and gradients can interrogate specific aspects of physiology, such as perfusion, flow, necrosis, and oxygenation [177]. Administration of paramagnetic contrast agents reveals 
flow, perfusion and vascular leakage, as applied in pre-clinical studies to develop many VDAs and subsequent clinical investigations (Tables 1 and 3).

The most common application regarding VDA activity examines changes in tissue contrast accompanying intravenous infusion of a paramagnetic contrast agent such as gadolinium-DTPA (Gd-DTPA, Magnevist), referred to as dynamic contrast enhanced (DCE) MRI. Spin lattice relaxation rate $\left(R_{1}=1 / T_{1}\right)$ is directly related to the concentration of small molecule contrast agents. Following IV infusion of a contrast agent, the inflow, perfusion and accumulation due to leakage and clearance are observed readily revealing changes following administration of VDAs. Usually the initial area under the contrast curve (IAUC) is used to examine perfusion, often characterized by the signal amplitude $(\% \Delta \mathrm{SI})$ and time to reach maximum (TTM) (Figure 7). More sophisticated analysis can reveal perfusion kinetics; to provide rigor with quantitative approaches the arterial input function (AIF) is required or a reference tissue model may be applied [217] (Figure 7). The reference tissue model compares the contrast agent curves in a tissue of interest (tumor) to that of a reference region (muscle). A typical experimental approach is described in Appendix B. Using reported values for the volume transfer constant of muscle, $\mathrm{K}^{\text {trans }}, \mathrm{M},\left(0.1 \mathrm{~min}^{-1}\right)$ and the extravascular-extracellular volume fraction, $\mathrm{v}_{\mathrm{e}}, \mathrm{M},(0.1)$ in the muscle $[217,218]$, it is possible to extract the $\mathrm{K}^{\text {trans }}$ and $\mathrm{v}_{\mathrm{e}}$ values for the tumor without knowledge of the AIF. The contrast concentration curve, $\mathrm{C}(\mathrm{t})$, in tumor tissue is then given by [217]:

$$
C(t)=R^{*} C^{M}(t)+R^{*}\left[\left(K^{\operatorname{transM}} / v_{e}{ }^{M}\right)-\left(K^{\text {trans }} / v_{e}\right)\right]^{*} \int{ }^{t} C^{M}\left(t^{\prime}\right) * \exp \left(-\left(K^{\text {trans }} / v_{e}\right)^{*}\left(t-t^{\prime}\right) d t\right.
$$

where $\mathrm{R}=\left(\mathrm{K}^{\text {trans }} / \mathrm{K}^{\text {transM }}\right)$ and $\mathrm{C}^{\mathrm{M}}(\mathrm{t})$ is the contrast agent curve in muscle tissue. $\mathrm{K}^{\text {trans }} / \mathrm{V}_{\mathrm{e}}$ is often referred to as $k_{e p}$.

Table 3. Imaging VDA activity using MRI.

\begin{tabular}{cccc}
\hline MRI ${ }^{\text {a }}$ & VDA & Tumor Type & References \\
\hline $\begin{array}{c}\text { Perfusion flow/vascular } \\
\text { permeability } \\
\text { DCE; DSC }\end{array}$ & $\begin{array}{c}\text { CA4P, DMXAA, EPC2407, } \\
\text { ZD6126, CKD-516 }\end{array}$ & $\begin{array}{c}\text { Liver, colorectal, pancreatic, } \\
\text { breast, glioma, prostate, } \\
\text { carcinosarcoma, VX2, kidney, } \\
\text { H\&N }\end{array}$ & $\begin{array}{c}\text { 106,117,124-128,131,132,135- } \\
{[5,27,37,96,97,100,102-} \\
138,219-221]\end{array}$ \\
\hline $\begin{array}{c}\text { Diffusion } \\
\text { DWI/IVIM }\end{array}$ & CA4P, CKD-516 & $\begin{array}{c}\text { Liver, rhabdomyosarcoma, lung, } \\
\text { VX2 }\end{array}$ & {$[98,102,104,117,219,222]$} \\
\hline ASL & CA1P & Colorectal & {$[116]$} \\
\hline $\begin{array}{c}\text { BOLD, OE-MRI, } \\
\text { F oximetry }\end{array}$ & ZD6126, CA4P, OXi8007 & Breast, bladder & {$[5,93-95,223]$} \\
\hline CEST & TNF- $\alpha$ & SC colon tumors & {$[224]$} \\
\hline pH & CA4P, DMXAA, ZD6126 & Breast & {$[91]$} \\
\hline HP-pyruvate & CA1P, CA4P & Lymphoma, Breast & {$[105,225]$} \\
\hline
\end{tabular}

a DSC: dynamic susceptibility contrast; IVIM: intra voxel incoherent motion; OE: oxygen-enhanced; CEST: chemical exchange saturation transfer; HP hyperpolarized.

Widespread DCE investigations were used in the development of the combretastatins (CA4P and CA1P) as well as DMXAA and ZD6126) $[5,27,37,96,97,100,102-104,106,117$, 124-128,131,132,135-138,219-221] and continue to be popular in pre-clinical development (Table 3), since they may also be implemented readily in clinical trials (Table 1). Examples of parametric images derived from DCE-MRI are presented in Figure 7, where tumor heterogeneity is apparent at baseline, as well as in response to the novel vascular disrupting agent OXi6197, the phosphate prodrug of OXi6196 (Figure 2A) a dihydronaphthalene analog of combretastatin. It is apparent that the initial area under the curve is much lower $24 \mathrm{~h}$ after VDA, while the TTM is much greater in many regions. The extracellular-extra vascular volume $\left(v_{e}\right)$ is considerably greater indicating enhanced vascular permeability. Others have used polymeric or particulate contrast agents (e.g., ultra small paramagnetic 
iron oxide: USPIO), which are retained in the vasculature for longer periods giving a sustained indication of vessel caliber and induced vascular leakage [106,127,128].

While MRI was incorporated into many clinical trials regarding anti-angiogenesis agents, there have been far fewer trials with respect to vascular disrupting agents. In principle, assessment of VDAs should be particularly easy since response is generally acute and substantial, however in terms of DCE-MRI, various questions remain open: which parameter is most relevant (e.g., changes in $\mathrm{v}_{\mathrm{e}}$ or $\mathrm{K}^{\text {trans }}$ ); when should imaging be performed; what threshold serves as a useful predictive biomarker [24]?

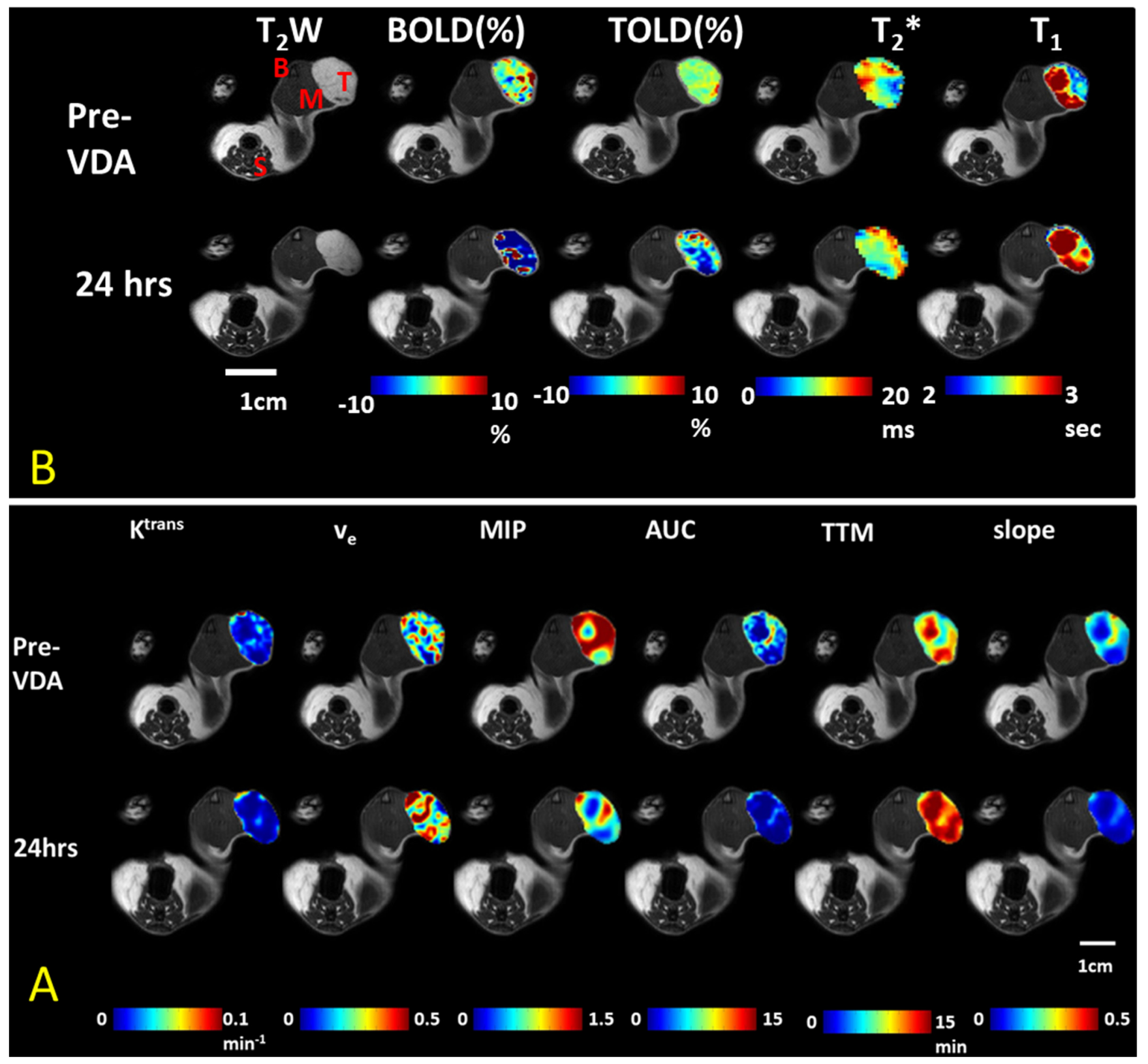

Figure 7. Multiparametric MRI assessment of ischemia and hypoxia in A549 human lung cancer in a rat model. The combretastatin analog OXi6197 was used as an experimental VDA in an SC model in the leg [159]. Labels shown on $\mathrm{T}_{2} \mathrm{~W}$. T-Tumor; M-Muscle; B-Bone marrow; S-Spine; $\mathrm{T}_{2}{ }^{*}$ is a physical variation on $\mathrm{T}_{2}$. (A) DCE confirms decreased perfusion based on area under the curve (AUC), time to maximum (TTM) and slope of DCE contrast curves following dose of $15 \mathrm{mg} / \mathrm{kg}$ OXi6197; (B) Oxygen-sensitive parameters (BOLD and TOLD) show much smaller response in vascular oxygenation to an oxygen gas breathing challenge after VDA. BOLD is sensitive to the amount of deoxyhemoglobin and has considerable similarity to the MSOT measurements (Figures 8-10). Data in B were acquired prior to A. 


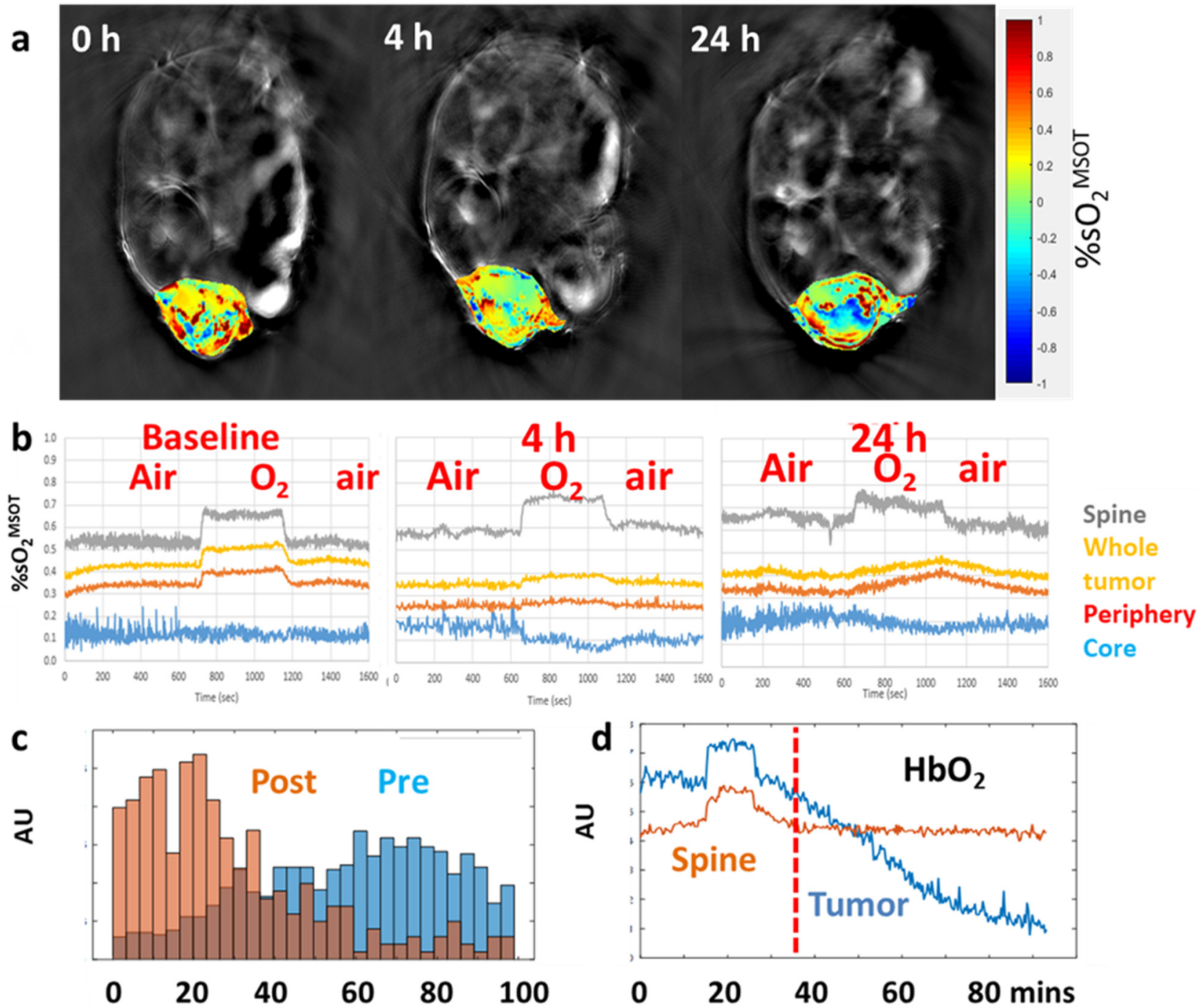

Figure 8. MSOT reveals progression of vascular shutdown. (a) Trans-axial MSOT images of nude mice with MDA-MB231-luc breast tumor. Color oxygenation maps overlaid on single wavelength anatomical grayscale images. Progression of hypoxiation in a mouse treated with CA4P $(120 \mathrm{mg} / \mathrm{kg})$, with strong response to treatment (white arrows) resulting in vascular impairment within $4 \mathrm{~h}$. (b) Traces show vascular oxygen saturation response $\left(\mathrm{sO}_{2}{ }^{\mathrm{MSOT}}\right)$ to $\mathrm{O}_{2}$-breathing challenge at baseline, 4 and $24 \mathrm{~h}$ after CA4P. Yellow (whole tumor), red (tumor periphery), blue (tumor center), grey (spine, which serves as effective control tissue). At $4 \mathrm{~h}$, the response of the tumor periphery was depressed and at $24 \mathrm{~h}$, it showed a very different (sluggish) pattern. (c) Histogram of vascular oxygen saturation in tumor periphery before and after CA4P in a second tumor bearing mouse; (d) Traces show concentration of $\mathrm{HbO}_{2}$ before CA4P and over $1 \mathrm{~h}$ following CA4P IP.

DCE-MRI has been used for many years and implementation and analysis are quite straightforward and readily translated to human studies. A downside to DCE-MRI is the need for the paramagnetic contrast agent; in rodents, this adds to the complexity by requiring effective IV infusion, while in human subjects there is recent concern that the gadolinium ions may cause kidney damage due to nephrogenic systemic fibrosis (NSF), or from as yet unknown problems due to deposition and long-term retention in the brain [226,227]. It appears that cyclic paramagnetic contrast agents have fewer potential issues, but contrast agent administration is now avoided in patients when possible. As such, various other MRI methods have been developed. Notably, arterial spin labeling allows non-invasive observation of blood flow based on physical spin tagging alone [116]. It has been effectively applied to colorectal cancer in mice revealing ischemia, but the method does require adequate through-plane signal motion to reveal flow. Acute vascular shutdown is the most obvious early effect revealed by MRI. Later effects may also be examined such 
as using diffusion-weighted imaging (DWI) to observe changes in cell structure, whereby diffusion is restricted in well-structured tissue, but becomes more mobile with necrosis, which occurs extensively within $24 \mathrm{~h}$ after VDA $[98,102,104,117,219,222]$. MR Elastography indicated reduction in tumor viscoelasticity $24 \mathrm{~h}$ after ZD6126 at which time no significant change in tumor apparent diffusion coefficient (ADC) was observed [228].
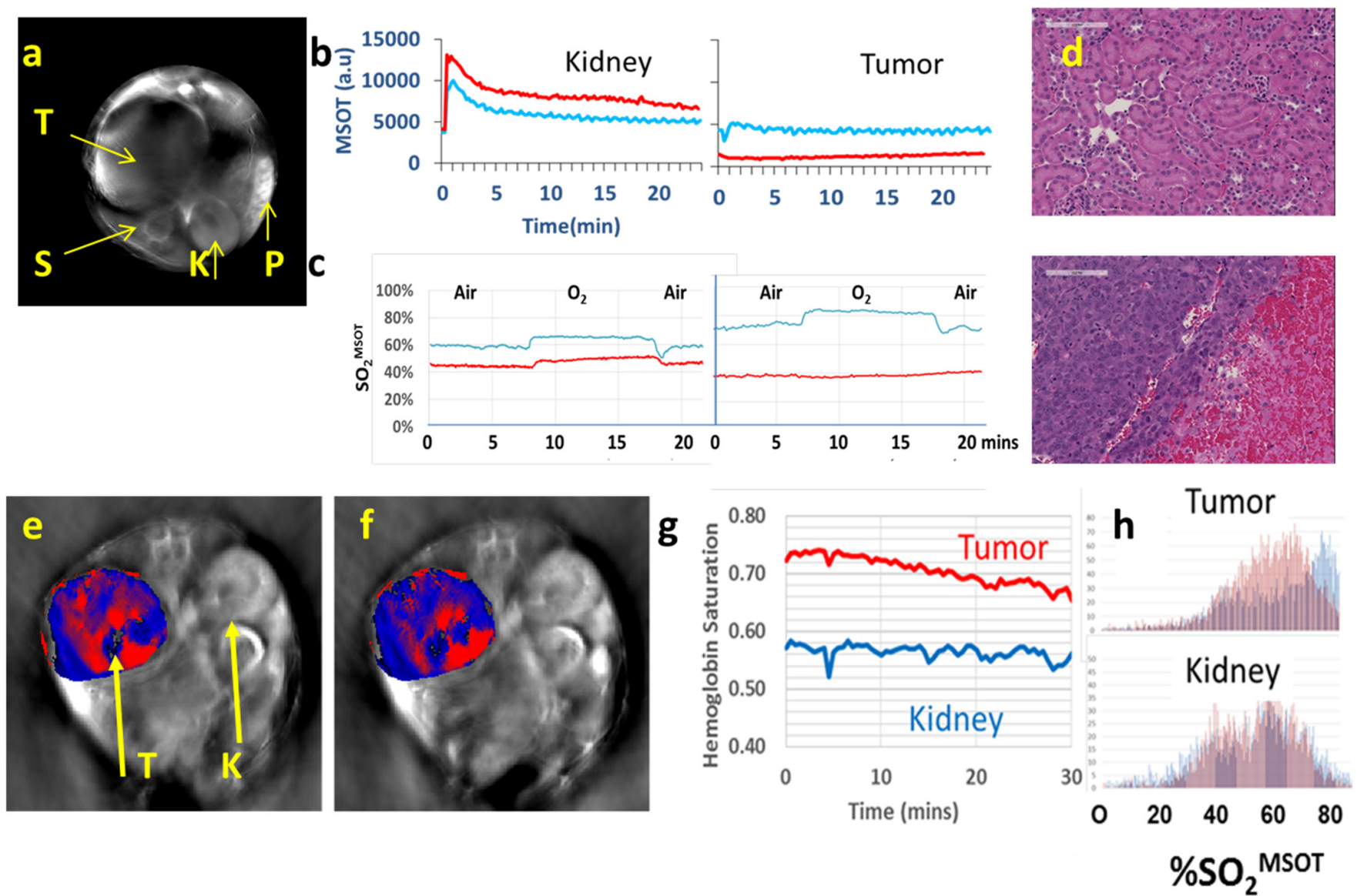

Figure 9. Photoacoustic assessment of vascular disruption in kidney tumors. (a) MSOT of orthotopic RENCA tumor in BALB/C mouse. Transaxial $800 \mathrm{~nm}$ MSOT image showing tumor (T), spine (S), contra lateral kidney (K) and spleen (P). (b) Dynamic contrast enhanced MSOT accompanying IV infusion of the blood pool agent Genhance. Similar curves were observed at baseline (blue) and $24 \mathrm{~h}$ (red) in kidney. In tumor, inflow of Genhance was observed at baseline, but much less at $24 \mathrm{~h}$ commensurate with vascular shutdown matching. Blue baseline and red $24 \mathrm{~h}$ after OXi8007 (350 mg/kg). (c) Traces showing hemoglobin oxygen saturation derived from dynamic MSOT images in spine and tumor accompanying oxygen-breathing challenge. Traces for the tumor showing baseline response, but no activity after $24 \mathrm{~h}$ indicating vascular shutdown. Area under the curve indicates about 95\% less signal. (d) H\&E stained section of RENCA tumor (lower panel) and contralateral kidney (upper panel) from resected tissue obtained $72 \mathrm{~h}$ after OXi8007. Extensive hemorrhage is seen in the tumor. (e) Acute response of human RCC XP373 to CA4P. Distinct anatomy is apparent in the transaxial slice MSOT image showing tumor $(\mathrm{T})$ and contralateral control kidney $(\mathrm{K})$. Red indicates predominant oxyhemoglobin and blue deoxyhemoglobin in tumor at baseline. (f) Regional hypoxiation is seen in the tumor vasculature following CA4P. (g) Dynamic changes were observed in tumor over $30 \mathrm{~min}$ following CA4P (120 mg/kg, IP), while contralateral normal kidney showed no change as confirmed in (h) histograms, verifying selective activity against the tumor. 


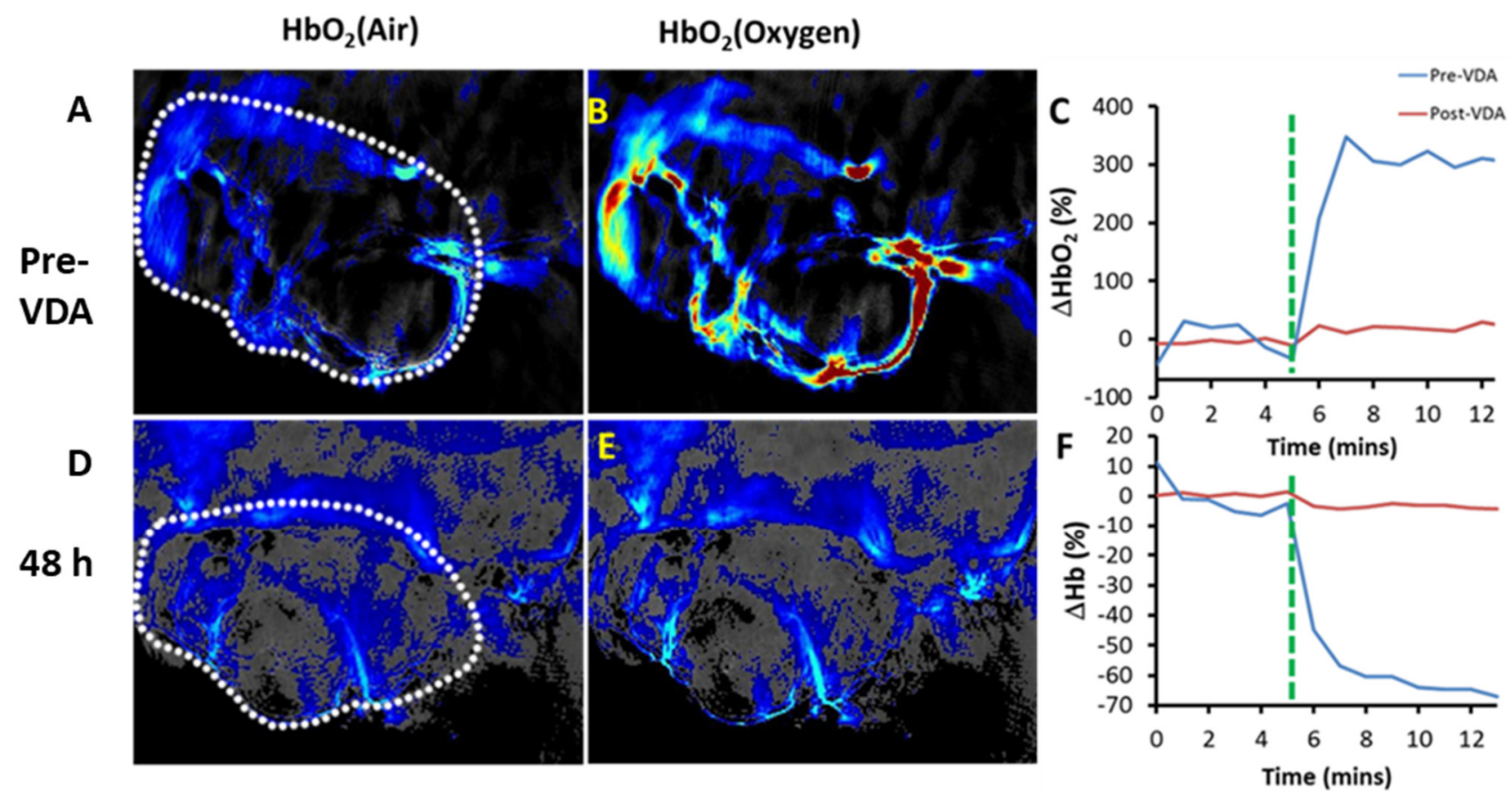

Figure 10. Photoacoustic imaging showed increase of oxyhemoglobin from air (A) to oxygen breathing (B) at baseline (tumor outlined in A and D). (D,E) Two days after the administration of VDA OXi6197 only minimal response to oxygen was observed. (A, D: air breathing; B, E: oxygen breathing). Comparison of normalized (C) oxy- $\left(\Delta \mathrm{HbO}_{2}\right)$ and $(\mathbf{F})$ deoxyhemoglobin $(\Delta \mathrm{Hb})$ at both time points. These data closely match the MRI obtained as part of the same study (Figure 7). Part of this Figure adapted from [175].

Hypoxia may be observed using oxygen-sensitive MRI including Blood Oxygen Level Dependent (BOLD) and Tissue Oxygen Level Dependent (TOLD) contrast [229-233]. In principle, vascular disruption causes ischemia and yields hypoxiation. Deoxyhemoglobin $(\mathrm{Hb})$ is paramagnetic leading to accelerated dephasing in transverse relaxation and increased $R_{2}{ }^{*}\left(1 / T_{2}{ }^{*}\right)$ related to [Hb] [126]. Indeed, Robinson et al. found a dose response increase in $\mathrm{R}_{2}$ * in both prolactinomas and RIF-1 fibrosarcomas following ZD6126 administration [126]. However, vascular collapse could lead to exclusion of blood from the tumor generating an opposite effect. Thomas et al. examined the BOLD response to a carbogen breathing challenge before and after administration of CA4P (100 mg/kg) to rat bladder tumor bearing mice and found much reduced response within $35 \mathrm{~min}$ [94]. The spin lattice relaxation rate, $\mathrm{R}_{1}$, is directly sensitive to $\mathrm{pO}_{2}$. One day after administering OXi6197 to a rat bearing a subcutaneous A549 lung tumor in the leg, the tumor $R_{2}{ }^{*}$ and $R_{1}$ showed little change under baseline air breathing conditions, but now there was much less response to an oxygen gas breathing challenge (much reduced $\Delta R_{1}$ and $\Delta R_{2}{ }^{*}$ ) indicating impaired perfusion and implying hypoxiation (Figure $7 \mathrm{~B}$ ). Changes in $R_{1}$ and $R_{2}{ }^{*}$ appear to be particularly effective at identifying tumor perfusion and lack of response is associated with hypoxia [231].

$$
\mathrm{Hb}+\mathrm{O}_{2} \longrightarrow \mathrm{HbO}_{2}
$$

However, high concentrations of $\mathrm{Hb}$, e.g., accompanying hemorrhage can also accelerate $R_{1}$, giving potentially anomalous results $[233,234]$. The signal changes observed using TOLD in response to a hyperoxic gas breathing challenge are much smaller than seen in DCE following Gd-contrast and thus TOLD must be performed first, as in Figure 7, or separate cohorts of animals used [95].

Hypoxiation is expected to enhance metabolic dependence on glycolysis, but the ratio of pyruvate to lactate was unchanged based on HP (hyperpolarized)-MRI [105], and others reported decreased intrinsic lactate $24 \mathrm{~h}$ after ZD6126 [235]. ${ }^{31} \mathrm{P}$ NMR indicated loss of high energy phosphate metabolites (ATP and PCr) and increased lactate in HT29 tumors 
$6 \mathrm{~h}$ following DMXAA [236]. Hypoxiation has been definitively examined using ${ }^{19} \mathrm{~F}$ MRI of the reporter molecule hexafluorobenzene (HFB) following intra tumoral injection and administration of OXi8007 IP [93]. Meanwhile, Diepart et al. [80] found increased $\mathrm{pO}_{2}$ based on ${ }^{19} \mathrm{~F}$ MRI of HFB in TLT tumors following administration of low dose ATO, which acted as a mitochondrial inhibitor, as opposed to showing the vascular disrupting activity observed at high doses [161].

MRI is particularly effective for observing the effects of VDA administration, but does require substantial expertise, magnets and associated hardware. In pre-clinical studies, it provides effective characterization of tumor heterogeneity, but suffers from low throughput and need for sophisticated image acquisition and data analysis, thereby reducing efficiency. The great strength is that observation may be made in rodents and reproduced in humans. MRI may not be feasible if the subject has metal implants or a pacemaker, or is particularly obese or severely claustrophobic.

\subsection{Photoacoustics-Multispectral Optoacoustic Tomography (MSOT)}

Photoacoustics has recently become feasible in many laboratories with the availability of commercial small animal imaging systems, as well as experimental devices suitable for patients in clinical trials (iThera (Munich, Germany) [237] and Fuji Visual Sonics (Toronto, ON, Canada) [238]. Notably, the iThera MSOT and Fuji Visual Sonics LAZR-X systems readily provide rapid high spatial resolution images (approaching $120 \mu \mathrm{m}$ in plane) of oxy- and deoxyhemoglobin. Single wavelength images may be acquired in $100 \mathrm{~ms}$ each, but the need for signal averaging and acquisition of several wavelengths to allow spectral unmixing for precise quantitation, typically provides temporal resolution of 1 to $20 \mathrm{~s}$. While the concept of photoacoustics was described over 100 years ago, it represents the newest modality available for probing dynamic vascular disrupting activity in vivo. Pulsed light at a specific wavelength is selectively absorbed by chromophores depending on concentration yielding local thermoelastic expansion and generating shock waves, which are detected using ultrasound transducers to provide spatial resolution. Oxy- and deoxyhemoglobin are both abundant and strongly absorbing, with well-defined separate spectra allowing vascular oxygen saturation to be estimated.

The iThera MSOT operates through excitation of a tissue plane ( 1 $\mathrm{mm}$ thick) using 10 fiber optic excitation bundles and an array of 128, 256 or 512 acoustic transducers placed toroidally around the subject providing a bore size of $4 \mathrm{~cm}$, which is ideal for investigating mice. Meanwhile, the LAZR excites and detects from a single direction, allowing the interrogation of larger subjects, but providing less uniform excitation and detection. The LAZR-X has the advantage of incorporating ultrasound excitation, which provides enhanced anatomical imaging and Doppler flow detection. This is also available on the iThera Acuity system, which is designed for larger animals and human investigations. Several studies have reported dynamic vascular response of tumors in mice or rats to vascular disruption caused by CA4P, CA1P and EPC2407 [92,118,119,130,239,240]. In most cases, changes in $\left[\mathrm{HbO}_{2}\right]$ and $[\mathrm{Hb}]$ are examined, thereby also revealing vascular oxygen saturation $\left(\mathrm{sO}_{2}\right)$. Ron et al. explored natural cycling hypoxia in human breast tumor xenografts in mice [241]. Tomaszewski et al. showed rigorously that the response to an oxygen gas breathing challenge provides a better picture of tumor oxygenation than a static baseline measure of $\mathrm{sO}_{2}$ alone [240]. Additionally, blood flow and perfusion may be revealed by DCE-MSOT following IV infusion of a strongly absorbing contrast agent such as ICG, Genhance or gold nanoparticles [240,242,243].

Rich \& Seshadri compared oxygen-sensitive MRI and photoacoustics to cross validate the observations [130], while Tomaszewski et al. compared oxygen-enhanced-MSOT and DCE-MSOT [240]. In other studies, immunohistochemistry was used to validate vascular perfusion and hypoxiation [92,240]. The commercial systems can observe large blood vessels and general oxygenation of the capillary bed (individual capillaries do not need to be resolved). Meanwhile, much higher resolution photoacoustic microcopy has been used 
to examine the vascular tree and show oxygenation and hypoxiation in individual blood vessels following administration of VDA [118].

Matching recent reports, we used an InVision 256-TF small animal imaging system to reveal spatial heterogeneity of tumor vasculature (Figures 8-10). We have applied three different paradigms to examine vascular disruption. Firstly, dynamic observation revealed changes in tumor hemoglobin oxygen-saturation response $\left(\Delta \mathrm{sO}_{2}\right)$ accompanying an $\mathrm{O}_{2}$-breathing challenge (Figures 8-10). At baseline, the tumor center of MDA-MB-231 tumors showed little response, but the tumor periphery showed a significant change, as also seen in the muscle surrounding the spine (Figure 8). Following administration of VDA the response to oxygen gas breathing challenge was much smaller as seen in the orthotopic MDA-MB-231 breast tumor (Figure 8), a syngeneic orthotopic RENCA kidney tumor (Figure 9) and a subcutaneous human A549 lung tumor xenograft in the leg of a rat (Figure 10). The response to an oxygen gas breathing challenge appears far more effective at revealing vascular patency and hypoxia compared with baseline measurements alone $[244,245]$. Secondly, progressive hypoxiation may be observed by continuous imaging following administration of VDA (Figures 8 and 9). Histograms of vascular oxygenation emphasized distinct hypoxiation (Figures 8 and 9). Response to oxygen gas challenge and progressive hypoxiation are apparent in the video (See Video S2). Thirdly, DCE-MSOT based on the pharmacokinetic distribution of a contrast agent such as ICG or Genhance reveals changes in perfusion [242,243]. MSOT is often applied to a single imaging plane through a tumor, but acquisition of multiple slices can readily provide 3D information. A typical experimental approach is described in Appendix C.

Similar to the breast tumors in Figure 8, vascular disruption has also been observed based on an oxygen gas breathing challenge at successive time points in orthotopic syngeneic RENCA tumors (Figure 9). In addition to detecting vascular shutdown based on an oxygen gas breathing challenge DCE-MSOT showed much reduced perfusion based on Genhance, while the contralateral kidney was largely unaffected by VDA (Figure 9b). MSOT is particularly well suited for investigations of the kidney and renal cell carcinoma (RCC) because of the extensive vasculature. The RENCA tumors also expressed luciferase and could have been assessed using BLI, but such transfection is not feasible in primary tumors (PDX and GEM models). We have also observed hypoxiation in human XP373 explant tumors following administration of OXi8007 IP (Figure 9). Hong et al. used MSOT to show that application of DMXAA could enhance the local trapping of gold nanoparticles in CT26 tumors thereby increasing the effectiveness of photothermal excitation and tumor growth delay [133]. Photoacoustic imaging revealed the uptake of gold nanoparticles and BLI was used to assess tumor progress following therapy. Liu et al. used MSOT to examine the activity of a novel poly(L-glutamic acid)-CA conjugate (PLG-CA4) designed to restrict transport and enhance accumulation in tumors [154]. In addition to evaluating changes in vascular oxygenation they added an IR820 fluorochrome allowing direct visualization of the PLG-CA4 itself. While most MSOT studies of VDA activity have been performed in tumor bearing mice, we have also observed vascular disruption in lung tumor xenografts growing in the leg of a rat (Figure 10). The A549 lung tumor has extremely sparse vasculature [246], but this is initially highly responsive to an oxygen gas breathing challenge. Two days after administration of the novel combretastatin analog OXi6197, the remaining vasculature showed minimal response, matching the MRI performed on the same tumors (Figure 7).

While spectral unmixing directly indicates relative concentrations of oxy- and de- oxyhemoglobin, spectral coloring can perturb effective quantitation at depth due to differential light absorption by overlying tissues. Recent studies have sought to compensate for spectral coloring [242]. Rapid image acquisition reveals motion [247], which could compromise effective spectral unmixing indicating a need for image co-registration. Acquisition of individual spectral frames can avoid averaging misregistered images, potentially allowing corrections or deletion of offset images. Additionally, appropriate filtering algorithms 
can enhance signal to noise and contrast, though they may also introduce damping into transitions [248].

It should be noted that oxygen breathing challenge (the simplest theranostic) is recognized as optimal for assessing vascular patency, as we have often used for MRI [231,249,250] and we and others now apply to MSOT [92,240,244,245]. Exogenous vascular contrast agents can also be used (e.g., ICG or Genhance) $[240,242,243]$ and could be particularly relevant for sparse vasculature where there is little hemoglobin signal (e.g., Figure 10).

MSOT directly reveals relative spatial and temporal variations of oxy- and deoxyhemoglobin concentrations without the need for exogenous reporter molecules or cell transfection with reporter genes $[245,251,252]$. While investigators often present $\mathrm{sO}_{2}$, it should be noted that values of $\left[\mathrm{HbO}_{2}\right]$ and $[\mathrm{Hb}]$ are not strictly quantitative and thus vascular oxygen saturation should be described as $\mathrm{sO}_{2}{ }^{\mathrm{MSOT}}$. Limited anatomical contrast is also observed (Figures 8 and 9). MSOT is however, a complicated procedure requiring considerable practice to achieve effective images and requiring sophisticated analysis. While all tissue may be observed in a mouse, the method becomes ineffective in melanin rich dark skinned mice. Rigorous hair removal essential, effective optical and acoustic contact are required using acoustic gel and it is important to ensure there are no bubbles. Some systems require mice to be immersed under water with breathing via a snorkel. Rapid image acquisition means that respiratory and cardiac motion may be observed and potentially co-registration should be applied to minimize motion artifacts. Animals are imaged individually. Photoacoustics may be enhanced with the development of new contrast agents, an area of active investigation [252,253].

\subsection{Other Modalities}

Ultrasound imaging (US) applies sound waves to a subject and receives echoes, which provide anatomical structures with exceedingly high spatial and temporal resolution. Blood flow and vasculature may be observed using color- or power-Doppler methods. These approaches have been applied to assess VDA activity in various species ranging from mouse to rat, rabbit, dog and human subjects $[5,74,91,109-112,161]$. Use of high frequency sound waves provides finer spatial resolution, but limits depth of signal penetration. Sound waves are also subject to severe scattering by bones and do not transmit through air. US can be entirely non-invasive, but Doppler methods do require sufficient flow to provide an observable signal. Examples of color-Doppler imaging of VDA activity are presented in Figure 11, for subcutaneous human tumor xenografts. The lung tumor showed very sparse vasculature, while much stronger flow was seen in the prostate tumor, with each showing substantial diminution after about $1.5 \mathrm{~h}$. A typical experimental approach is described in Appendix D. Observation of low flow regions may be enhanced using microbubble contrast [5], as exploited extensively by Abma et al. in canine subjects $[109,254]$. Alhasan et al. compared power Doppler with dynamic BLI showing consistent diminution in flow following administration of ATO based on both methods [161]. Meanwhile, fluorescent signal from constitutively expressed mCherry in transfected tumor cells showed no changes over $24 \mathrm{~h}$ following ATO.

Positron Emission Tomography (PET) uses coincidence detection of gamma rays following annihilation of a positron to determine the site of radioactive decay in a subject following administration of a positron-emitting isotope. Typical isotopes include ${ }^{15} \mathrm{O},{ }^{11} \mathrm{C}$ and ${ }^{13} \mathrm{~N}$ for labeled gases and water. Meanwhile, ${ }^{18} \mathrm{~F}$ FDG is now routinely used to assess metastatic spread based on the metabolic hyperactivity of tumors. PET is exceptionally sensitive allowing the use of very low concentrations of tracer, but spatial resolution is typically much poorer than MRI and temporal resolution is slow. The biggest obstacle to routine use is the need to safely handle radioactivity and the rapid decay of isotopes that have typically been used to assess flow $\left(\mathrm{T}_{1 / 2}{ }^{15} \mathrm{O}=122 \mathrm{~s}\right)$. There has been comparison of FDG PET and ${ }^{13} \mathrm{C}$ hyperpolarized NMR of pyruvate [105]. Uptake of ${ }^{18} \mathrm{~F}-\mathrm{FDG}$ in subcutaneous U251 glioblastoma xenografts was reduced following administration of 
DMXAA, likely due to both vascular disruption impeding delivery of FDG and also cell death after $24 \mathrm{~h}$ [141].
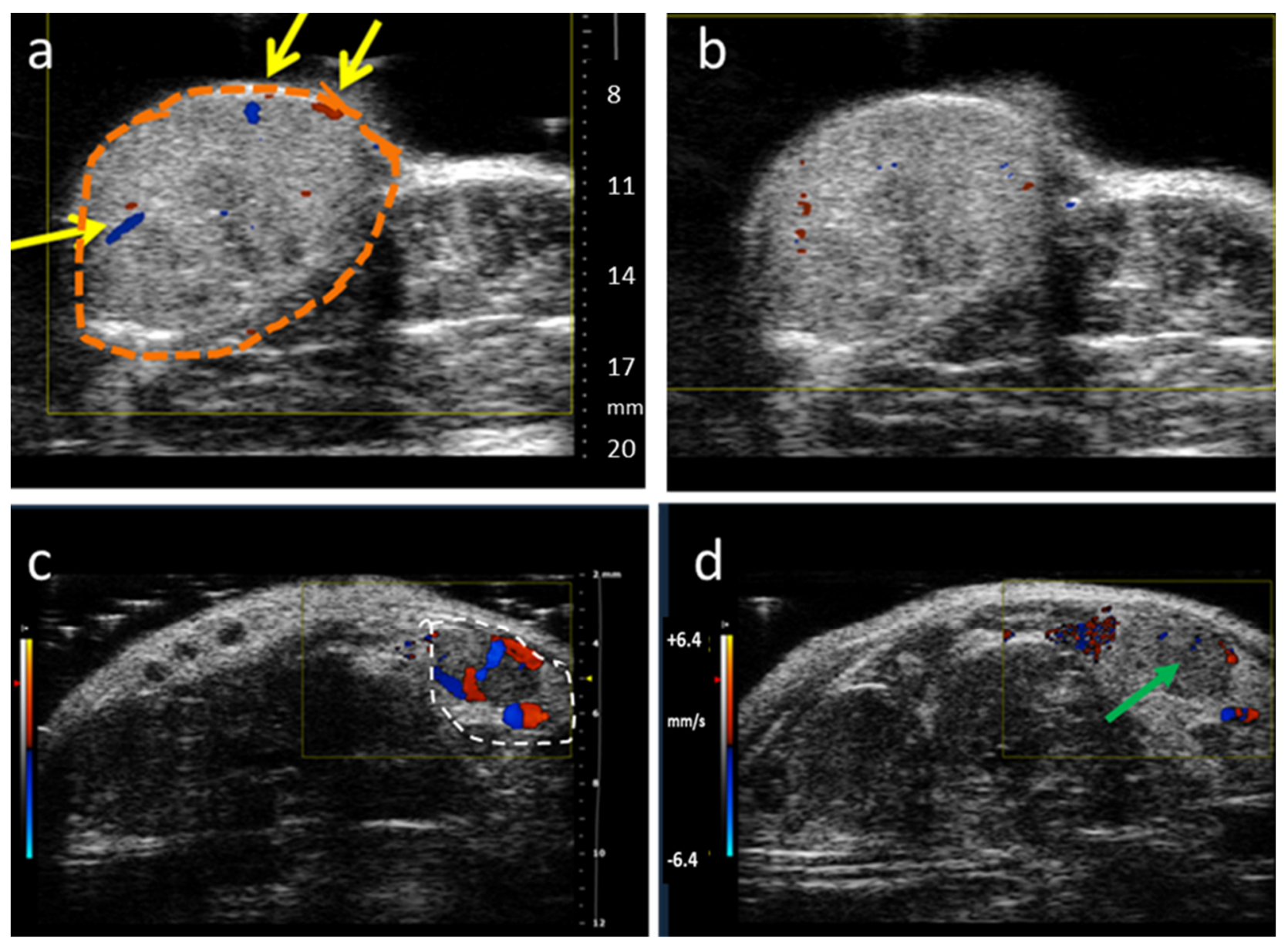

Figure 11. Color-Doppler ultrasound of tumor vascular oxygenation. A549 human lung tumor xenograft growing in hind leg of rat was imaged (a) before and (b) 90 min after administration of OXi6197 IP (15 mg/kg). A catheter with solution of OXi6197 was secured IP to avoid moving the animal during the experiment. Tumor outlined in orange, yellow arrows indicate regions of substantial flow, which was initially very sparse and diminished following administration of VDA. Transmit Frequency: $16 \mathrm{MHz}$ Similar study of subcutaneous human prostate tumor PC-3 xenograft in a SCID mouse observed (Transmit Frequency: $24 \mathrm{MHz}$ ) (c) immediately after and (d) about $80 \mathrm{~min}$ after injection of OXi8007 (350 mg/kg IP). This tumor was initially far better vascularized, but tumor perfusion was essentially halted by 80 min (green arrow), as published for other time points previously [74]. Heat scale bar representing flow in the range $\pm 64.2 \mathrm{~mm} / \mathrm{s}$. Both investigations were performed using a Vevo 2100.

Single photon emission computed tomography (SPECT). Other radioisotope approaches have explored SPECT/CT of ${ }^{131} \mathrm{I}$-Hoechst 33258 ( $\left.{ }^{131} \mathrm{I}-\mathrm{H} 33258\right)$ in W256 tumorbearing rats as an early predictive biomarker of tumor response to CA4P based on its avidity for necrotic tissue [113]. Planar scintigraphy was used to explore hypoxia in subcutaneous RIF-1 tumors following DMXAA or CA4P [255]. In each case ${ }^{99 \mathrm{~m}}$ Tc-labeled HL-91 (Prognox) and VDA were administered simultaneously and mice imaged $3 \mathrm{~h}$ later revealing increased uptake of ${ }^{99 \mathrm{~m}} \mathrm{Tc}$ and hence increased hypoxia. Studies additionally applied ${ }^{86} \mathrm{RbCl}$ to assess perfusion, though this required sacrifice and correction for residual radioactivity from the ${ }^{99 \mathrm{~m}} \mathrm{Tc}$.

Optical imaging. Tissue perfusion may be effectively observed based on fluorescenttagged substrates, though this is typically limited to superficial tissues. Dynamic contrast enhanced fluorescent imaging (DyCE FLI) has been applied to examine perfusion of 
subcutaneous tumors implanted in the backs of mice and reduced flow was observed following administration of CA4P [256]. Laser Doppler flowmetry can directly reveal flow, though signal is limited to very superficial tissues. Optical microscopy has been applied to tumors in superficial dorsal window chamber modes where vascular disruption could be assessed at high resolution, showing shutdown or individual vessels, as well as induced hyperactive permeability and leakage of contrast agents [257]. Hyperspectral imaging revealed changes in vascular oxygen saturation.

\subsection{Optimizing Combination Therapy}

As mentioned in the Introduction, effective treatment with VDAs will likely require combination therapy, specifically to overcome the peripheral surviving tumor tissue ring observed in most studies $[11,41,56,258]$. Imaging should be particularly effective in facilitating optimal combination based on timing and extent of acute vascular changes. Notably, enhanced permeability may promote delivery of additional drugs, though ischemia may limit access. Consequent hypoxia is expected to reduce the efficacy of radiation therapy, though could promote hypoxia activated pro-drugs [259].

Building on earlier DCE MRI evaluations of tumor perfusion following VDA treatment [106], Fruytier et al. established that delivery of gemcitabine was diminished in TLT hepatocarcinomas growing intramuscularly in mice $2 \mathrm{~h}$ after CA4P. They elegantly showed changes in vascular perfusion and permeability based on DCE-MRI, as well as assessing uptake and metabolic conversion of gemcitabine using ${ }^{19} \mathrm{~F}$ NMR spectroscopy [107]. Such an approach could allow effective determination of optimal timing of combined therapy by establishing both the pharmacokinetics and uptake of a particular therapeutic agent, as well as the pharmacodynamic vascular perturbation caused by the VDA.

Folaron et al. examined "vascular priming" to enhance the efficacy of several common chemotherapeutic drugs through combination with DMXAA. They specifically applied dynamic BLI to examine tumor growth and DCE-MRI to evaluate changes in tumor perfusion and permeability in relation to the efficacy of irinotecan, docetaxel, and doxorubicin [134]. Intriguingly, they found increased BLI signal $1 \mathrm{~h}$ after DMXAA suggesting enhanced delivery of luciferin substrate, but significantly diminished signal at $24 \mathrm{~h}$. consistent with vascular collapse, as confirmed by DCE-MRI.

Delivery of chemotherapeutic agents can be enhanced through active targeting and encapsulation in nanoparticles to improve local retention. Sun et al. designed a "cooperative polymeric platform" for tumor-targeted drug delivery. Recognizing that the peptide GNQEQVSPLTLLKXC (A15) is a substrate of activated blood coagulation factor XIII (a transglutaminase), they created A15 peptide-decorated poly(L-glutamic acid)-cisplatin conjugates as coagulation-targeted nanoparticles [140]. They then exploited the VDA DMXAA to induce hemorrhage in tumors yielding "a unique coagulation environment". Using MSOT they were able to convincingly show elevated uptake of such fluorescently (NIR830)labeled NPs after administration of DMXAA and ultimately demonstrate enhanced tumor growth delay in mice.

Zhao et al. showed distinct hypoxiation of 13762NF rat breast tumors within $30 \mathrm{~min}$ of $30 \mathrm{mg} / \mathrm{kg}$ CA4P using near infrared spectroscopy and additionally found that the tumors became essentially unresponsive to an oxygen gas breathing challenge at $2 \mathrm{~h}$, although some response was restored after $24 \mathrm{~h}$ [260]. This coincided with greatest tumor growth delay being achieved when tumors were irradiated ( $5 \mathrm{~Gy})$, while rats breathed oxygen $24 \mathrm{~h}$ after CA4P, whereas other sequences of treatment were less effective. Diepart et al. used ${ }^{19} \mathrm{~F}$ MRI to determine that tumor $\mathrm{pO}_{2}$ increased transiently for about $2 \mathrm{~h}$ after administration of ATO $(5 \mathrm{mg} / \mathrm{kg})$ to mice [80]. This suggested tumor irradiation at $90 \mathrm{~min}$ following ATO would be particularly effective, as indeed observed.

VDA induced hypoxia has also been explored to promote activation of bioreductivelyactivated prodrugs $[148,261]$. Notably, Shen et al. developed a paradigm for modulation of host immunological responses during cancer treatment by exploiting CA4 and the immune modulator Imiquimod (IMQ) [261]. Noting that TIE2+ tumor-associated macrophages 
$(\mathrm{M} \Phi)$ and endothelial progenitor cells have been reported to infiltrate tumors after treatment with CA4P, thereby promoting tumor angiogenesis, [262], it was reasoned that the immune modulator IMQ could potentially convert immature plasmacytoid dendritic cells (pDCs) into their active form, leading to the robust infiltration and priming of natural killer cells and cytotoxic T-lymphocytes in treated tumors. To seek tumor specificity a bioreducible prodrug hs-IMQ was prepared and co-administered with CA4 in poly(L-glutamic acid)-graft-methoxy poly(ethylene glycol nanoparticles (NPs). The NP depots ensured longer-term delivery/release of CA4, which induced additional tumor hypoxia promoting nitroreductase activity and IMQ release. Therapeutic efficacy in $4 \mathrm{~T} 1$ breast tumors in mice was enhanced. Pimonidazole was also administered to reveal increased hypoxia in tissue slices commensurate with release of IMQ. In vivo imaging was not applied, but this study represents an ideal opportunity for applying ${ }^{18} \mathrm{~F}$-miso PET, oxygen-sensitive MRI or MSOT to examine the dynamic evolution of hypoxia non-invasively.

\section{Discussion}

Diverse imaging modalities are available to provide non-invasive insights into the mode of action of vascular disrupting agents. Technologies offer various levels of resolution, sophistication, complexity and cost in terms of implementation as summarized in Table 4. The simplest observations are sensitive to flow and perfusion and readily reveal acute changes indicative of vascular disruption. Dose response may be determined efficiently since each tumor serves as its own control. The more sophisticated methods additionally reveal tumor heterogeneity and heterogeneity of response. Beyond flow and ischemia, other technologies can reveal hypoxiation, necrosis and more subtle pathophysiology and metabolism. Imaging has become increasingly routine in small animal preclinical research and is increasingly encouraged in companion studies to optimize clinical trials. Ultimately, assessment of the pharmacokinetics of drug delivery together with the pharmacodynamics of tumor pathophysiological response should enable more effective personalized medicine tailored to optimizing therapeutic efficacy based on predictive/prognostic imaging biomarkers.

Table 4. Comparison of imaging modalities.

\begin{tabular}{ccccccc}
\hline Modality & Cost & Throughput & $\begin{array}{c}\text { Spatial } \\
\text { Resolution }\end{array}$ & $\begin{array}{c}\text { Temporal } \\
\text { Resolution }\end{array}$ & $\begin{array}{c}\text { Need for } \\
\text { Contrast Agent }\end{array}$ & Ease of Use \\
\hline BLI & $\$$ & High 5-10 mice & Surface planar & $1 \mathrm{~s}$ & Yes & Easy \\
\hline MRI & $\$ \$ \$ \$$ & Usually single subject & $\begin{array}{c}200 \mu \mathrm{m} \text { in plane } \\
\times 2 \mathrm{~mm}\end{array}$ & s-mins & Typically, yes & Nophisticated \\
methods available
\end{tabular}

\section{Materials and Methods}

The results presented in Figures 1-11 are all unpublished though in many cases closely analogous to investigations presented previously. All studies were approved by the UTSW Institutional Animal Care and Use Committee and performed in line with State and Federal guidelines. Specific details are presented in the text and figure legends and general description of the technologies in the Appendix for each technology. 


\section{Patents}

1. Kevin G. Pinney, Haichan Niu, Depoprosad Mondal, "Benzosuberene Analogues and Related Compounds with Activity as Anticancer Agents" (United States Patent: US 10,807,932 B2), issued 20 October 2020.

2. Kevin G. Pinney and Madhavi Sriram, "Combretastatin Analogs with Tubulin Binding Activity" (United States Patent: US 8,394,859), issued 12 March 2013.

3. David J. Chaplin, Klaus Edvardsen, Kevin G. Pinney, Joseph Prezioso, Mark Wood, "Compositions and Methods with Enhanced Therapeutic Activity" (United States Patent: US 8,198,302), issued 12 June 2012.

4. Kevin G. Pinney, Feng Wang, Maria Del Pilar Mejia, "Indole-Containing and Combre tastatin-Related Anti-Mitotic and Anti-Tubulin Polymerization Agents" (EP 1214298 B1), issued 30 May 2012.

Supplementary Materials: The following are available online, Video S1. Dynamic BLI of MDA-MB231-luc breast tumor following injection of luciferin and effect of VDA (OXi8007 $250 \mathrm{mg} / \mathrm{kg} \mathrm{IP}$ ). Video S2. Dynamic MSOT of MDA-MB-231 breast tumor with respect to an oxygen gas breathing challenge and following administration of CA4P $(120 \mathrm{mg} / \mathrm{kg}$, IP) showing tumor heterogeneity and the effect of VDA.

Author Contributions: Conceptualization, L.L., M.L.T., K.G.P. and R.P.M.; methodology, L.L., D.O., R.S., H.Z.; software, D.O., H.Z.; validation, L.L., D.O., H.Z., R.P.M.; formal analysis, L.L., D.O., R.P.M.; investigation, L.L., D.O., H.Z., M.L.T., K.G.P. and R.P.M.; resources, L.L., M.L.T., K.G.P., R.P.M.; data curation, L.L., D.O., H.Z.; writing-original draft preparation, L.L., R.P.M.; writing-review and editing, L.L., G.C., M.L.T., K.G.P., R.P.M.; supervision, K.G.P., R.P.M.; project administration, K.G.P., R.P.M.; funding acquisition, L.L., M.L.T., K.G.P., R.P.M. All authors have read and agreed to the published version of the manuscript.

Funding: Studies were facilitated in part by grants from the National Institutes of Health National Cancer Institute (5R01 CA140674 and 1R01CA244579-01A1 to KGP, MLT, RPM, LL), Mateon Therapeutics, Inc. (to KGP, MLT), Cancer Prevention and Research Institute of Texas (CPRIT, RP100406, RP140399, to KGP, MLT, RPM, LL), and infrastructure provided by the Southwestern Small Animal Imaging Resource (SW-SAIR) supported in part by 1U24 CA126608 and P30 CA142543 and Shared Instrumentation grants S10 OD018094-01A1, 1S10 RR024757, and S10 RR031859.

Institutional Review Board Statement: All animal procedures were approved by the Institutional Animal Care and Use Committee of the University of Texas Southwestern Medical Center.

Informed Consent Statement: Not applicable.

Data Availability Statement: The data presented in this study are available on request from the corresponding author.

Acknowledgments: Jenifer Gerberich, Ramona Lopez, Luis Vasquez and Maoping Li acquired preliminary BLI data. 4T1 tumor cells were kindly provided by Professor Edward Graves (Stanford), XP373 by James Brugarolas (UTSW), human lung cancer A549-luc cells by Jerry Shay (UTSW) and RENCA-luc by Hans Hammers (UTSW). David J. Chaplin of Mateon Therapeutics, Inc. kindly provided CA4P. Erin E. Moore, MA of the Creative Services group kindly generated Figure 1.

Conflicts of Interest: The funders had no role in the design of the study; in the collection, analyses, or interpretation of data; in the writing of the manuscript, or in the decision to publish the results. KGP holds several patents relevant to the synthesis and use of vascular disrupting agents.

Sample Availability: The authors are eager to establish collaboration and can provide materials upon execution of appropriate Materials Transfer Agreement and financial support to cover expenses.

\section{Appendix A. Typical Procedure for BLI}

BLI: For effective bioluminescence imaging mice bearing luciferase transfected tumors (e.g., MDA-MB-231-luc) are anaesthetized $\left(\mathrm{O}_{2}, 2 \%\right.$ isoflurane), placed on the heated bed of an IVIS Spectrum instrument and injected subcutaneously in the fore-back neck region with $80 \mu \mathrm{L}$ of a solution of luciferase substrate, $D$-luciferin (sodium salt, $120 \mathrm{mg} / \mathrm{kg}$, as 
$40 \mathrm{mg} / \mathrm{mL}$ solution in saline). Mice are maintained under anesthesia ( $2 \%$ isoflurane in oxygen, $1 \mathrm{dm}^{3} / \mathrm{min}$,) while baseline bioluminescence imaging is performed often over a period of $30 \mathrm{~min}$. VDA is administered after baseline BLI and BLI is repeated, with new luciferin injections at later times, e.g., 4, 24, 48, 72 and 96 h. Between 3 and 10 mice may generally be imaged simultaneously. Quantitative data as photon flux were automatically normalized for camera aperture, camera to subject distance and exposure time. For each mouse a region of interest (ROI) was selected, which was readily identified based on the appearance of the tumor in the photograph and more importantly the emitted light. Since there is essentiality, no background signal, contours may extend beyond the tumor without significantly altering the measured light intensity $[129,256]$.

\section{Appendix B. Typical Procedure for MRI}

MRI: Magnetic resonance imaging is typically performed on a tumor bearing mouse or rat using a horizontal bore scanner. Anesthesia is induced at $3 \%$ isoflurane in air and maintained with isoflurane $(1.5 \%)$ in air $(1 \mathrm{~L} / \mathrm{min})$ and the animal is kept warm using a circulating warm water blanket. Animal body temperature and respiration are monitored with a small animal physiological monitoring system. $\mathrm{T}_{1}$ maps (spin echo) are acquired during initial air breathing and with an oxygen challenge prior to DCE. Interleaved BOLD (multi-echo gradient echo) and TOLD (gradient echo) MRI are acquired during an oxygen breathing challenge (from air to $100 \% \mathrm{O}_{2}$ after about $10 \mathrm{~min}$ ). For DCE (spin echo) gadolinium contrast (e.g., $0.1 \mathrm{mmol} / \mathrm{kg}$ body weight Gadovist) is injected IV and a series of $T_{1}$-weighted images is acquired over a period of 20 min, ideally with sufficient time resolution to capture the transient rapid inflow of contrast. Extensive image processing provides images revealing changes in signal sensitivity and parametric functions such as transport functions $[209,246]$.

\section{Appendix C. Typical Procedure for MSOT}

MSOT: Animals are anesthetized in an induction chamber (isoflurane/oxygen). As needed, they are shaved and NAIR used for thorough depilation. Degassed warmed acoustic gel is applied to the torso/tumor regions to be imaged and a nose cone (snorkel) applied to maintain anesthesia. For imaging with the InVision 256-TF small animal imaging system the animal in wrapped in a polyethylene membrane and placed in an animal holder which is placed in the imaging chamber where the water temperature is maintained at $35^{\circ} \mathrm{C}$. Multi wavelength data sets are acquired to image oxy- and deoxyhemoglobin. Dynamic observations are performed with a preliminary oxygen challenge, followed by a short stabilization period on air, VDA administration in situ IP, and continuous imaging for $60 \mathrm{~min}$. Oxygen gas challenge may be repeated at later times. Contrast agent such as Genhance may also be infused to examine tumor perfusion by analysis with DCEMRI [92,240,242].

\section{Appendix D. Typical Procedure for US for Dog and Mouse}

Ultrasound: Skin over tumor must be thoroughly shaved and depilated with NAIR lotion to ensure complete local hair removal. The animal is anesthetized ( $2 \%$ isoflurane in oxygen), and acoustic gel applied to ensure effective ultrasound coupling to the solid-state transducers, typically $24 \mathrm{MHz}$ ) (Typical Procedure for US for Dog [109], Mouse [161]). Data may be acquired using $B$ and color- or power-Doppler modes. Contrast may be enhanced by IV infusion of a microbubble contrast agent.

\section{References}

1. Folkman, J. Tumor angiogenesis. Adv. Cancer Res. 1985, 43, 175-203. [CrossRef]

2. Siemann, D.W.; Bibby, M.C.; Dark, G.G.; Dicker, A.P.; Eskens, F.A.; Horsman, M.R.; Marme, D.; Lorusso, P.M. Differentiation and definition of vascular-targeted therapies. Clin. Cancer Res. 2005, 11, 416-420.

3. Denekamp, J. Vascular Attack as a Therapeutic Strategy for Cancer. Cancer Metastasis Rev. 1990, 9, 267-282. [CrossRef] [PubMed]

4. Tozer, G.M.; Kanthou, C.; Baguley, B.C. Disrupting tumour blood vessels. Nat. Rev. Cancer 2005, 5, 423-435. [CrossRef] [PubMed] 
5. Mason, R.P.; Zhao, D.W.; Liu, L.; Trawick, M.L.; Pinney, K.G. A perspective on vascular disrupting agents that interact with tubulin: Preclinical tumor imaging and biological assessment. Integr. Biol. 2011, 3, 375-387. [CrossRef] [PubMed]

6. Thorpe, P.E. Vascular targeting agents as cancer therapeutics. Clin. Cancer Res. 2004, 10, 415-427. [CrossRef]

7. McDonald, D.M.; Choyke, P.L. Imaging of angiogenesis: From microscope to clinic. Nat. Med. 2003, 9, 713-725. [CrossRef]

8. Kanthou, C.; Tozer, G.M. Microtubule depolymerizing vascular disrupting agents: Novel therapeutic agents for oncology and other pathologies. Int. J. Exp. Pathol. 2009, 90, 284-294. [CrossRef]

9. Jayson, G.C.; Kerbel, R.; Ellis, L.M.; Harris, A.L. Antiangiogenic therapy in oncology: Current status and future directions. Lancet 2016, 388, 518-529. [CrossRef]

10. Siemann, D.W. The unique characteristics of tumor vasculature and preclinical evidence for its selective disruption by TumorVascular Disrupting Agents. Cancer Treat. Rev. 2011, 37, 63-74. [CrossRef]

11. Liang, W.; Ni, Y.; Chen, F. Tumor resistance to vascular disrupting agents: Mechanisms, imaging, and solutions. Oncotarget 2016, 7, 15444-15459. [CrossRef]

12. Hill, S.A.; Lonergan, S.J.; Denekamp, J.; Chaplin, D.J. Vinca Alkaloids-Antivascular Effects in a Murine Tumor. Eur. J. Cancer 1993, 29, 1320-1324. [CrossRef]

13. Bai, R.; Hamel, E. (-)-Rhazinilam and the diphenylpyridazinone NSC 613241: Two compounds inducing the formation of morphologically similar tubulin spirals but binding apparently to two distinct sites on tubulin. Arch. Biochem. Biophys. 2016, 604, 63-73. [CrossRef] [PubMed]

14. Pettit, G.R.; Singh, S.B.; Niven, M.L.; Hamel, E.; Schmidt, J.M. Isolation, structure, and synthesis of combretastatins A-1 and B-1, potent new inhibitors of microtubule assembly, derived from Combretum caffrum. J. Nat. Prod. 1987, 50, 119-131. [CrossRef] [PubMed]

15. Pettit, G.R.; Singh, S.B.; Hamel, E.; Lin, C.M.; Alberts, D.S.; Garcia-Kendall, D. Isolation and structure of the strong cell growth and tubulin inhibitor combretastatin A-4. Experientia 1989, 45, 209-211. [CrossRef]

16. Kanthou, C.; Tozer, G.M. The tumor vascular targeting agent combretastatin A-4-phosphate induces reorganization of the actin cytoskeleton and early membrane blebbing in human endothelial cells. Blood 2002, 99, 2060-2069. [CrossRef]

17. Strecker, T.E.; Odutola, S.O.; Lopez, R.; Cooper, M.S.; Tidmore, J.K.; Charlton-Sevcik, A.K.; Li, L.; MacDonough, M.T.; Hadimani, M.B.; Ghatak, A.; et al. The vascular disrupting activity of OXi8006 in endothelial cells and its phosphate prodrug OXi8007 in breast tumor xenografts. Cancer Lett. 2015, 369, 229-241. [CrossRef]

18. Sheng, Y.; Hua, J.; Pinney, K.G.; Garner, C.M.; Kane, R.R.; Prezioso, J.A.; Chaplin, D.J.; Edvardsen, K. Combretastatin family member OXI4503 induces tumor vascular collapse through the induction of endothelial apoptosis. Int. J. Cancer 2004, 111, 604-610. [CrossRef]

19. Nepali, K.; Ojha, R.; Lee, H.Y.; Liou, J.P. Early investigational tubulin inhibitors as novel cancer therapeutics. Expert Opin. Investig. Drugs 2016, 25, 917-936. [CrossRef] [PubMed]

20. Chase, D.M.; Chaplin, D.J.; Monk, B.J. The development and use of vascular targeted therapy in ovarian cancer. Gynecol. Oncol. 2017, 145, 393-406. [CrossRef]

21. Sosa, J.A.; Elisei, R.; Jarzab, B.; Bal, C.S.; Koussis, H.; Gramza, A.W.; Ben-Yosef, R.; Gitlitz, B.J.; Haugen, B.; Karandikar, S.M.; et al. A randomized phase II/III trial of a tumor vascular disrupting agent fosbretabulin tromethamine (CA4P) with carboplatin (C) and paclitaxel (P) in anaplastic thyroid cancer (ATC): Final survival analysis for the FACT trial. J. Clin. Oncol. 2011, $29,5502$. [CrossRef]

22. Ya-Ting, J.; Yan-Na, L.; Zhao-Peng, L. Tubulin Colchicine Binding Site Inhibitors as Vascular Disrupting Agents in Clinical Developments. Curr. Med. Chem. 2015, 22, 1348-1360. [CrossRef]

23. Blay, J.Y.; Pápai, Z.; Tolcher, A.W.; Italiano, A.; Cupissol, D.; López-Pousa, A.; Chawla, S.P.; Bompas, E.; Babovic, N.; Penel, N.; et al. Ombrabulin plus cisplatin versus placebo plus cisplatin in patients with advanced soft-tissue sarcomas after failure of anthracycline and ifosfamide chemotherapy: A randomised, double-blind, placebo-controlled, phase 3 trial. Lancet Oncol. 2015, 16, 531-540. [CrossRef]

24. O'Connor, J.P.; Jackson, A.; Parker, G.J.; Roberts, C.; Jayson, G.C. Dynamic contrast-enhanced MRI in clinical trials of antivascular therapies. Nat. Rev. Clin. Oncol. 2012, 9, 167-177. [CrossRef]

25. Smolarczyk, R.; Czapla, J.; Jarosz-Biej, M.; Czerwinski, K.; Cichon, T. Vascular disrupting agents in cancer therapy. Eur. J. Pharmacol. 2021, 891, 173692. [CrossRef] [PubMed]

26. Ng, Q.S.; Goh, V.; Carnell, D.; Meer, K.; Padhani, A.R.; Saunders, M.I.; Hoskin, P.J. Tumor antivascular effects of radiotherapy combined with combretastatin a4 phosphate in human non-small-cell lung cancer. Int. J. Radiat. Oncol. Biol. Phys. 2007, 67, 1375-1380. [CrossRef]

27. Galbraith, S.M.; Maxwell, R.J.; Lodge, M.A.; Tozer, G.M.; Wilson, J.; Taylor, N.J.; Stirling, J.J.; Sena, L.; Padhani, A.R.; Rustin, G.J.S. Combretastatin A4 phosphate has tumor antivascular activity in rat and man as demonstrated by dynamic magnetic resonance imaging. J. Clin. Oncol. 2003, 21, 2831-2842. [CrossRef]

28. Stevenson, J.P.; Rosen, M.; Sun, W.; Gallagher, M.; Haller, D.G.; Vaughn, D.; Giantonio, B.; Zimmer, R.; Petros, W.P.; Stratford, M.; et al. Phase I trial of the antivascular agent combretastatin A4 phosphate on a 5-day schedule to patients with cancer: Magnetic resonance imaging evidence for altered tumor blood flow. J. Clin. Oncol. 2003, 21, 4428-4438. [CrossRef] [PubMed] 
29. Dowlati, A.; Robertson, K.; Cooney, M.; Petros, W.P.; Stratford, M.; Jesberger, J.; Rafie, N.; Overmoyer, B.; Makkar, V.; Stambler, B.; et al. A phase I pharmacokinetic and translational study of the novel vascular targeting agent combretastatin a-4 phosphate on a single-dose intravenous schedule in patients with advanced cancer. Cancer Res. 2002, 62, 3408-3416.

30. Koh, D.M.; Blackledge, M.; Collins, D.J.; Padhani, A.R.; Wallace, T.; Wilton, B.; Taylor, N.J.; Stirling, J.J.; Sinha, R.; Walicke, P.; et al. Reproducibility and changes in the apparent diffusion coefficients of solid tumours treated with combretastatin A4 phosphate and bevacizumab in a two-centre phase I clinical trial. Eur. Radiol. 2009, 19, 2728-2738. [CrossRef]

31. Anderson, H.L.; Yap, J.T.; Miller, M.P.; Robbins, A.; Jones, T.; Price, P.M. Assessment of pharmacodynamic vascular response in a phase I trial of combretastatin A4 phosphate. J. Clin. Oncol. 2003, 21, 2823-2830. [CrossRef]

32. Patterson, D.M.; Zweifel, M.; Middleton, M.R.; Price, P.M.; Folkes, L.K.; Stratford, M.R.L.; Ross, P.; Halford, S.; Peters, J.; Balkissoon, J.; et al. Phase I Clinical and Pharmacokinetic Evaluation of the Vascular-Disrupting Agent OXi4503 in Patients with Advanced Solid Tumors. Clin. Cancer Res. 2012, 18, 1415-1425. [CrossRef] [PubMed]

33. Rischin, D.; Bibby, D.C.; Chong, G.; Kremmidiotis, G.; Leske, A.F.; Matthews, C.A.; Wong, S.S.; Rosen, M.A.; Desai, J. Clinical, pharmacodynamic, and pharmacokinetic evaluation of BNC105P: A phase I trial of a novel vascular disrupting agent and inhibitor of cancer cell proliferation. Clin. Cancer Res. 2011, 17, 5152-5160. [CrossRef] [PubMed]

34. Lickliter, J.D.; Francesconi, A.B.; Smith, G.; Burge, M.; Coulthard, A.; Rose, S.; Griffin, M.; Milne, R.; McCarron, J.; Yeadon, T.; et al. Phase I trial of CYT997, a novel cytotoxic and vascular-disrupting agent. Br. J. Cancer 2010, 103, 597-606. [CrossRef]

35. Conte, G.D.; Bahleda, R.; Moreno, V.; Damian, S.; Perotti, A.; Lassau, N.; Farace, F.; Ong, M.; Stimpson, S.J.; Tunariu, N.; et al. A phase I study of ombrabulin (O) combined with bevacizumab (B) in patients with advanced solid tumors (NCT01193595). J. Clin. Oncol. 2012, 30, 3080. [CrossRef]

36. Mita, M.M.; Spear, M.A.; Yee, L.K.; Mita, A.C.; Heath, E.I.; Papadopoulos, K.P.; Federico, K.C.; Reich, S.D.; Romero, O.; Malburg, L.; et al. Phase 1 first-in-human trial of the vascular disrupting agent plinabulin(NPI-2358) in patients with solid tumors or lymphomas. Clin. Cancer Res. 2010, 16, 5892-5899. [CrossRef]

37. Evelhoch, J.L.; LoRusso, P.M.; He, Z.; DelProposto, Z.; Polin, L.; Corbett, T.H.; Langmuir, P.; Wheeler, C.; Stone, A.; Leadbetter, J.; et al. Magnetic resonance imaging measurements of the response of murine and human tumors to the vascular-targeting agent ZD6126. Clin. Cancer Res. 2004, 10, 3650-3657. [CrossRef] [PubMed]

38. Lorza, A.M.A.; Ravi, H.; Philip, R.C.; Galons, J.P.; Trouard, T.P.; Parra, N.A.; Von Hoff, D.D.; Read, W.L.; Tibes, R.; Korn, R.L.; et al. Dose-response assessment by quantitative MRI in a phase 1 clinical study of the anti-cancer vascular disrupting agent crolibulin. Sci. Rep. 2020, 10, 14449. [CrossRef]

39. Ricart, A.D.; Ashton, E.A.; Cooney, M.M.; Sarantopoulos, J.; Brell, J.M.; Feldman, M.A.; Ruby, K.E.; Matsuda, K.; Munsey, M.S.; Medina, G.; et al. A phase I study of MN-029 (denibulin), a novel vascular-disrupting agent, in patients with advanced solid tumors. Cancer Chemother. Pharmacol. 2011, 68, 959-970. [CrossRef]

40. McKeage, M.; Fong, P.; Jeffery, M.; Baguley, B.C.; Kestell, P.; Ravic, M.; Jameson, M.B. 5,6-Dimethylxanthenone-4-acetic acid in the treatment of refractory tumors: A phase I safety study of a vascular disrupting agent. Clin. Cancer Res. 2006, 12, 1776-1784. [CrossRef]

41. Horsman, M.R.; Siemann, D.W. Pathophysiologic effects of vascular-targeting agents and the implications for combination with conventional therapies. Cancer Res. 2006, 66, 11520-11539. [CrossRef]

42. Clemenson, C.; Chargari, C.; Deutsch, E. Combination of vascular disrupting agents and ionizing radiation. Crit. Rev. Oncol. Hematol. 2013, 86, 143-160. [CrossRef] [PubMed]

43. Pedley, R.B.; Hill, S.A.; Boxer, G.M.; Flynn, A.A.; Boden, R.; Watson, R.; Dearling, J.; Chaplin, D.J.; Begent, R.H. Eradication of colorectal xenografts by combined radioimmunotherapy and combretastatin a-4 3-O-phosphate. Cancer Res. 2001, 61, 4716-4722. [PubMed]

44. Kim, M.Y.; Shin, J.Y.; Kim, J.O.; Son, K.H.; Kim, Y.S.; Jung, C.K.; Kang, J.H. Anti-tumor efficacy of CKD-516 in combination with radiation in xenograft mouse model of lung squamous cell carcinoma. BMC Cancer 2020, 20, 1057. [CrossRef] [PubMed]

45. Satterlee, A.B.; Rojas, J.D.; Dayton, P.A.; Huang, L. Enhancing Nanoparticle Accumulation and Retention in Desmoplastic Tumors via Vascular Disruption for Internal Radiation Therapy. Theranostics 2017, 7, 253-269. [CrossRef]

46. Horsman, M.R. Enhancing the radiation response of tumors but not early or late responding normal tissues using a vascular disrupting agent. Acta Oncol. 2017, 56, 1634-1638. [CrossRef] [PubMed]

47. Siemann, D.W.; Chaplin, D.J.; Horsman, M.R. Realizing the Potential of Vascular Targeted Therapy: The Rationale for Combining Vascular Disrupting Agents and Anti-Angiogenic Agents to Treat Cancer. Cancer Investig. 2017, 35, 519-534. [CrossRef] [PubMed]

48. Tewari, K.S.; Sill, M.W.; Coleman, R.L.; Aghajanian, C.; Mannel, R.; DiSilvestro, P.A.; Powell, M.; Randall, L.M.; Farley, J.; Rubin, S.C.; et al. Bevacizumab plus fosbretabulin in recurrent ovarian cancer: Overall survival and exploratory analyses of a randomized phase II NRG oncology/gynecologic oncology group study. Gynecol. Oncol. 2020, 159, 79-87. [CrossRef]

49. Martinelli, M.; Bonezzi, K.; Riccardi, E.; Kuhn, E.; Frapolli, R.; Zucchetti, M.; Ryan, A.J.; Taraboletti, G.; Giavazzi, R. Sequence dependent antitumour efficacy of the vascular disrupting agent ZD6126 in combination with paclitaxel. Br. J. Cancer 2007, 97, 888-894. [CrossRef] [PubMed]

50. Rustin, G.J.; Shreeves, G.; Nathan, P.D.; Gaya, A.; Ganesan, T.S.; Wang, D.; Boxall, J.; Poupard, L.; Chaplin, D.J.; Stratford, M.R.; et al. A Phase Ib trial of CA4P (combretastatin A-4 phosphate), carboplatin, and paclitaxel in patients with advanced cancer. Br. J. Cancer 2010, 102, 1355-1360. [CrossRef] 
51. Staflin, K.; Jarnum, S.; Hua, J.; Honeth, G.; Kannisto, P.; Lindvall, M. Combretastatin A-1 phosphate potentiates the antitumor activity of carboplatin and paclitaxel in a severe combined immunodeficiency disease (SCID) mouse model of human ovarian carcinoma. Int. J. Gynecol. Cancer 2006, 16, 1557-1564. [CrossRef]

52. Yeung, S.C.; She, M.; Yang, H.; Pan, J.; Sun, L.; Chaplin, D. Combination chemotherapy including combretastatin A4 phosphate and paclitaxel is effective against anaplastic thyroid cancer in a nude mouse xenograft model. J. Clin. Endocrinol. Metab. 2007, 92, 2902-2909. [CrossRef]

53. Gao, M.; Zhang, D.J.; Yao, N.; Jin, Q.M.; Jiang, C.H.; Zhang, J.; Wang, F. Enhancing intratumoral biodistribution and antitumor activity of nab-paclitaxel through combination with a vascular disrupting agent, combretastatin A-4-phosphate. Cancer Chemother. Pharmacol. 2019, 84, 1187-1194. [CrossRef] [PubMed]

54. Pal, S.; Azad, A.; Bhatia, S.; Drabkin, H.; Costello, B.; Sarantopoulos, J.; Kanesvaran, R.; Lauer, R.; Starodub, A.; Hauke, R.; et al. A Phase I/II Trial of BNC105P with Everolimus in Metastatic Renal Cell Carcinoma. Clin. Cancer Res. 2015, 21, 3420-3427. [CrossRef]

55. Bellone, M.; Mondino, A.; Corti, A. Vascular targeting, chemotherapy and active immunotherapy: Teaming up to attack cancer. Trends Immunol. 2008, 29, 235-241. [CrossRef] [PubMed]

56. Horsman, M.R.; Wittenborn, T.R.; Nielsen, P.S.; Elming, P.B. Tumors Resistant to Checkpoint Inhibitors Can Become Sensitive after Treatment with Vascular Disrupting Agents. Int. J. Mol. Sci. 2020, 21, 4778. [CrossRef] [PubMed]

57. Cui, M.T.; Jiang, L.; Goto, M.; Hsu, P.L.; Li, L.; Zhang, Q.; Wei, L.; Yuan, S.J.; Hamel, E.; Morris-Natschke, S.L.; et al. In Vivo and Mechanistic Studies on Antitumor Lead 7-Methoxy-4-(2-methylquinazolin-4-yl)-3,4-dihydroquinoxalin-2(1H)-one and Its Modification as a Novel Class of Tubulin-Binding Tumor-Vascular Disrupting Agents. J. Med. Chem. 2017, 60, 5586-5598. [CrossRef] [PubMed]

58. Chen, M.; Lei, X.; Shi, C.; Huang, M.; Li, X.; Wu, B.; Li, Z.; Han, W.; Du, B.; Hu, J.; et al. Pericyte-targeting prodrug overcomes tumor resistance to vascular disrupting agents. J. Clin. Investig. 2017, 127, 3689-3701. [CrossRef]

59. Rickardson, L.; Kutvonen, E.; Orasniemi, S.; Hogberg, M.; Kallio, M.J.; Rehnmark, S. Evaluation of the antitumor activity of NOV202, a novel microtubule targeting and vascular disrupting agent. Drug Des. Dev. Ther. 2017, 11, 1335-1351. [CrossRef] [PubMed]

60. Brown, A.W.; Holmes, T.; Fisher, M.; Tozer, G.M.; Harrity, J.P.A.; Kanthou, C. Evaluation of Sydnone-Based Analogues of Combretastatin A-4 Phosphate (CA4P) as Vascular Disrupting Agents for Use in Cancer Therapy. ChemMedChem 2018, 13, 2618-2626. [CrossRef]

61. Zhai, X.; Wang, X.; Wang, J.; Liu, J.; Zuo, D.; Jiang, N.; Zeng, T.; Yang, X.; Jing, T.; Gong, P. Discovery and Optimization of Novel 5-Indolyl-7-arylimidazo[1,2-a]pyridine-8-carbonitrile Derivatives as Potent Antitubulin Agents Targeting Colchicine-binding Site. Sci. Rep. 2017, 7, 43398. [CrossRef]

62. Han, F.; Wang, P.; Zhang, W.; Li, J.; Zhang, Q.; Qi, X.; Liu, M. CA-1H, a novel oxazole bearing analogue of combretastatin A-4, disrupts the tumor vasculatures and inhibits the tumor growth via inhibiting tubulin polymerization. Biomed. Pharmacother. 2016, 80, 151-161. [CrossRef] [PubMed]

63. Sriram, M.; Hall, J.J.; Grohmann, N.C.; Strecker, T.E.; Wootton, T.; Franken, A.; Trawick, M.L.; Pinney, K.G. Design, synthesis and biological evaluation of dihydronaphthalene and benzosuberene analogs of the combretastatins as inhibitors of tubulin polymerization in cancer chemotherapy. Bioorg. Med. Chem. 2008, 16, 8161-8171. [CrossRef] [PubMed]

64. Tanpure, R.P.; George, C.S.; Sriram, M.; Strecker, T.E.; Tidmore, J.K.; Hamel, E.; Charlton-Sevcik, A.K.; Chaplin, D.J.; Trawick, M.L.; Pinney, K.G. An Amino-Benzosuberene Analogue That Inhibits Tubulin Assembly and Demonstrates Remarkable Cytotoxicity. Medchemcomm 2012, 3, 720-724. [CrossRef] [PubMed]

65. Chen, Z.; Maderna, A.; Sukuru, S.C.; Wagenaar, M.; O’Donnell, C.J.; Lam, M.H.; Musto, S.; Loganzo, F. New cytotoxic benzosuberene analogs. Synthesis, molecular modeling and biological evaluation. Bioorg. Med. Chem. Lett. 2013, 23, 6688-6694. [CrossRef] [PubMed]

66. Devkota, L.; Lin, C.M.; Strecker, T.E.; Wang, Y.; Tidmore, J.K.; Chen, Z.; Guddneppanavar, R.; Jelinek, C.J.; Lopez, R.; Liu, L.; et al. Design, synthesis, and biological evaluation of water-soluble amino acid prodrug conjugates derived from combretastatin, dihydronaphthalene, and benzosuberene-based parent vascular disrupting agents. Bioorg. Med. Chem. 2016, 24, 938-956. [CrossRef] [PubMed]

67. Perez-Perez, M.J.; Priego, E.M.; Bueno, O.; Martins, M.S.; Canela, M.D.; Liekens, S. Blocking Blood Flow to Solid Tumors by Destabilizing Tubulin: An Approach to Targeting Tumor Growth. J. Med. Chem. 2016, 59, 8685-8711. [CrossRef] [PubMed]

68. Hura, N.; Sawant, A.V.; Kumari, A.; Guchhait, S.K.; Panda, D. Combretastatin-Inspired Heterocycles as Antitubulin Anticancer Agents. ACS Omega 2018, 3, 9754-9769. [CrossRef]

69. Hamze, A.; Alami, M.; Provot, O. Developments of isoCombretastatin A-4 derivatives as highly cytotoxic agents. Eur. J. Med. Chem. 2020, 190, 112110. [CrossRef]

70. Gracheva, I.A.; Shchegravina, E.S.; Schmalz, H.-G.; Beletskaya, I.P.; Fedorov, A.Y. Colchicine Alkaloids and Synthetic Analogues: Current Progress and Perspectives. J. Med. Chem. 2020, 63, 10618-10651. [CrossRef]

71. Bukhari, S.N.A.; Kumar, G.B.; Revankar, H.M.; Qin, H.L. Development of combretastatins as potent tubulin polymerization inhibitors. Bioorg. Chem. 2017, 72, 130-147. [CrossRef] 
72. Agut, R.; Falomir, E.; Murga, J.; Martín-Beltrán, C.; Gil-Edo, R.; Pla, A.; Carda, M.; Marco, J.A. Synthesis of Combretastatin A-4 and 3'-Aminocombretastatin A-4 derivatives with Aminoacid Containing Pendants and Study of their Interaction with Tubulin and as Downregulators of the VEGF, hTERT and c-Myc Gene Expression. Molecules 2020, 25, 660. [CrossRef]

73. Siemann, D.W.; Chaplin, D.J.; Walicke, P.A. A review and update of the current status of the vasculature-disabling agent combretastatin-A4 phosphate (CA4P). Expert Opin. Investig. Drugs 2009, 18, 189-197. [CrossRef]

74. Hadimani, M.B.; Macdonough, M.T.; Ghatak, A.; Strecker, T.E.; Lopez, R.; Sriram, M.; Nguyen, B.L.; Hall, J.J.; Kessler, R.J.; Shirali, A.R.; et al. Synthesis of a 2-aryl-3-aroyl indole salt (OXi8007) resembling combretastatin A-4 with application as a vascular disrupting agent. J. Nat. Prod. 2013, 76, 1668-1678. [CrossRef]

75. Tozer, G.M.; Prise, V.E.; Wilson, J.; Locke, R.J.; Vojnovic, B.; Stratford, M.R.L.; Dennis, M.F.; Chaplin, D.J. Combretastatin A-4 Phosphate as a Tumor Vascular-Targeting Agent. Cancer Res. 1999, 59, 1626-1634. [PubMed]

76. Karatoprak, G.Ş.; Küpeli Akkol, E.; Genç, Y.; Bardakc1, H.; Yücel, Ç.; Sobarzo-Sánchez, E. Combretastatins: An Overview of Structure, Probable Mechanisms of Action and Potential Applications. Molecules 2020, 25, 2560. [CrossRef] [PubMed]

77. Lew, Y.S.; Brown, S.L.; Griffin, R.J.; Song, C.W.; Kim, J.H. Arsenic trioxide causes selective necrosis in solid murine tumors by vascular shutdown. Cancer Res. 1999, 59, 6033-6037.

78. Griffin, R.J.; Lee, S.H.; Rood, K.L.; Stewart, M.J.; Lyons, J.C.; Lew, Y.S.; Park, H.; Song, C.W. Use of arsenic trioxide as an antivascular and thermosensitizing agent in solid tumors. Neoplasia 2000, 2, 555-560. [CrossRef]

79. Brown, S.L.; Kolozsvary, A.; Kim, J.H. Vascular targeting therapies for treatment of malignant disease. Cancer 2005, 104, 216-217; author reply 217. [CrossRef] [PubMed]

80. Diepart, C.; Karroum, O.; Magat, J.; Feron, O.; Verrax, J.; Calderon, P.B.; Gregoire, V.; Leveque, P.; Stockis, J.; Dauguet, N.; et al. Arsenic trioxide treatment decreases the oxygen consumption rate of tumor cells and radiosensitizes solid tumors. Cancer Res. 2012, 72, 482-490. [CrossRef]

81. Mason, R.P.; Ran, S.; Thorpe, P.E. Quantitative assessment of tumor oxygen dynamics: Molecular imaging for prognostic radiology. J. Cell Biochem. Suppl. 2002, 39, 45-53. [CrossRef]

82. Chen, B.; Pogue, B.W.; Hoopes, P.J.; Hasan, T. Combining vascular and cellular targeting regimens enhances the efficacy of photodynamic therapy. Int. J. Radiat. Oncol. Biol. Phys. 2005, 61, 1216-1226. [CrossRef] [PubMed]

83. Neuschmelting, V.; Kim, K.; Malekzadeh-Najafabadi, J.; Jebiwott, S.; Prakash, J.; Scherz, A.; Coleman, J.A.; Kircher, M.F.; Ntziachristos, V. WST11 Vascular Targeted Photodynamic Therapy Effect Monitoring by Multispectral Optoacoustic Tomography (MSOT) in Mice. Theranostics 2018, 8, 723-734. [CrossRef] [PubMed]

84. Karwicka, M.; Pucelik, B.; Gonet, M.; Elas, M.; Dabrowski, J.M. Effects of Photodynamic Therapy with Redaporfin on Tumor Oxygenation and Blood Flow in a Lung Cancer Mouse Model. Sci. Rep. 2019, 9, 15. [CrossRef] [PubMed]

85. Mallidi, S.; Watanabe, K.; Timerman, D.; Schoenfeld, D.; Hasan, T. Prediction of Tumor Recurrence and Therapy Monitoring Using Ultrasound-Guided Photoacoustic Imaging. Theranostics 2015, 5, 289-301. [CrossRef]

86. Rennert, J.; Wiesinger, I.; Beyer, L.P.; Schicho, A.; Stroszczynski, C.; Wiggermann, P.; Jung, E.M. Color coded perfusion analysis and microcirculation imaging with contrast enhanced ultrasound (CEUS) for post-interventional success control following thermal ablative techniques of primary and secondary liver malignancies. Clin. Hemorheol. Microcirc. 2019, 73, 73-83. [CrossRef]

87. Brown, S.L.; Nagaraja, T.N.; Aryal, M.P.; Panda, S.; Cabral, G.; Keenan, K.A.; Elmghirbi, R.; Mikkelsen, T.; Hearshen, D.; Knight, R.A.; et al. MRI-Tracked Tumor Vascular Changes in the Hours after Single-Fraction Irradiation. Radiat. Res. 2015, 183, 713-721. [CrossRef]

88. Virani, N.A.; Kelada, O.J.; Kunjachan, S.; Detappe, A.; Kwon, J.; Hayashi, J.; Vazquez-Pagan, A.; Biancur, D.E.; Ireland, T.; Kumar, R.; et al. Noninvasive imaging of tumor hypoxia after nanoparticle-mediated tumor vascular disruption. PLoS ONE 2020, 15, e0236245. [CrossRef]

89. Paroo, Z.; Bollinger, R.A.; Braasch, D.A.; Richer, E.; Corey, D.R.; Antich, P.P.; Mason, R.P. Validating Bioluminescence Imaging as a High-Throughput, Quantitative Modality for Assessing Tumor Burden. Mol. Imaging 2004, 3, 117-124. [CrossRef]

90. Liu, Y.W.; De Keyzer, F.; Feng, Y.B.; Chen, F.; Song, S.L.; Swinnen, J.; Bormans, G.; Oyen, R.; Huang, G.; Ni, Y.C. Intra-individual comparison of therapeutic responses to vascular disrupting agent CA4P between rodent primary and secondary liver cancers. World J. Gastroenterol. 2018, 24, 2710-2721. [CrossRef]

91. Breidahl, T.; Nielsen, F.U.; Stodkilde-Jorgensen, H.; Maxwell, R.J.; Horsman, M.R. The effects of the vascular disrupting agents combretastatin A-4 disodium phosphate, 5,6-dimethylxanthenone-4-acetic acid and ZD6126 in a murine tumour: A comparative assessment using MRI and MRS. Acta Oncol. 2006, 45, 306-316. [CrossRef]

92. Dey, S.; Kumari, S.; Kalainayakan, S.P.; Campbell, J., 3rd; Ghosh, P.; Zhou, H.; FitzGerald, K.E.; Li, M.; Mason, R.P.; Zhang, L.; et al. The vascular disrupting agent combretastatin A-4 phosphate causes prolonged elevation of proteins involved in heme flux and function in resistant tumor cells. Oncotarget 2018, 9, 4090-4101. [CrossRef]

93. Zhou, H.; Hallac, R.R.; Lopez, R.R.; Denney, R.; MacDonough, M.T.; Li, L.; Liu, L.; Graves, E.E.; Trawick, M.L.; Pinney, K.G.; et al. Evaluation of tumor ischemia in response to an indole-based vascular disrupting agent using BLI and 19F MRI. Am. J. Nucl. Med. Mol. Imaging 2015, 5, 143-153.

94. Thomas, C.D.; Walczak, C.; Kaffy, J.; Pontikis, R.; Jouanneau, J.; Volk, A. Early effects of combretastatin A4 phosphate assessed by anatomic and carbogen-based functional magnetic resonance imaging on rat bladder tumors implanted in nude mice. Neoplasia 2006, 8, 587-595. [CrossRef] 
95. Colliez, F.; Fruytier, A.C.; Magat, J.; Neveu, M.A.; Cani, P.D.; Gallez, B.; Jordan, B.F. Monitoring Combretastatin A4-induced tumor hypoxia and hemodynamic changes using endogenous MR contrast and DCE-MRI. Magn. Reson. Med. 2016, 75, 866-872. [CrossRef] [PubMed]

96. Beauregard, D.A.; Pedley, R.B.; Hill, S.A.; Brindle, K.M. Differential sensitivity of two adenocarcinoma xenografts to the antivascular drugs combretastatin A4 phosphate and 5,6-dimethylxanthenone-4-acetic acid, assessed using MRI and MRS. NMR Biomed. 2002, 15, 99-105. [CrossRef] [PubMed]

97. Yin, T.; Liu, Y.; Peeters, R.; Feng, Y.; Yu, J.; Himmelreich, U.; Oyen, R.; Ni, Y. Vascular disrupting agent in pancreatic and hepatic tumour allografts: Observations of location-dependent efficacy by MRI, microangiography and histomorphology. Br. J. Cancer 2017, 117, 1529-1536. [CrossRef] [PubMed]

98. Thoeny, H.C.; De Keyzer, F.; Chen, F.; Vandecaveye, V.; Verbeken, E.K.; Ahmed, B.; Sun, X.; Ni, Y.; Bosmans, H.; Hermans, R.; et al Diffusion-weighted magnetic resonance imaging allows noninvasive in vivo monitoring of the effects of combretastatin a-4 phosphate after repeated administration. Neoplasia 2005, 7, 779-787. [CrossRef]

99. Song, W.T.; Tang, Z.H.; Zhang, D.W.; Yu, H.Y.; Chen, X.S. Coadministration of Vascular Disrupting Agents and Nanomedicines to Eradicate Tumors from Peripheral and Central Regions. Small 2015, 11, 3755-3761. [CrossRef] [PubMed]

100. Liu, Y.W.; De Keyzer, F.; Wang, Y.X.; Wang, F.N.; Feng, Y.B.; Chen, F.; Yu, J.; Liu, J.J.; Song, S.L.; Swinnen, J.; et al. The first study on therapeutic efficacies of a vascular disrupting agent CA4P among primary hepatocellular carcinomas with a full spectrum of differentiation and vascularity: Correlation of MRI-microangiography-histopathology in rats. Int. J. Cancer 2018, 143, 1817-1828. [CrossRef]

101. Nielsen, T.; Bentzen, L.; Pedersen, M.; Tramm, T.; Rijken, P.F.J.W.; Bussink, J.; Horsman, M.R.; Ostergaard, L. Combretastatin A-4 Phosphate Affects Tumor Vessel Volume and Size Distribution as Assessed Using MRI-Based Vessel Size Imaging. Clin. Cancer Res. 2012, 18, 6469-6477. [CrossRef]

102. Wang, H.J.; Sun, X.H.; Chen, F.; De Keyzer, F.; Yu, J.; Landuyt, W.; Vandecaveye, V.; Peeters, R.; Bosmans, H.; Hermans, R.; et al. Treatment of Rodent Liver Tumor with Combretastatin A4 Phosphate Noninvasive Therapeutic Evaluation Using Multiparametric Magnetic Resonance Imaging in Correlation With Microangiography and Histology. Investig. Radiol. 2009, 44, 44-53. [CrossRef]

103. Salmon, H.W.; Siemann, D.W. Effect of the second-generation vascular disrupting agent OXi4503 on tumor vascularity. Clin. Cancer Res. 2006, 12, 4090-4094. [CrossRef] [PubMed]

104. Shi, C.Z.; Liu, D.X.; Xiao, Z.Y.; Zhang, D.; Liu, G.F.; Liu, G.S.; Chen, H.W.; Luo, L.P. Monitoring Tumor Response to Antivascular Therapy Using Non-Contrast Intravoxel Incoherent Motion Diffusion-Weighted MRI. Cancer Res. 2017, 77, 3491-3501. [CrossRef] [PubMed]

105. Iversen, A.B.; Busk, M.; Bertelsen, L.B.; Laustsen, C.; Munk, O.L.; Nielsen, T.; Wittenborn, T.R.; Bussink, J.; Lok, J.; StodkildeJorgensen, H.; et al. The potential of hyperpolarized C-13 magnetic resonance spectroscopy to monitor the effect of combretastatin based vascular disrupting agents. Acta Oncol. 2017, 56, 1626-1633. [CrossRef] [PubMed]

106. Fruytier, A.C.; Magat, J.; Neveu, M.A.; Karroum, O.; Bouzin, C.; Feron, O.; Jordan, B.; Cron, G.O.; Gallez, B. Dynamic contrastenhanced MRI in mouse tumors at 11.7T: Comparison of three contrast agents with different molecular weights to assess the early effects of combretastatin A4. NMR Biomed. 2014, 27, 1403-1412. [CrossRef] [PubMed]

107. Fruytier, A.C.; Le Duff, C.S.; Po, C.; Magat, J.; Bouzin, C.; Neveu, M.A.; Feron, O.; Jordan, B.F.; Gallez, B. The Blood Flow Shutdown Induced by Combretastatin A4 Impairs Gemcitabine Delivery in a Mouse Hepatocarcinoma. Front. Pharmacol. 2016, 7 , 8. [CrossRef]

108. Li, J.J.; Zhou, M.; Liu, F.Y.; Xiong, C.Y.; Wang, W.Q.; Cao, Q.Z.; Wen, X.X.; Robertson, J.D.; Ji, X.; Wang, Y.A.; et al. Hepatocellular Carcinoma: Intra-arterial Delivery of Doxorubicin-loaded Hollow Gold Nanospheres for Photothermal AblationChemoembolization Therapy in Rats. Radiology 2016, 281, 427-435. [CrossRef] [PubMed]

109. Abma, E.; Stock, E.; De Spiegelaere, W.; Van Brantegem, L.; Vanderperren, K.; Ni, Y.; Vynck, M.; Daminet, S.; De Clercq, K.; de Rooster, H. Power Doppler ultrasound and contrast-enhanced ultrasound demonstrate non-invasive tumour vascular response to anti-vascular therapy in canine cancer patients. Sci. Rep. 2019, 9, 9262. [CrossRef] [PubMed]

110. Zhang, P.; Chen, Y.; Liu, J.; Yang, Y.; Lv, Q.; Wang, J.; Zhang, L.; Xie, M. Quantitative Evaluation of Combretastatin A4 Phosphate Early Efficacy in a Tumor Model with Dynamic Contrast-Enhanced Ultrasound. Ultrasound Med. Biol. 2018, 44, 840-852. [CrossRef]

111. Sunar, U.; Makonnen, S.; Zhou, C.; Durduran, T.; Yu, G.; Wang, H.W.; Lee, W.M.; Yodh, A.G. Hemodynamic responses to antivascular therapy and ionizing radiation assessed by diffuse optical spectroscopies. Opt. Express 2007, 15, 15507-15516. [CrossRef]

112. Seguin, J.; Mignet, N.; Latorre Ossa, H.; Tanter, M.; Gennisson, J.-L. Evaluation of Antivascular Combretastatin A4 P Efficacy Using Supersonic Shear Imaging Technique of Ectopic Colon Carcinoma CT26. Ultrasound Med. Biol. 2017, 43, $2352-2361$. [CrossRef]

113. Zhang, D.; Gao, M.; Yao, N.; Jiang, C.; Liu, W.; Li, T.; Song, S.; Huang, D.; Yin, Z.; Qiu, Y.; et al. Preclinical Evaluation of Radioiodinated Hoechst 33258 for Early Prediction of Tumor Response to Treatment of Vascular-Disrupting Agents. Contrast Media Mol. Imaging 2018, 2018, 5237950. [CrossRef]

114. Bothwell, K.D.; Folaron, M.; Seshadri, M. Preclinical Activity of the Vascular Disrupting Agent OXi4503 against Head and Neck Cancer. Cancers 2016, 8, 11. [CrossRef] [PubMed] 
115. Benezra, M.; Phillips, E.; Tilki, D.; Ding, B.S.; Butler, J.; Dobrenkov, K.; Siim, B.; Chaplin, D.; Rafii, S.; Rabbany, S.; et al. Serial monitoring of human systemic and xenograft models of leukemia using a novel vascular disrupting agent. Leukemia 2012, 26, 1771-1778. [CrossRef]

116. Johnson, S.P.; Ramasawmy, R.; Campbell-Washburn, A.E.; Wells, J.A.; Robson, M.; Rajkumar, V.; Lythgoe, M.F.; Pedley, R.B.; Walker-Samuel, S. Acute changes in liver tumour perfusion measured non-invasively with arterial spin labelling. Br. J. Cancer 2016, 114, 897-904. [CrossRef]

117. Shao, H.B.; Ni, Y.C.; Zhang, J.; Chen, F.; Dai, X.; Fan, G.G.; Sun, Z.P.; Xu, K. Dynamic Contrast-Enhanced and Diffusion-Weighted Magnetic Resonance Imaging Noninvasive Evaluation of Vascular Disrupting Treatment on Rabbit Liver Tumors. PLoS ONE 2013, 8, e82649. [CrossRef] [PubMed]

118. Laufer, J.; Johnson, P.; Zhang, E.; Treeby, B.; Cox, B.; Pedley, B.; Beard, P. In vivo preclinical photoacoustic imaging of tumor vasculature development and therapy. J. Biomed. Opt. 2012, 17, 056016. [CrossRef]

119. Johnson, S.P.; Ogunlade, O.; Lythgoe, M.F.; Beard, P.; Pedley, R.B. Longitudinal Photoacoustic Imaging of the Pharmacodynamic Effect of Vascular Targeted Therapy on Tumors. Clin. Cancer Res. 2019, 25, 7436-7447. [CrossRef] [PubMed]

120. Lavranos, T.; Leske, A.; Beaumont, D.; Gasic, J.; Kremmidiotis, G. Evaluation of the anti-cancer effects of the tumor selective Vascular Disruption Agent BNC105 in preclinical renal cancer models. In Proceedings of the 102nd Annual Meeting of AACR, Orlando, FL, USA, 2-6 April 2011; p. 662.

121. Ravoori, M.K.; Margalit, O.; Singh, S.; Kim, S.-H.; Wei, W.; Menter, D.G.; DuBois, R.N.; Kundra, V. Magnetic Resonance Imaging and Bioluminescence Imaging for Evaluating Tumor Burden in Orthotopic Colon Cancer. Sci. Rep. 2019, 9, 6100. [CrossRef]

122. Kim, T.J.; Ravoori, M.; Landen, C.N.; Kamat, A.A.; Han, L.Y.; Lu, C.; Lin, Y.G.; Merritt, W.M.; Jennings, N.; Spannuth, W.A.; et al. Antitumor and Antivascular Effects of AVE8062 in Ovarian Carcinoma. Cancer Res. 2007, 67, 9337-9345. [CrossRef]

123. Clemenson, C.; Jouannot, E.; Merino-Trigo, A.; Rubin-Carrez, C.; Deutsch, E. The vascular disrupting agent ombrabulin (AVE8062) enhances the efficacy of standard therapies in head and neck squamous cell carcinoma xenograft models. Investig. New Drugs 2013, 31, 273-284. [CrossRef]

124. Bertelsen, L.B.; Shen, Y.Y.; Nielsen, T.; Stodkilde-Jorgensen, H.; Lloyd, G.K.; Siemann, D.W.; Horsman, M.R. Vascular effects of plinabulin (NPI-2358) and the influence on tumour response when given alone or combined with radiation. Int. J. Radiat. Biol. 2011, 87, 1126-1134. [CrossRef] [PubMed]

125. McIntyre, D.J.O.; Robinson, S.P.; Howe, F.A.; Griffiths, J.R.; Ryan, A.J.; Blakey, D.C.; Peers, I.S.; Waterton, J.C. Single dose of the antivascular agent, ZD6126 (N-acetylcoichinol-O-phosphate), reduces perfusion for at least $96 \mathrm{~h}$ in the GH3 prolactinoma rat tumor model. Neoplasia 2004, 6, 150-157. [CrossRef]

126. Robinson, S.P.; McIntyre, D.J.; Checkley, D.; Tessier, J.J.; Howe, F.A.; Griffiths, J.R.; Ashton, S.E.; Ryan, A.J.; Blakey, D.C.; Waterton, J.C. Tumour dose response to the antivascular agent ZD6126 assessed by magnetic resonance imaging. Br. J. Cancer 2003, 88, 1592-1597. [CrossRef] [PubMed]

127. Burrell, J.S.; Bradley, R.S.; Walker-Samuel, S.; Jamin, Y.; Baker, L.C.J.; Boult, J.K.R.; Withers, P.J.; Halliday, J.; Waterton, J.C.; Robinson, S.P. MRI measurements of vessel calibre in tumour xenografts: Comparison with vascular corrosion casting. Microvasc. Res. 2012, 84, 323-329. [CrossRef] [PubMed]

128. Walker-Samuel, S.; Boult, J.K.R.; McPhail, L.D.; Box, G.; Eccles, S.A.; Robinson, S.P. Non-invasive in vivo imaging of vessel calibre in orthotopic prostate tumour xenografts. Int. J. Cancer 2012, 130, 1284-1293. [CrossRef]

129. Liu, L.; Beck, H.; Wang, X.; Hsieh, H.P.; Mason, R.P.; Liu, X. Tubulin-destabilizing agent BPR0L075 induces vascular-disruption in human breast cancer mammary fat pad xenografts. PLOS ONE 2012, 7, e43314. [CrossRef] [PubMed]

130. Rich, L.J.; Seshadri, M. Photoacoustic imaging of vascular hemodynamics: Validation with blood oxygenation level-dependent MR imaging. Radiology 2015, 275, 110-118. [CrossRef]

131. Folaron, M.; Seshadri, M. Bioluminescence and MR Imaging of the Safety and Efficacy of Vascular Disruption in Gliomas. Mol. Imaging Biol. Mib Off. Publ. Acad. Mol. Imaging 2016, 18, 860-869. [CrossRef]

132. Kalmuk, J.; Folaron, M.; Buchinger, J.; Pili, R.; Seshadri, M. Multimodal imaging guided preclinical trials of vascular targeting in prostate cancer. Oncotarget 2015, 6, 24376-24392. [CrossRef]

133. Hong, S.; Zheng, D.W.; Zhang, C.; Huang, Q.X.; Cheng, S.X.; Zhang, X.Z. Vascular disrupting agent induced aggregation of gold nanoparticles for photothermally enhanced tumor vascular disruption. Sci. Adv. 2020, 6. [CrossRef] [PubMed]

134. Folaron, M.; Kalmuk, J.; Lockwood, J.; Frangou, C.; Vokes, J.; Turowski, S.G.; Merzianu, M.; Rigual, N.R.; Sullivan-Nasca, M.; Kuriakose, M.A.; et al. Vascular priming enhances chemotherapeutic efficacy against head and neck cancer. Oral Oncol. 2013, 49, 893-902. [CrossRef] [PubMed]

135. McPhail, L.D.; McIntyre, D.J.O.; Ludwig, C.; Kestell, P.; Griffiths, J.R.; Kelland, L.R.; Robinson, S.P. Rat tumor response to the vascular-disrupting agent 5,6-dimethylxanthenone-4-acetic acid as measured by dynamic contrast-enhanced magnetic resonance imaging, plasma 5-hydroxyindoleacetic acid levels, and tumor necrosis. Neoplasia 2006, 8, 199-206. [CrossRef]

136. Seshadri, M.; Ciesielski, M.J. MRI-based characterization of vascular disruption by 5,6-dimethylxanthenone-acetic acid in gliomas. J. Cereb. Blood Flow Metab. 2009, 29, 1373-1382. [CrossRef] [PubMed]

137. Hectors, S.J.; Jacobs, I.; Lok, J.; Peters, J.; Bussink, J.; Hoeben, F.J.; Keizer, H.M.; Janssen, H.M.; Nicolay, K.; Schabel, M.C.; et al. Improved Evaluation of Antivascular Cancer Therapy Using Constrained Tracer-Kinetic Modeling for Multiagent Dynamic Contrast-Enhanced MRI. Cancer Res. 2018, 78, 1561-1570. [CrossRef] 
138. Ellis, L.; Shah, P.; Hammers, H.; Lehet, K.; Sotomayor, P.; Azabdaftari, G.; Seshadri, M.; Pili, R. Vascular disruption in combination with mTOR inhibition in renal cell carcinoma. Mol. Cancer Ther. 2012, 11, 383-392. [CrossRef] [PubMed]

139. Fadhel, M.N.; Baskoy, S.A.; Wang, Y.J.; Hysi, E.; Kolios, M.C. Use of photoacoustic imaging for monitoring vascular disrupting cancer treatments. J. Biophotonics 2020. [CrossRef]

140. Song, W.T.; Tang, Z.H.; Zhang, D.W.; Li, M.Q.; Gu, J.K.; Chen, X.S. A cooperative polymeric platform for tumor-targeted drug delivery. Chem. Sci. 2016, 7, 728-736. [CrossRef]

141. Milanović, D.; Braun, F.; Weber, W.; Grosu, A.L.; Behe, M.; Niedermann, G. The influence of the combined treatment with Vadimezan (ASA404) and taxol on the growth of U251 glioblastoma xenografts. BMC Cancer 2012, 12, 242. [CrossRef]

142. He, J.; Liu, C.; Li, T.; Liu, Y.; Wang, S.; Zhang, J.; Chen, L.; Wang, C.; Feng, Y.; Floris, G.; et al. Pictorial Imaging-Histopathology Correlation in a Rabbit with Hepatic VX2 Tumor Treated by Transarterial Vascular Disrupting Agent Administration. Int. J. Med. Sci. 2020, 17, 2269-2275. [CrossRef]

143. Luo, Y.; Hradil, V.P.; Frost, D.J.; Rosenberg, S.H.; Gordon, G.B.; Morgan, S.J.; Gagne, G.D.; Cox, B.F.; Tahir, S.K.; Fox, G.B. ABT-751, a novel tubulin-binding agent, decreases tumor perfusion and disrupts tumor vasculature. Anticancer Drugs 2009, 20, 483-492. [CrossRef] [PubMed]

144. Herdman, C.A.; Devkota, L.; Lin, C.M.; Niu, H.; Strecker, T.E.; Lopez, R.; Liu, L.; George, C.S.; Tanpure, R.P.; Hamel, E.; et al. Structural interrogation of benzosuberene-based inhibitors of tubulin polymerization. Bioorg. Med. Chem. 2015, 23, 7497-7520. [CrossRef]

145. Niu, H.C.; Strecker, T.E.; Gerberich, J.L.; Campbell, J.W.; Saha, D.; Mondal, D.; Hamel, E.; Chaplin, D.J.; Mason, R.P.; Trawick, M.L.; et al. Structure Guided Design, Synthesis, and Biological Evaluation of Novel Benzosuberene Analogues as Inhibitors of Tubulin Polymerization. J. Med. Chem. 2019, 62, 5594-5615. [CrossRef]

146. Herdman, C.A.; Strecker, T.E.; Tanpure, R.P.; Chen, Z.; Winters, A.; Gerberich, J.; Liu, L.; Hamel, E.; Mason, R.P.; Chaplin, D.J.; et al. Synthesis and Biological Evaluation of Benzocyclooctene-based and Indene-based Anticancer Agents that Function as Inhibitors of Tubulin Polymerization. Medchemcomm 2016, 7, 2418-2427. [CrossRef] [PubMed]

147. Maguire, C.J.; Chen, Z.; Mocharla, V.P.; Sriram, M.; Strecker, T.E.; Hamel, E.; Zhou, H.; Lopez, R.; Wang, Y.; Mason, R.P.; et al. Synthesis of dihydronaphthalene analogues inspired by combretastatin A-4 and their biological evaluation as anticancer agents. Medchemcomm 2018, 9, 1649-1662. [CrossRef]

148. Winn, B.A.; Devkota, L.; Kuch, B.; MacDonough, M.T.; Strecker, T.E.; Wang, Y.; Shi, Z.; Gerberich, J.L.; Mondal, D.; Ramirez, A.J.; et al. Bioreductively Activatable Prodrug Conjugates of Combretastatin A-1 and Combretastatin A-4 as Anticancer Agents Targeted toward Tumor-Associated Hypoxia. J. Nat. Prod. 2020, 83, 937-954. [CrossRef] [PubMed]

149. Thebault, C.J.; Ramniceanu, G.; Boumati, S.; Michel, A.; Seguin, J.; Larrat, B.; Mignet, N.; Menager, C.; Doan, B.T. Theranostic MRI liposomes for magnetic targeting and ultrasound triggered release of the antivascular CA4P. J. Control. Release 2020, 322, 137-148. [CrossRef]

150. Paris, J.L.; Villaverde, G.; Gomez-Grana, S.; Vallet-Regi, M. Nanoparticles for multimodal antivascular therapeutics: Dual drug release, photothermal and photodynamic therapy. Acta Biomater. 2020, 101, 459-468. [CrossRef]

151. Hao, Y.; Peng, J.R.; Zhang, Y.G.; Chen, L.J.; Luo, F.; Wang, C.; Qian, Z.Y. Tumor Neovasculature-Targeted APRPG-PEGPDLLA/MPEG-PDLLA Mixed Micelle Loading Combretastatin A-4 for Breast Cancer Therapy. ACS Biomater. Sci. Eng. 2018, 4, 1986-1999. [CrossRef] [PubMed]

152. Lv, S.; Tang, Z.; Song, W.; Zhang, D.; Li, M.; Liu, H.; Cheng, J.; Zhong, W.; Chen, X. Inhibiting Solid Tumor Growth In Vivo by Non-Tumor-Penetrating Nanomedicine. Small 2017, 13, 1600954. [CrossRef]

153. Fentahun Darge, H.; Yibru Hanurry, E.; Simegniew Birhan, Y.; Worku Mekonnen, T.; Tizazu Andrgie, A.; Chou, H.-Y.; Lai, J.-Y.; Tsai, H.-C. Multifunctional drug-loaded micelles encapsulated in thermo-sensitive hydrogel for in vivo local cancer treatment: Synergistic effects of anti-vascular and immuno-chemotherapy. Chem. Eng. J. 2021, 406, 126879. [CrossRef]

154. Liu, T.; Zhang, D.; Song, W.; Tang, Z.; Zhu, J.; Ma, Z.; Wang, X.; Chen, X.; Tong, T. A poly(l-glutamic acid)-combretastatin A4 conjugate for solid tumor therapy: Markedly improved therapeutic efficiency through its low tissue penetration in solid tumor. Acta Biomater. 2017, 53, 179-189. [CrossRef] [PubMed]

155. Hori, K.; Saito, S.; Sato, Y.; Akita, H.; Kawaguchi, T.; Sugiyama, K.; Sato, H. Differential relationship between changes in tumour size and microcirculatory functions induced by therapy with an antivascular drug and with cytotoxic drugs: Implications for the evaluation of therapeutic efficacy of AC7700 (AVE8062). Eur. J. Cancer 2003, 39, 1957-1966. [CrossRef]

156. Davis, P.D.; Dougherty, G.J.; Blakey, D.C.; Galbraith, S.M.; Tozer, G.M.; Holder, A.L.; Naylor, M.A.; Nolan, J.; Stratford, M.R.L.; Chaplin, D.J.; et al. ZD6126. Nov. Vasc.-Target. Agent That Causes Sel. Destr. Tumor Vasc. 2002, 62, 7247-7253.

157. Inglis, D.J.; Lavranos, T.C.; Beaumont, D.M.; Leske, A.F.; Brown, C.K.; Hall, A.J.; Kremmidiotis, G. The vascular disrupting agent BNC105 potentiates the efficacy of VEGF and mTOR inhibitors in renal and breast cancer. Cancer Biol. Ther. 2014, 15, 1552-1560. [CrossRef] [PubMed]

158. Kim, K.W.; Lee, J.M.; Jeon, Y.S.; Lee, I.J.; Choi, Y.; Park, J.; Kiefer, B.; Kim, C.; Han, J.K.; Choi, B.I. Vascular disrupting effect of CKD-516: Preclinical study using DCE-MRI. Investig. New Drugs 2013, 31, 1097-1106. [CrossRef]

159. Zhou, H.L.; Campbell, J.; Lopez, R.; Zhang, Z.; Saha, D.; Denney, R.; Twawick, M.L.; Pinney, K.; Mason, R. Monitoring Tumor Response to Vascular Disrupting Agent Using Photoacoustic Tomography and Multiparametric MRI. J. Nucl. Med. 2016, $57,1408$. 
160. Kuo, C.C.; Hsieh, H.P.; Pan, W.Y.; Chen, C.P.; Liou, J.P.; Lee, S.J.; Chang, Y.L.; Chen, L.T.; Chen, C.T.; Chang, J.Y. BPR0L075, a novel synthetic indole compound with antimitotic activity in human cancer cells, exerts effective antitumoral activity in vivo. Cancer Res. 2004, 64, 4621-4628. [CrossRef] [PubMed]

161. Alhasan, M.K.; Liu, L.; Lewis, M.A.; Magnusson, J.; Mason, R.P. Comparison of Optical and Power Doppler Ultrasound Imaging for Non-Invasive Evaluation of Arsenic Trioxide as a Vascular Disrupting Agent in Tumors. PLoS ONE 2012, 7, e46106. [CrossRef]

162. Cesca, M.; Bizzaro, F.; Zucchetti, M.; Giavazzi, R. Tumor delivery of chemotherapy combined with inhibitors of angiogenesis and vascular targeting agents. Front. Oncol. 2013, 3. [CrossRef] [PubMed]

163. Natsume, T.; Watanabe, J.; Ogawa, K.; Yasumura, K.; Kobayashi, M. Tumor-specific antivascular effect of TZT-1027 (Soblidotin) elucidated by magnetic resonance imaging and confocal laser scanning microscopy. Cancer Sci. 2007, 98, 598-604. [CrossRef] [PubMed]

164. Glowa, C.; Karger, C.P.; Brons, S.; Zhao, D.; Mason, R.P.; Huber, P.E.; Debus, J.; Peschke, P. Carbon ion radiotherapy decreases the impact of tumor heterogeneity on radiation response in experimental prostate tumors. Cancer Lett. 2016, 378, 97-103. [CrossRef]

165. Corliss, B.A.; Mathews, C.; Doty, R.; Rohde, G.; Peirce, S.M. Methods to label, image, and analyze the complex structural architectures of microvascular networks. Microcirculation 2019, 26, e12520. [CrossRef]

166. Chaplin, D.J.; Olive, P.L.; Durand, R.E. Intermittent blood flow in a murine tumor: Radiobiological effects. Cancer Res. 1987, 47, 597-601.

167. Trotter, M.J.; Chaplin, D.J.; Durand, R.E.; Olive, P.L. The Use of Fluorescent-Probes to Identify Regions of Transient Perfusion in Murine Tumors. Int. J. Radiat. Oncol. Biol. Phys. 1989, 16, 931-934. [CrossRef]

168. Prinzen, F.W.; Bassingthwaighte, J.B. Blood flow distributions by microsphere deposition methods. Cardiovasc. Res. 2000, 45, 13-21. [CrossRef]

169. Hodeige, D.; De Pauw, M.; Eechaute, W.; Weyne, J.; Heyndrickx, G.R. On the validity of blood flow measurement using colored microspheres. Am. J. Physiol.-Heart Circ. Physiol. 1999, 276, H1150-H1158. [CrossRef]

170. Robertson, R.T.; Levine, S.T.; Haynes, S.M.; Gutierrez, P.; Baratta, J.L.; Tan, Z.; Longmuir, K.J. Use of labeled tomato lectin for imaging vasculature structures. Histochem. Cell Biol. 2015, 143, 225-234. [CrossRef]

171. Lippert, J.W., 3rd. Vascular disrupting agents. Bioorg. Med. Chem. 2007, 15, 605-615. [CrossRef]

172. McLoughlin, E.C.; O’Boyle, N.M. Colchicine-Binding Site Inhibitors from Chemistry to Clinic: A Review. Pharmaceuticals 2020, 13, 8. [CrossRef] [PubMed]

173. McPhail, L.D.; Robinson, S.P. Lessons from Animal Imaging in Preclinical Models; Springer: New York, NY, USA, $2010 ;$ pp. $95-116$.

174. Zweifel, M.; Padhani, A.R. MRI to Assess. Vascular Disruptive Agents; Springer: New York, NY, USA, $2010 ;$ pp. 137-163.

175. Serkova, N.J.; Glunde, K.; Haney, C.R.; Farhoud, M.; DeLille, A.; Redente, E.F.; Simberg, D.; Westerly, D.C.; Griffin, L.; Mason, R.P. Preclinical Applications of Multi-Platform Imaging in Animal Models of Cancer. Cancer Res. 2020, 81, 1189-1200. [CrossRef]

176. Gill, J.H.; Rockley, K.L.; De Santis, C.; Mohamed, A.K. Vascular Disrupting Agents in cancer treatment: Cardiovascular toxicity and implications for co-administration with other cancer chemotherapeutics. Pharmacol. Ther. 2019, 202, 18-31. [CrossRef] [PubMed]

177. Hormuth, D.A., 2nd; Sorace, A.G.; Virostko, J.; Abramson, R.G.; Bhujwalla, Z.M.; Enriquez-Navas, P.; Gillies, R.; Hazle, J.D.; Mason, R.P.; Quarles, C.C.; et al. Translating preclinical MRI methods to clinical oncology. J. Magn. Reson. Imaging 2019, 50, 1377-1392. [CrossRef] [PubMed]

178. Contag, C.H.; Ross, B.D. It's not just about anatomy: In vivo bioluminescence imaging as an eyepiece into biology. J. Magn. Reson. Imaging 2002, 16, 378-387. [CrossRef] [PubMed]

179. Alsawaftah, N.; Farooq, A.; Dhou, S.; Majdalawieh, A.F. Bioluminescence Imaging Applications in Cancer: A Comprehensive Review. IEEE Rev. Biomed. Eng. 2021, 14, 307-326. [CrossRef] [PubMed]

180. Contero, A.; Richer, E.; Gondim, A.; Mason, R.P. High-throughput quantitative bioluminescence imaging for assessing tumor burden. Methods Mol. Biol. 2009, 574, 37-45. [CrossRef]

181. PerkinElmer. In Vivo Imaging. Available online: https://www.perkinelmer.com/category/in-vivo-imaging-instruments (accessed on 22 April 2021).

182. SpectralInstruments. In Vivo, Optimized. Available online: https://spectralinvivo.com/imaging-systems/ (accessed on 22 April 2021).

183. Scintica. Newton 7.0. Available online: https://www.scintica.com/products/vilber-imaging/vilber-newton-7/ (accessed on 22 April 2021).

184. Sonovol. Molecular Imaging with Soft Tissue Contrast. Available online: https://sonovol.com/products/strata/ (accessed on 22 April 2021).

185. Medilume. Prism In Vivo Imaging System. Available online: https:/ /www.medilumine.com/product/prism-in-vivo-imagingsystem/ (accessed on 22 April 2021).

186. Vieworks. Bioimaging. Available online: https:/ / bioimaging.vieworks.com/?_ga $=2.75796496 .489309006 .1613065635-13611236$ 55.1613065635 (accessed on 20 March 2021).

187. Lewis, M.A.; Richer, E.; Slavine, N.V.; Kodibagkar, V.D.; Soesbe, T.C.; Antich, P.P.; Mason, R.P. A Multi-Camera System for Bioluminescence Tomography in Preclinical Oncology Research. Diagnostics 2013, 3, 325-343. [CrossRef] 
188. Zhang, B.; Wang, K.K.-H.; Yu, J.; Eslami, S.; Iordachita, I.; Reyes, J.; Malek, R.; Tran, P.T.; Patterson, M.S.; Wong, J.W. Bioluminescence Tomography-Guided Radiation Therapy for Preclinical Research. Int. J. Radiat. Oncol. Biol. Phys. 2016, 94, $1144-1153$. [CrossRef]

189. Deng, Z.; Xu, X.; Garzon-Muvdi, T.; Xia, Y.; Kim, E.; Belcaid, Z.; Luksik, A.; Maxwell, R.; Choi, J.; Wang, H.; et al. In Vivo Bioluminescence Tomography Center of Mass-Guided Conformal Irradiation. Int. J. Radiat. Oncol. Biol. Phys. 2020, 106, 612-620. [CrossRef]

190. Kuo, C.; Coquoz, O.; Troy, T.L.; Xu, H.; Rice, B.W. Three-dimensional reconstruction of in vivo bioluminescent sources based on multispectral imaging. J. Biomed. Opt. 2007, 12, 024007. [CrossRef]

191. Yamashita, S.; Katsumi, H.; Hibino, N.; Isobe, Y.; Yagi, Y.; Tanaka, Y.; Yamada, S.; Naito, C.; Yamamoto, A. Development of PEGylated aspartic acid-modified liposome as a bone-targeting carrier for the delivery of paclitaxel and treatment of bone metastasis. Biomaterials 2018, 154, 74-85. [CrossRef]

192. Bollinger, R.A. Evaluation of the Light Emission Kinetics in Luciferin/Luciferase-Based In Vivo Bioluminescence Imaging for Guidance in the Development of Small Animal Imaging Study Design. Ph.D. Thesis, UT Southwestern, Dallas, TX, USA, 2006.

193. Dikmen, Z.G.; Gellert, G.; Dogan, P.; Mason, R.; Antich, P.; Richer, E.; Wright, W.E.; Shay, J.E. A New Diagnostic System in Cancer Research: Bioluminescent Imaging (BLI). Turk. J. Med. Sci. 2005, 35, 65-70.

194. Dikmen, Z.G.; Gellert, G.C.; Jackson, S.; Gryaznov, S.; Tressler, R.; Dogan, P.; Wright, W.E.; Shay, J.W. In vivo inhibition of lung cancer by GRN163L: A novel human telomerase inhibitor. Cancer Res. 2005, 65, 7866-7873. [CrossRef]

195. Ghosh, P.; Guo, Y.; Ashrafi, A.; Chen, J.; Dey, S.; Zhong, S.; Liu, J.; Campbell, J.; Konduri, P.C.; Gerberich, J.; et al. Oxygenenhanced optoacoustic tomography reveals the effectiveness of targeting heme and oxidative phosphorylation at normalizing tumor vascular oxygenation. Cancer Res. 2020. [CrossRef] [PubMed]

196. Kim, S.; Zhang, Y.; Tang, S.N.; Qin, C.T.; Karelia, D.; Sharma, A.; Jiang, C.; Lu, J.X. Optimizing live-animal bioluminescence imaging prediction of tumor burden in human prostate cancer xenograft models in SCID-NSG mice. Prostate 2019, 79, 949-960. [CrossRef] [PubMed]

197. Xu, P.; Xu, N.; Guo, K.; Xu, A.; Takenaka, F.; Matsuura, E.; Liu, C.; Kumon, H.; Huang, P. Real-time monitoring of tumor progression and drug responses in a preclinical mouse model of prostate cancer. Oncotarget 2016, 7, 33025-33034. [CrossRef]

198. Tumati, V.; Mathur, S.; Song, K.; Hsieh, J.T.; Zhao, D.; Takahashi, M.; Dobin, T.; Gandee, L.; Solberg, T.D.; Habib, A.A.; et al. Development of a locally advanced orthotopic prostate tumor model in rats for assessment of combined modality therapy. Int. J. Oncol. 2013, 42, 1613-1619. [CrossRef]

199. Zhou, H.L.; Zhao, D.W. Ultrasound Imaging-guided Intracardiac Injection to Develop a Mouse Model of Breast Cancer Brain Metastases Followed by Longitudinal MRI. J. Vis. Exp. 2014. [CrossRef] [PubMed]

200. Chu, C.Y.; Davis, C.M.; Lan, X.Y.; Hienz, R.D.; Jablonska, A.; Thomas, A.M.; Velarde, E.; Li, S.; Janowski, M.; Kai, M.; et al. Neuroinflammation After Stereotactic Radiosurgery-Induced Brain Tumor Disintegration Is Linked to Persistent Cognitive Decline in a Mouse Model of Metastatic Disease. Int. J. Radiat. Oncol. Biol. Phys. 2020, 108, 745-757. [CrossRef] [PubMed]

201. Kimbrough, C.W.; Hudson, S.; Khanal, A.; Egger, M.E.; McNally, L.R. Orthotopic pancreatic tumors detected by optoacoustic tomography using Syndecan-1. J. Surg. Res. 2015, 193, 246-254. [CrossRef] [PubMed]

202. Poeschinger, T.; Renner, A.; Weber, T.; Scheuer, W. Bioluminescence Imaging Correlates with Tumor Serum Marker, Organ Weights, Histology, and Human DNA Levels during Treatment of Orthotopic Tumor Xenografts with Antibodies. Mol. Imaging Biol. 2013, 15, 28-39. [CrossRef] [PubMed]

203. Nakayama, J.; Saito, R.; Hayashi, Y.; Kitada, N.; Tamaki, S.; Han, Y.X.; Semba, K.; Maki, S.A. High Sensitivity In Vivo Imaging of Cancer Metastasis Using a Near-Infrared Luciferin Analogue seMpai. Int. J. Mol. Sci. 2020, 21, 7896. [CrossRef] [PubMed]

204. Zhao, Z.; Dai, J.J.; Yu, Y.; Zhang, Q.; Liu, S.; Huang, G.M.; Zhang, Z.; Chen, T.K.; Pan, R.L.; Lu, L.T.; et al. Non-invasive Bioluminescence Monitoring of Hepatocellular Carcinoma Therapy in an HCR Mouse Model. Front. Oncol. 2019, 9, 8. [CrossRef] [PubMed]

205. Labitzky, V.; Baranowsky, A.; Maar, H.; Hanika, S.; Starzonek, S.; Ahlers, A.K.; Stubke, K.; Koziolek, E.J.; Heine, M.; Schafer, P.; et al. Modeling Spontaneous Bone Metastasis Formation of Solid Human Tumor Xenografts in Mice. Cancers 2020, 12, 385. [CrossRef]

206. Wang, W.D.; Belosay, A.; Yang, X.J.; Hartman, J.A.; Song, H.X.; Iwaniec, U.T.; Turner, R.T.; Churchwell, M.I.; Doerge, D.R.; Helferich, W.G. Effects of letrozole on breast cancer micro-metastatic tumor growth in bone and lung in mice inoculated with murine 4 T1 cells. Clin. Exp. Metastasis 2016, 33, 475-485. [CrossRef]

207. Kato, Y.; Yoshimura, K.; Shin, T.; Verheul, H.; Hammers, H.; Sanni, T.B.; Salumbides, B.C.; Van Erp, K.; Schulick, R.; Pili, R. Synergistic in vivo antitumor effect of the histone deacetylase inhibitor MS-275 in combination with interleukin 2 in a murine model of renal cell carcinoma. Clin. Cancer Res. 2007, 13, 4538-4546. [CrossRef]

208. Sarraf-Yazdi, S.; Mi, J.; Dewhirst, M.W.; Clary, B.M. Use of in vivo bioluminescence imaging to predict hepatic tumor burden in mice. J. Surg. Res. 2004, 120, 249-255. [CrossRef]

209. Zhao, D.; Richer, E.; Antich, P.P.; Mason, R.P. Antivascular effects of combretastatin A4 phosphate in breast cancer xenograft assessed using dynamic bioluminescence imaging (BLI) and confirmed by magnetic resonance imaging (MRI). FASEB J. 2008, 22, 2445-2451. [CrossRef]

210. Cecic, I.; Chan, D.A.; Sutphin, P.D.; Ray, P.; Gambhir, S.S.; Giaccia, A.J.; Graves, E.E. Oxygen sensitivity of reporter genes: Implications for preclinical imaging of tumor hypoxia. Mol. Imaging 2007, 6, 219-228. [CrossRef] 
211. Liu, L.; Trawick, M.L.; Pinney, K.; Mason, R.P. Abstract 4194: Assessment of novel benzosuberene-based vascular disrupting agents (VDA) on diverse tumor lines. Cancer Res. 2016, 76, 4194. [CrossRef]

212. Mura, S.; Zouhiri, F.; Lerondel, S.; Maksimenko, A.; Mougin, J.; Gueutin, C.; Brambilla, D.; Caron, J.; Sliwinski, E.; Lepape, A.; et al. Novel isoprenoyl nanoassembled prodrug for paclitaxel delivery. Bioconjug. Chem. 2013, 24, 1840-1849. [CrossRef]

213. Mowday, A.M.; Lieuwes, N.G.; Biemans, R.; Marcus, D.; Rezaeifar, B.; Reniers, B.; Verhaegen, F.; Theys, J.; Dubois, L.J. Use of a Luciferase-Expressing Orthotopic Rat Brain Tumor Model to Optimize a Targeted Irradiation Strategy for Efficacy Testing with Temozolomide. Cancers 2020, 12, 1585. [CrossRef] [PubMed]

214. Zhou, H.; Belzile, O.; Zhang, Z.; Wagner, J.; Ahn, C.; Richardson, J.A.; Saha, D.; Brekken, R.A.; Mason, R.P. The effect of flow on blood oxygen level dependent $\left(\mathrm{R}^{*}\right)$ 2) MRI of orthotopic lung tumors. Magn. Reson. Med. 2019, 81, 3787-3797. [CrossRef] [PubMed]

215. Bruker. Imaging in Life Sciences. Available online: https://www.bruker.com/en/applications/academia-life-science/imaging. html (accessed on 22 April 2021).

216. MRSolutions. Magnetic Resonance Imaging. Available online: https://www.mrsolutions.com/mr-imaging-main/mr-imaging/ (accessed on 22 April 2021).

217. Yankeelov, T.E.; Luci, J.J.; Lepage, M.; Li, R.; Debusk, L.; Lin, P.C.; Price, R.R.; Gore, J.C. Quantitative pharmacokinetic analysis of DCE-MRI data without an arterial input function: A reference region model. Magn. Reson. Imaging 2005, 23, 519-529. [CrossRef]

218. Padhani, A.R. Dynamic contrast-enhanced MRI in clinical oncology: Current status and future directions. J. Magn. Reson. Imaging 2002, 16, 407-422. [CrossRef]

219. Liu, Y.W.; Wang, S.C.; Zhao, X.H.; Feng, Y.B.; Bormans, G.; Swinnen, J.; Oyen, R.; Huang, G.; Ni, Y.C.; Li, Y. Predicting Clinical Efficacy of Vascular Disrupting Agents in Rodent Models of Primary and Secondary Liver Cancers: An Overview with Imaging-Histopathology Correlation. Diagnostics 2020, 10, 78. [CrossRef]

220. Shao, H.; Ni, Y.; Dai, X.; Zhang, J.; Chen, F.; Fan, G.; Sun, Z.; Li, Y.; Zhou, H.; Xu, K. Diffusion-weighted MR imaging allows monitoring the effect of combretastatin A4 phosphate on rabbit implanted VX2 tumor model: 12-day dynamic results. Eur. J. Radiol. 2012, 81, 578-583. [CrossRef]

221. Ahn, S.Y.; Goo, J.M.; Lee, K.H.; Ha, S.; Paeng, J.C. Monitoring tumor response to the vascular disrupting agent CKD-516 in a rabbit VX2 intramuscular tumor model using PET/MRI: Simultaneous evaluation of vascular and metabolic parameters. PLoS ONE 2018, 13, e0192706. [CrossRef] [PubMed]

222. Joo, I.; Lee, J.M.; Grimm, R.; Han, J.K.; Choi, B.I. Monitoring Vascular Disrupting Therapy in a Rabbit Liver Tumor Model: Relationship between Tumor Perfusion Parameters at IVIM Diffusion-weighted MR Imaging and Those at Dynamic Contrastenhanced MR Imaging. Radiology 2016, 278, 104-113. [CrossRef]

223. Zhao, D.; Jiang, L.; Hahn, E.W.; Mason, R.P. Tumor physiological response to combretastatin A4 phosphate assessed by MRI. Int. J. Radiat. Oncol. Biol. Phys. 2005, 62, 872-880. [CrossRef] [PubMed]

224. Chen, H.W.; Liu, D.X.; Li, Y.G.; Xu, X.; Xu, J.D.; Yadav, N.N.; Zhou, S.B.; van Zijl, P.C.M.; Liu, G.S. CEST MRI monitoring of tumor response to vascular disrupting therapy using high molecular weight dextrans. Magn. Reson. Med. 2019, 82, 1471-1479. [CrossRef]

225. Bohndiek, S.E.; Kettunen, M.I.; Hu, D.E.; Witney, T.H.; Kennedy, B.W.C.; Gallagher, F.A.; Brindle, K.M. Detection of Tumor Response to a Vascular Disrupting Agent by Hyperpolarized C-13 Magnetic Resonance Spectroscopy. Mol. Cancer Ther. 2010, 9 , 3278-3288. [CrossRef] [PubMed]

226. Rofsky, N.M.; Sherry, A.D.; Lenkinski, R.E. Nephrogenic systemic fibrosis: A chemical perspective. Radiology 2008, 247, 608-612. [CrossRef] [PubMed]

227. Fraum, T.J.; Ludwig, D.R.; Bashir, M.R.; Fowler, K.J. Gadolinium-based contrast agents: A comprehensive risk assessment. J. Magn. Reson. Imaging 2017, 46, 338-353. [CrossRef] [PubMed]

228. Li, J.; Jamin, Y.; Boult, J.K.R.; Cummings, C.; Waterton, J.C.; Ulloa, J.; Sinkus, R.; Bamber, J.C.; Robinson, S.P. Tumour biomechanical response to the vascular disrupting agent ZD6126 in vivo assessed by magnetic resonance elastography. Br. J. Cancer 2014, 110, 1727-1732. [CrossRef] [PubMed]

229. O'Connor, J.P.; Boult, J.K.; Jamin, Y.; Babur, M.; Finegan, K.G.; Williams, K.J.; Little, R.A.; Jackson, A.; Parker, G.J.; Reynolds, A.R.; et al. Oxygen-Enhanced MRI Accurately Identifies, Quantifies, and Maps Tumor Hypoxia in Preclinical Cancer Models. Cancer Res. 2016, 76, 787-795. [CrossRef] [PubMed]

230. Beeman, S.C.; Shui, Y.B.; Perez-Torres, C.J.; Engelbach, J.A.; Ackerman, J.J.; Garbow, J.R. O2 -sensitive MRI distinguishes brain tumor versus radiation necrosis in murine models. Magn. Reson. Med. 2016, 75, 2442-2447. [CrossRef]

231. Hallac, R.R.; Zhou, H.; Pidikiti, R.; Song, K.; Stojadinovic, S.; Zhao, D.; Solberg, T.; Peschke, P.; Mason, R.P. Correlations of noninvasive BOLD and TOLD MRI with pO2and relevance to tumor radiation response. Magn. Reson. Med. 2014, 71, 1863-1873. [CrossRef]

232. Matsumoto, K.; Bernardo, M.; Subramanian, S.; Choyke, P.; Mitchell, J.B.; Krishna, M.C.; Lizak, M.J. MR assessment of changes of tumor in response to hyperbaric oxygen treatment. Magn. Reson. Med. 2006, 56, 240-246. [CrossRef]

233. Yang, D.M.; Arai, T.J.; Campbell, J.W., 3rd; Gerberich, J.L.; Zhou, H.; Mason, R.P. Oxygen-sensitive MRI assessment of tumor response to hypoxic gas breathing challenge. NMR Biomed. 2019, 32, e4101. [CrossRef] [PubMed]

234. Remmele, S.; Mason, R.P.; O'Connor, J.P.B. MRI Hypoxia Measurements. In Functional Imaging in Oncology; Luna, A., Ed.; Springer: Heidelberg, Germany, 2014; pp. 269-289. 
235. Madhu, B.; Waterton, J.C.; Griffiths, J.R.; Ryan, A.J.; Robinson, S.P. Response of RIF-1 fibrosarcomas to the vascular-disrupting agent ZD6126 assessed by in vivo and ex vivo H-1 magnetic resonance spectroscopy. Neoplasia 2006, 8, 560-567. [CrossRef] [PubMed]

236. McPhail, L.D.; Chung, Y.L.; Madhu, B.; Clark, S.; Griffiths, J.R.; Kelland, L.R.; Robinson, S.P. Tumor dose response to the vascular disrupting agent, 5,6-dimethylxanthenone-4-acetic acid, using in vivo magnetic resonance spectroscopy. Clin. Cancer Res. 2005, 11,3705-3713. [CrossRef] [PubMed]

237. iThera. Listening to Molecules. Available online: https://www.ithera-medical.com/ (accessed on 22 April 2021).

238. FujiVisualsonics. Our Latest, Most Advanced Multi-Modal Imaging Platform. Available online: https:/ /www.visualsonics.com/ product/imaging-systems/vevo-lazr-x (accessed on 22 April 2021).

239. Balasundaram, G.; Ding, L.; Li, X.T.; Attia, A.B.E.; Dean-Ben, X.L.; Ho, C.J.H.; Chandrasekharan, P.; Tay, H.C.; Lim, H.Q.; Ong, C.B.; et al. Noninvasive Anatomical and Functional Imaging of Orthotopic Glioblastoma Development and Therapy using Multispectral Optoacoustic Tomography. Transl. Oncol. 2018, 11, 1251-1258. [CrossRef] [PubMed]

240. Tomaszewski, M.R.; Gehrung, M.; Joseph, J.; Quiros-Gonzalez, I.; Disselhorst, J.A.; Bohndiek, S.E. Oxygen-Enhanced and Dynamic Contrast-Enhanced Optoacoustic Tomography Provide Surrogate Biomarkers of Tumor Vascular Function, Hypoxia, and Necrosis. Cancer Res. 2018, 78, 5980-5991. [CrossRef]

241. Ron, A.; Deán-Ben, X.L.; Gottschalk, S.; Razansky, D. Volumetric Optoacoustic Imaging Unveils High-Resolution Patterns of Acute and Cyclic Hypoxia in a Murine Model of Breast Cancer. Cancer Res. 2019, 79, 4767-4775. [CrossRef]

242. Hupple, C.W.; Morscher, S.; Burton, N.C.; Pagel, M.D.; McNally, L.R.; Cardenas-Rodriguez, J. A light-fluence-independent method for the quantitative analysis of dynamic contrast-enhanced multispectral optoacoustic tomography (DCE MSOT). Photoacoustics 2018, 10, 54-64. [CrossRef]

243. Zhou, H.L.; Campbell, J.; O’Kelly, D.; Gerberich, J.; Mason, R. Exploring a fluorescent blood pool agent in photoacoustic imaging. J. Nucl. Med. 2016, 57, 1214.

244. Tomaszewski, M.R.; Gonzalez, I.Q.; O’Connor, J.P.; Abeyakoon, O.; Parker, G.J.; Williams, K.J.; Gilbert, F.J.; Bohndiek, S.E. Oxygen Enhanced Optoacoustic Tomography (OE-OT) Reveals Vascular Dynamics in Murine Models of Prostate Cancer. Theranostics 2017, 7, 2900-2913. [CrossRef]

245. Mason, R.P. Oxygen breathing challenge- the simplest theranostic. Theranostics 2017, 7, 3873-3875. [CrossRef]

246. Zhou, H.L.; Zhang, Z.; Denney, R.; Williams, J.S.; Gerberich, J.; Stojadinovic, S.; Saha, D.; Shelton, J.M.; Mason, R.P. Tumor physiological changes during hypofractionated stereotactic body radiation therapy assessed using multi-parametric magnetic resonance imaging. Oncotarget 2017, 8, 37464-37477. [CrossRef]

247. O'Kelly, D.; Zhou, H.; Mason, R.P. Tomographic breathing detection: A method to noninvasively assess in situ respiratory dynamics. J. Biomed. Opt. 2018, 23, 1-6. [CrossRef]

248. O'Kelly, D.; Guo, Y.; Mason, R. Evaluating Online Filtering Algorithms to Enhance Dynamic Multispectral Optoacoustic Tomography. Photoacoustics 2020, 100184. [CrossRef]

249. Zhao, D.; Pacheco-Torres, J.; Hallac, R.R.; White, D.; Peschke, P.; Cerdan, S.; Mason, R.P. Dynamic oxygen challenge evaluated by NMR T1 and T2*-insights into tumor oxygenation. NMR Biomed. 2015, 28, 937-947. [CrossRef] [PubMed]

250. White, D.A.; Zhang, Z.; Li, L.; Gerberich, J.; Stojadinovic, S.; Peschke, P.; Mason, R.P. Developing oxygen-enhanced magnetic resonance imaging as a prognostic biomarker of radiation response. Cancer Lett. 2016, 380, 69-77. [CrossRef] [PubMed]

251. Joseph, J.; Tomaszewski, M.R.; Quiros-Gonzalez, I.; Weber, J.; Brunker, J.; Bohndiek, S.E. Evaluation of Precision in Optoacoustic Tomography for Preclinical Imaging in Living Subjects. J. Nucl. Med. 2017, 58, 807-814. [CrossRef] [PubMed]

252. McNally, L.R.; Mezera, M.; Morgan, D.E.; Frederick, P.J.; Yang, E.S.; Eltoum, I.E.; Grizzle, W.E. Current and Emerging Clinical Applications of Multispectral Optoacoustic Tomography (MSOT) in Oncology. Clin. Cancer Res. 2016, 22, 3432-3439. [CrossRef]

253. Weber, J.; Beard, P.C.; Bohndiek, S.E. Contrast agents for molecular photoacoustic imaging. Nat. Methods 2016, 13, 639-650. [CrossRef]

254. Abma, E.; De Spiegelaere, W.; Vanderperren, K.; Stock, E.; Van Brantegem, L.; Cornelis, I.; Daminet, S.; Ni, Y.; Vynck, M.; Verstraete, G.; et al. A single dose of intravenous combretastatin A4-phosphate is reasonably well tolerated and significantly reduces tumour vascularization in canine spontaneous cancers. Vet. Comp. Oncol. 2018, 16, 467-477. [CrossRef]

255. Siim, B.G.; Laux, W.T.; Rutland, M.D.; Palmer, B.N.; Wilson, W.R. Scintigraphic imaging of the hypoxia marker (99m)technetiumlabeled 2,2 '-(1,4-diaminobutane)bis(2-methyl-3-butanone) dioxime (Tc-99m-labeled HL-91; Prognox): Noninvasive detection of tumor response to the antivascular agent 5,6-dimethylxanthenone-4-acetic acid. Cancer Res. 2000, 60, 4582-4588.

256. Liu, L.; Mason, R.P.; Gimi, B. Dynamic bioluminescence and fluorescence imaging of the effects of the antivascular agent Combretastatin-A4P (CA4P) on brain tumor xenografts. Cancer Lett. 2015, 356, 462-469. [CrossRef]

257. Lee, J.A.; Biel, N.M.; Kozikowski, R.T.; Siemann, D.W.; Sorg, B.S. In vivo spectral and fluorescence microscopy comparison of microvascular function after treatment with OXi4503, Sunitinib and their combination in Caki-2 tumors. Biomed. Opt. Express 2014, 5, 1965-1979. [CrossRef] [PubMed]

258. Mita, M.M.; Sargsyan, L.; Mita, A.C.; Spear, M. Vascular-disrupting agents in oncology. Expert Opin. Investig. Drugs 2013, 22, 317-328. [CrossRef] [PubMed]

259. Masunaga, S.; Nagasawa, H.; Nagata, K.; Suzuki, M.; Uto, Y.; Hori, H.; Kinashi, Y.; Ono, K. Dependency of the effect of a vascular disrupting agent on sensitivity to tirapazamine and gamma-ray irradiation upon the timing of its administration and tumor size, with reference to the effect on intratumor quiescent cells. J. Cancer Res. Clin. Oncol. 2007, 133, 47-55. [CrossRef] [PubMed] 
260. Zhao, D.; Chang, C.-H.; Kim, J.G.; Liu, H.; Mason, R.P. In vivo near-infrared spectroscopy and MRI monitoring of tumor response to Combretastatin A4 phosphate correlated with therapeutic outcome. Int. J. Radiat. Oncol. Biol. Phys. 2011, 80, 574-581. [CrossRef] [PubMed]

261. Shen, N.; Wu, J.; Yang, C.G.; Yu, H.Y.; Yang, S.C.; Li, T.T.; Chen, J.T.; Tang, Z.H.; Chen, X.S. Combretastatin A4 Nanoparticles Combined with Hypoxia-Sensitive Imiquimod: A New Paradigm for the Modulation of Host Immunological Responses during Cancer Treatment. Nano Lett. 2019, 19, 8021-8031. [CrossRef] [PubMed]

262. Welford, A.F.; Biziato, D.; Coffelt, S.B.; Nucera, S.; Fisher, M.; Pucci, F.; Di Serio, C.; Naldini, L.; De Palma, M.; Tozer, G.M.; et al. TIE2-expressing macrophages limit the therapeutic efficacy of the vascular-disrupting agent combretastatin A4 phosphate in mice. J. Clin. Investig. 2011, 121, 1969-1973. [CrossRef]

\section{Short Biography of Authors}
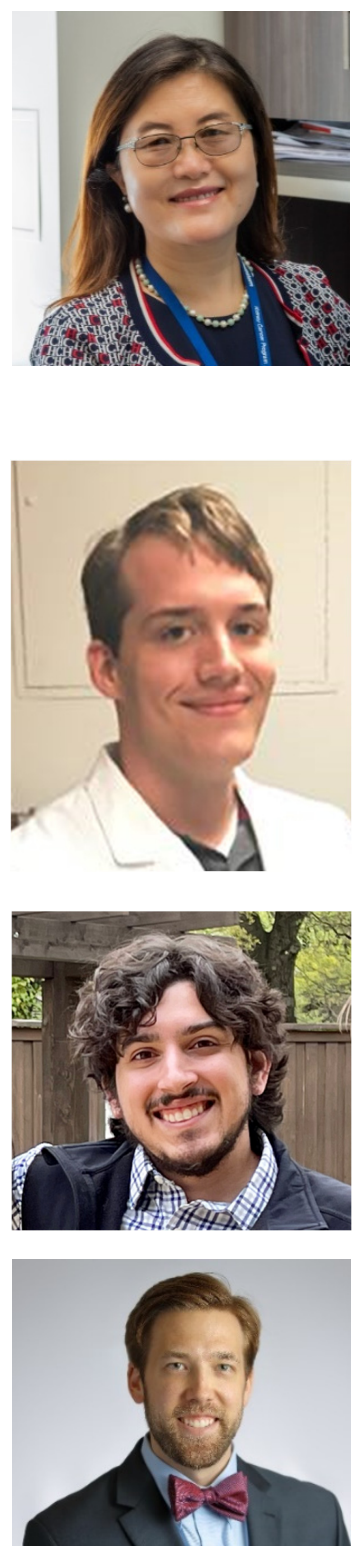

Li Liu has served on the faculty of UT Southwestern Medical Center in the department of Radiology since 2008 after completing her Ph.D. from Nankai University in Tianjin, China, and postdoctoral fellowship training in molecular pharmacology at the Max Planck Chemical and Ecology Institute in Jena, Germany, in genetics and microbiology at the University of Florida, and in molecular imaging at UT Southwestern. Dr. Liu's research focuses on development and application of reporter genes and molecular gene reporters for multimodality imaging, particularly related to cancer in small animal models. Dynamic imaging provides effective insight into tumor progression and response to therapy, particularly as applied to the development of vascular disputing agents in vivo. Most recently, she has explored multispectral optoacoustic tomography (MSOT) to provide real-time non-invasive insight into the vasculature of malignant tumors with respect to experimental drugs.

Devin O'Kelly is a Computational Scientist at the BioHPC high-performance computing facility, located at the University of Texas Southwestern Medical Center at Dallas. He earned his Ph.D. in biomedical and molecular imaging with a supplement in computational and systems biology, developing models and methods for interpreting MSOT data in the context of dynamic vascular imaging. His primary research interests focus on improving and enabling the effective analysis of high-dimensional imaging data, as well as relating acquired data to models of the underlying biological systems.

Regan J. Schuetze is a research technician in the Prognostic Imaging Research Lab. He joined the lab at UT Southwestern in 2020 after graduating from Furman University with a degree in neuroscience. His previous research investigated the role of dopamine in post-traumatic stress disorder and comorbid substance abuse and his current research represents a new interest in broader physiology.

Graham J. Carlson is a Ph.D. candidate at Baylor University carrying out research under the mentorship of Dr. Pinney. He joined the Pinney Laboratory in 2014 after graduating from Hope College with a degree in chemistry. His current research focuses on the design and synthesis of new inhibitors of tubulin polymerization together with corresponding vascular disrupting agents (VDAs) and various associated prodrugs, designed to enhance selectivity, efficacy and aqueous solubility of promising lead molecules. 

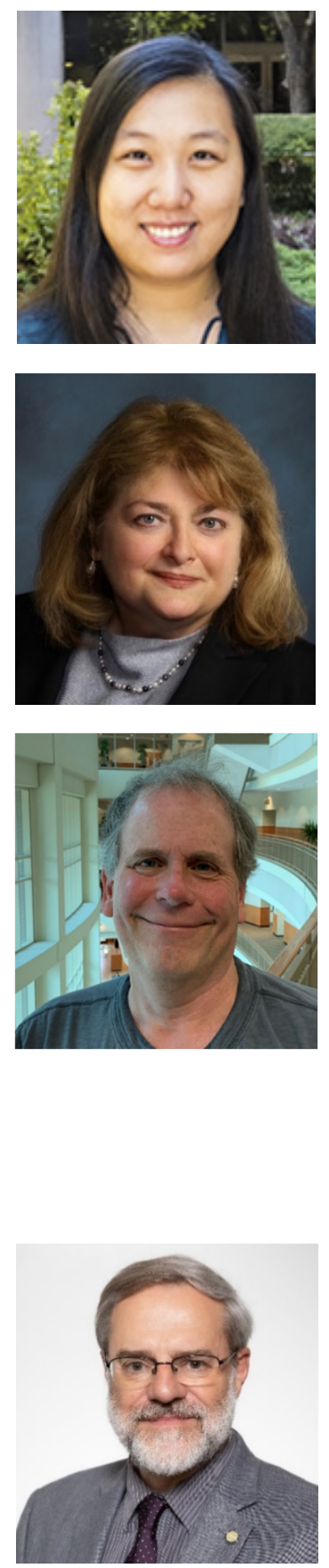

Heling Zhou received her undergraduate degree in biomedical engineering at Sun Yet-sen University and her doctorate degree in radiological sciences at UT Southwestern Medical Center. She developed imaging analytical techniques to assess tumor microenvironment and its relationship to treatment outcomes. She is now pursuing a career as a data engineer, building scalable data management and analytics solutions, and is currently a data engineer lead in a health-tech company developing artificial intelligence for radiologists.

Mary Lynn Trawick (formerly Dr. Mary Lynn Fink) is Associate Professor of Biochemistry in the Department of Chemistry and Biochemistry at Baylor University where she participates in the Institute for Biomedical Studies, the Molecular Biosciences Center, and the Center for Drug Discovery, and is a member of the Institutional Biosafety Committee. Her major research interests include the design, evaluation, and mechanism of action of novel anticancer agents with selectivity for the tumor microenvironment, and strategies to inhibit cancer metastasis.

Kevin G. Pinney has served on the faculty of Baylor University in the Department of Chemistry and Biochemistry since 1993 after completing his Ph.D. at the University of Illinois, Urbana-Champaign and postdoctoral studies at the University of South Carolina. He is a Professor of Chemistry leading a dynamic research group focused on the design and synthesis of structurally diverse and biologically interesting small-molecule analogues, many of which are inspired by natural products. Well-established, diverse research projects include vascular disrupting agents (VDAs), inhibitors of tubulin polymerization, inhibitors of cathepsin L (and/or K), hypoxia-activated prodrugs and related drug-linker constructs. He teaches classes at both the undergraduate and graduate level in the area of organic chemistry. Research in his laboratory has been funded over the years by various grants from the National Institutes of Health, the Cancer Prevention and Research Institute of Texas (CPRIT), and a pharmaceutical company. He continues to enjoy productive research collaborations including those with the Mason Group (UT Southwestern Medical Center, Dallas, TX) and the Trawick Group (Baylor University).

Ralph P. Mason is Professor of Radiology and Fellow of the Royal Society of Chemistry. He serves as the Director of the Small Animal Imaging Shared Resource at Simmons Comprehensive Cancer Center. He joined UT Southwestern 35 years ago after completing undergraduate and postgraduate studies at the University of Cambridge. His primary research interest is prognostic radiology: developing and implementing methods for predicting optimal cancer therapy and assessing early response to treatment (precision medicine). His particular interests have long related to prostate and breast cancer and most recently lung and kidney. He serves as advisor to graduate students in biomedical engineering and cancer biology and as mentor to postdocs and young faculty. He has been the recipient of multiple awards from the NCI and CPRIT. For 10 years, he has collaborated closely with the team at Baylor University to evaluate novel small molecule vascular disrupting agents for selective cancer treatment. 